\title{
DEVELOPING MAP MARGINALIA DESIGN RECOMMENDATIONS FOR THE ALASKA DIVISION OF GEOLOGICAL \& GEOPHYSICAL SURVEYS
}

Patricia Ekberg and Fritz Kessler
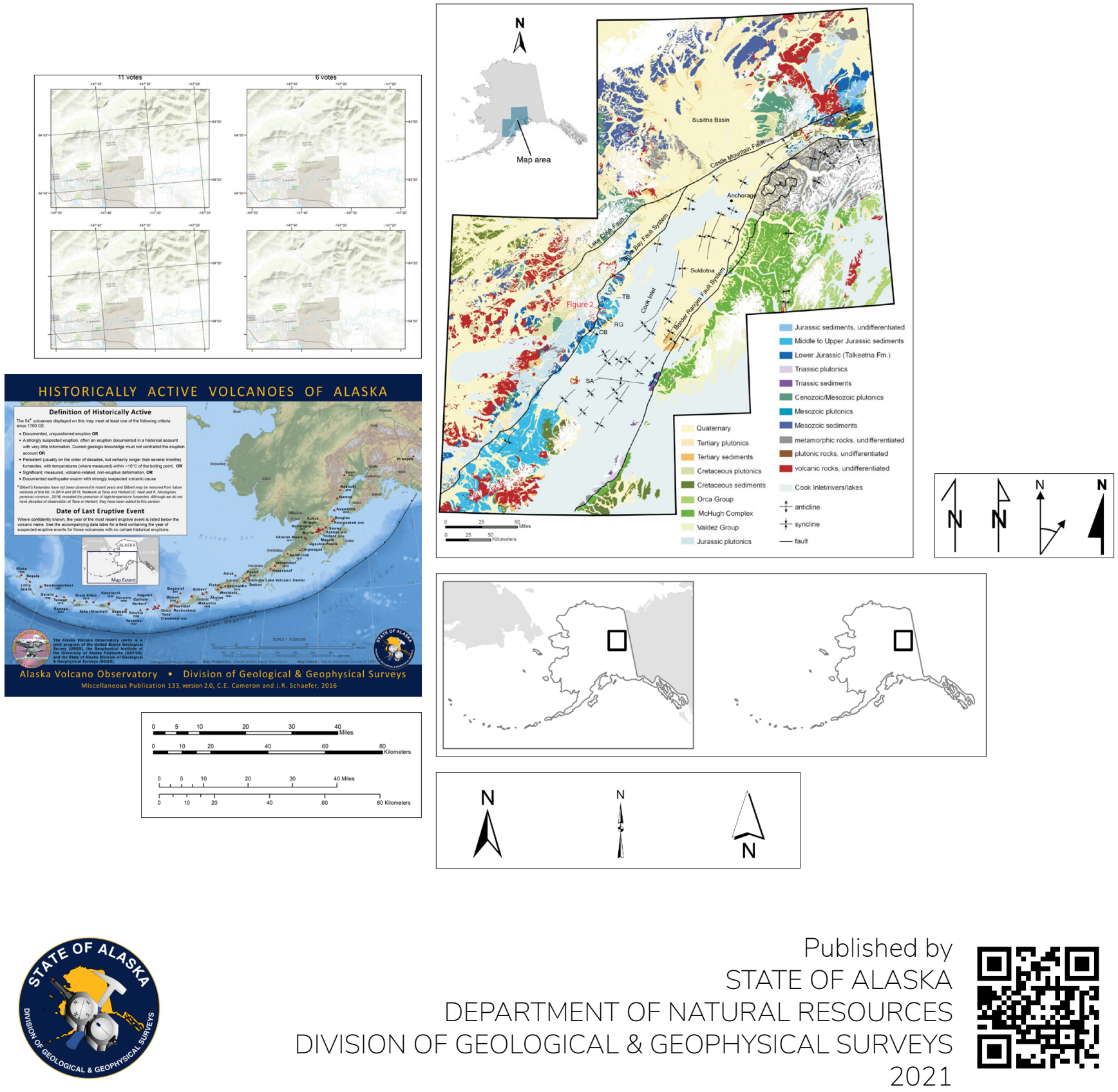



\section{DEVELOPING MAP MARGINALIA DESIGN RECOMMENDATIONS FOR THE ALASKA DIVISION OF GEOLOGICAL \& GEOPHYSICAL SURVEYS}

Patricia Ekberg and Fritz Kessler 


\section{STATE OF ALASKA}

Mike Dunleavy, Governor

\section{DEPARTMENT OF NATURAL RESOURCES}

Corri A. Feige, Commissioner

\section{DIVISION OF GEOLOGICAL \& GEOPHYSICAL SURVEYS}

Steve Masterman, State Geologist and Director

Publications produced by the Division of Geological \&

Geophysical Surveys (DGGS) are available for free download

from the DGGS website (dggs.alaska.gov). Publications on

hard-copy or digital media can be examined or purchased in

the Fairbanks office:

Alaska Division of Geological \& Geophysical Surveys

3354 College Rd., Fairbanks, Alaska 99709-3707

Phone: (907) 451-5010 Fax (907) 451-5050

dggspubs@alaska.gov|dggs.alaska.gov

\section{DGGS publications are also available at:}

Alaska State Library,

Historical Collections \& Talking Book Center

395 Whittier Street

Juneau, Alaska 99811

Alaska Resource Library and Information Services (ARLIS)

3150 C Street, Suite 100

Anchorage, Alaska 99503

\section{Suggested citation:}

Ekberg, P.G., and Kessler, Fritz, 2021, Developing map marginalia design recommendations for the Alaska Division of Geological \& Geophysical Surveys: Alaska Division of Geological \& Geophysical Surveys Report of Investigation 2021-2, 101 p. https://doi.org/10.14509/30661
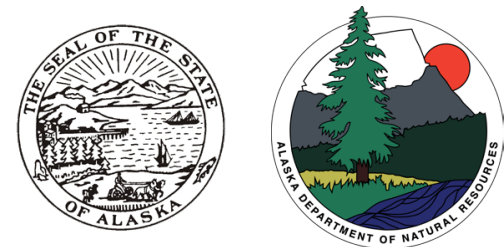

Cover. The reference map selected for inclusion in the user survey shows the historically active volcanoes of Alaska. The fullsize version of this map can be found in appendix A. 


\section{Contents}

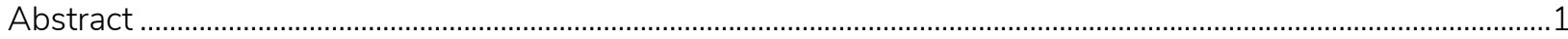

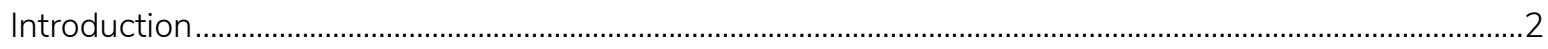

Literature Review of Accepted Cartographic Practices................................................................................................

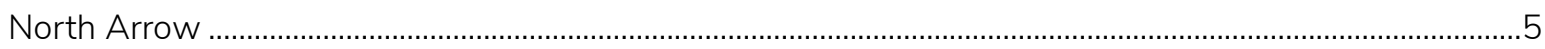

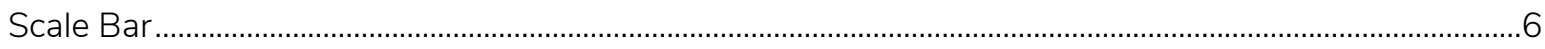

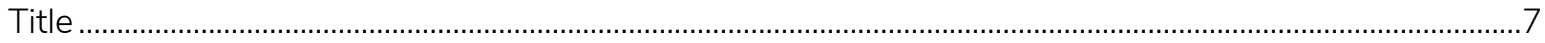

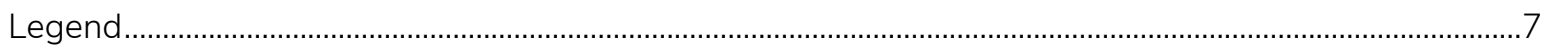

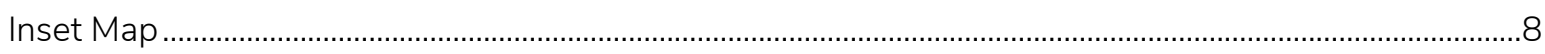

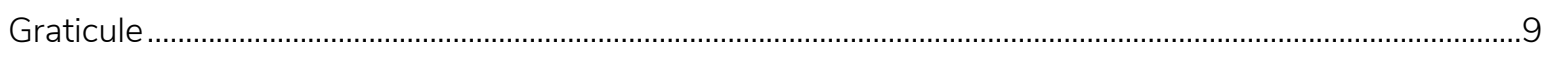

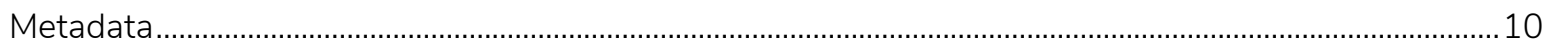

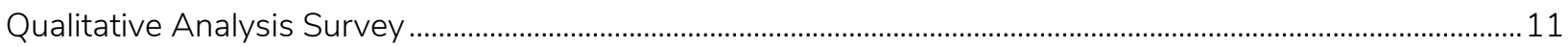

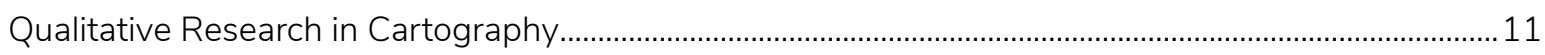

DGGS Small-format Map Survey Methodology...................................................................................................

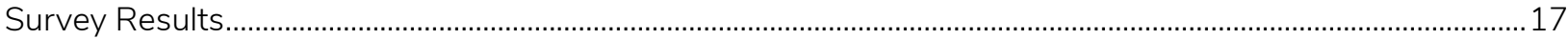

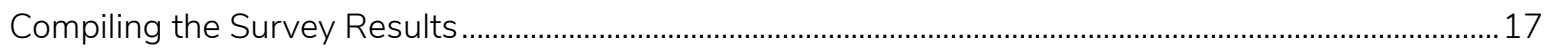

Summary of Survey Results .................................................................................................................................. 17

Survey Results for the Cook Inlet Bedrock Geology Map ........................................................................ 18

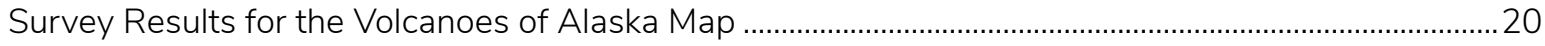

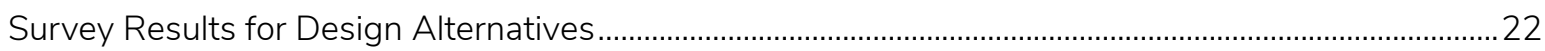

Survey Results for Metadata Element Inclusion .............................................................................................25

Comparison of Survey Results to Accepted Cartographic Practices.....................................................................2

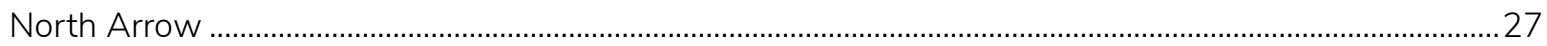

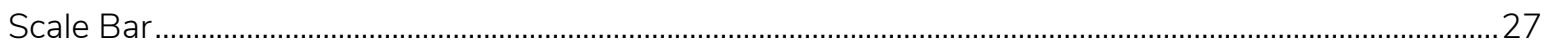

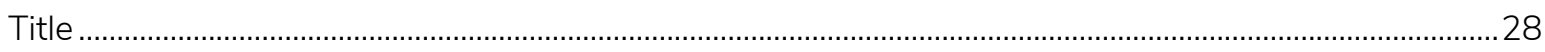

Legend

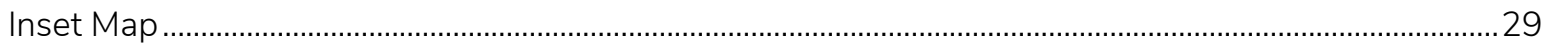

Graticule

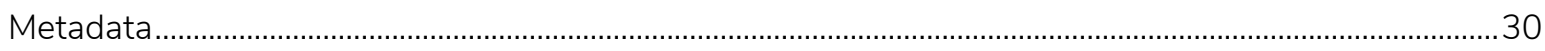

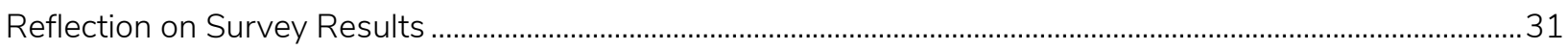

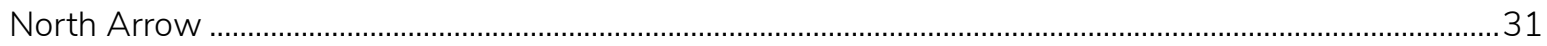

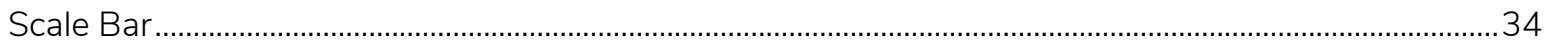

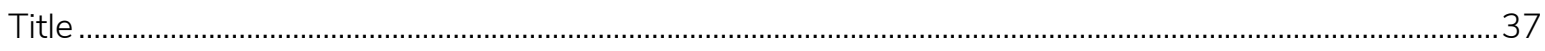

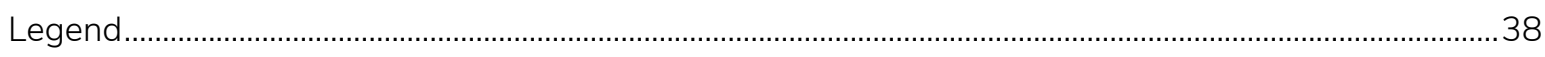

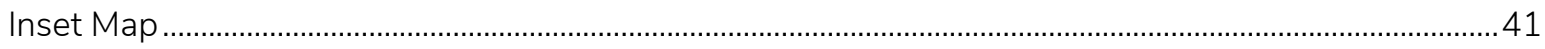

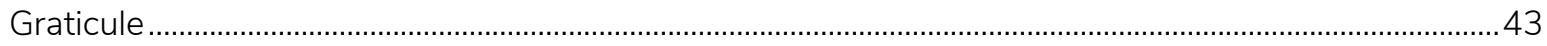

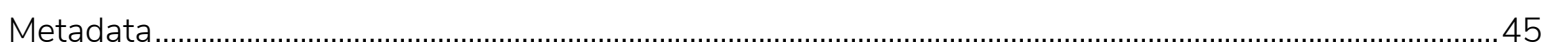

Guidelines and Design Recommendations for Small-Format Maps ……………...................................................49

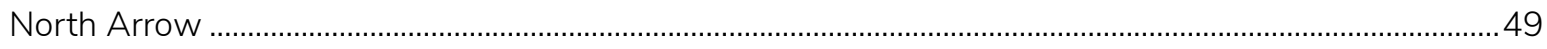

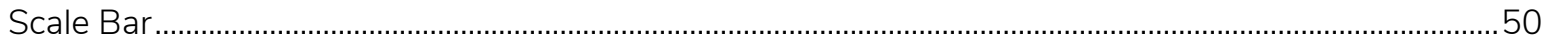

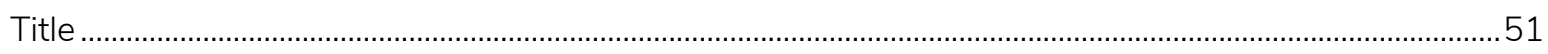

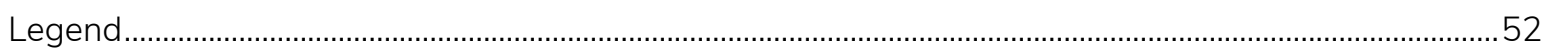

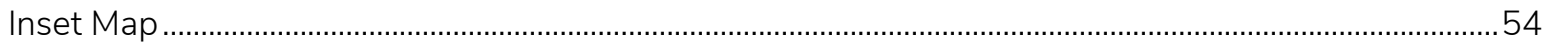

Graticule

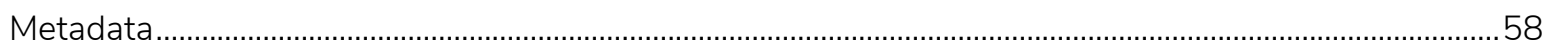

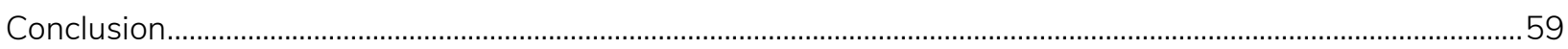

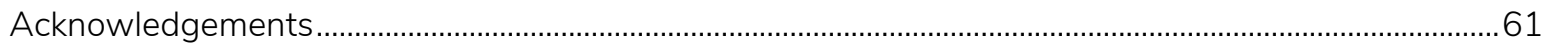

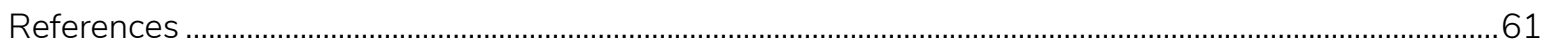




\section{Figures}

Figure 1. The thematic map selected for inclusion in the user survey ...............................................................13

Figure 2. The reference map selected for inclusion in the user survey ................................................................14

Figure 3. Survey questions associated with the user survey ........................................................................ 15

Figure 4. Example of participants' responses as recorded in the survey results .................................................17

Figure 5. The top design alternatives participants chose for the north arrow ...................................................22

Figure 6. Custom north arrows drawn by participants .......................................................................................23

Figure 7. The design alternatives participants chose most often for the scale bar ...........................................23

Figure 8. The design alternatives participants chose most often for the title.....................................................23

Figure 9. The design alternatives participants chose most often for the legend...............................................24

Figure 10. The design alternatives participants chose most often for the inset map .......................................24

Figure 11. The design alternatives participants chose most often for the graticule

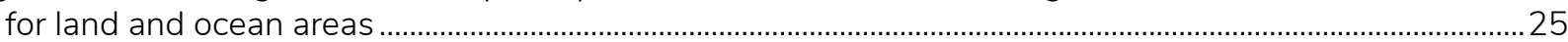

Figure 12. The top design alternatives participants chose most often for the graticule for land areas ..........26

Figure 13. The north arrow designs shown in the ESRI ArcMap 10.8 North Arrow Selector window ..........33

Figure 14. The Mercator cylindrical projection with the equator as the standard line.........................................35

Figure 15. The Albers equal area conic projection with standard lines at $55^{\circ}$ and $65^{\circ}$ north ...........................35

Figure 16. Comparison between an accurate representation of a graticule and how a map user may incorrectly visualize the graticule if only tic marks are provided.............................................................. 45

Figure 17. The recommended north arrow design (ESRI North Arrow 3) for DGGS small-format maps......50

Figure 18. The recommended scale bar design (ESRI Scale Line 1 and ESRI Scale Line 3) proposed for DGGS small-format maps .................................................................................................... 51

Figure 19. The alternate scale bar design (ESRI Alternating Scale Bar 1) for DGGS small-format maps......51

Figure 20. Examples of titles that follow the title guidelines and design recommendations ............................52

Figure 21. Examples of legends that follow the legend design recommendations ...........................................54

Figure 22. Two examples of recommended overview inset map designs for DGGS small-format maps......55

Figure 23. The recommended graticule design when the graticule is placed over all map features ..............57

Figure 24. The recommended graticule design when the graticule is placed over just the water features ..57

Figure 25. The recommended graticule design when the graticule is placed over land areas.........................57

Figure 26. The recommended graticule design when only tic marks appear on the map .................................58

\section{Tables}

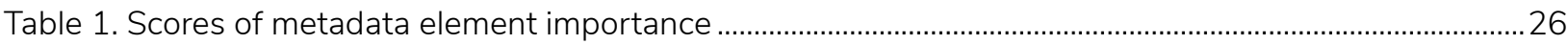

Table 2. Examples of maps where a north arrow would be considered functional, non-functional,

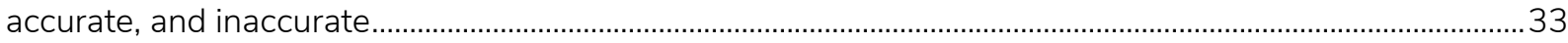

Table 3. Metadata elements listed by the mean and mode score of inclusion importance ...............................46

\section{Appendix}

Appendix A: Full-sized versions of the maps featured in the user survey Appendix B: DGGS map marginalia questionnaire

Appendix C: Marginalia element design choices for DGGS marginalia questionnaire 



\title{
DEVELOPING MAP MARGINALIA DESIGN RECOMMENDATIONS FOR THE ALASKA DIVISION OF GEOLOGICAL \& GEOPHYSICAL SURVEYS
}

Patricia Ekberg ${ }^{1}$ and Fritz Kessler ${ }^{2}$

\begin{abstract}
The mission of the Alaska Division of Geological \& Geophysical Surveys (DGGS) is to determine the potential of Alaskan land for production of metals, minerals, fuels, and geothermal resources, the locations and supplies of groundwater and construction materials, and the potential geologic hazards to buildings, roads, bridges, and other installations and structures. To help fulfill this mission, DGGS geologists and scientists distribute public information through the creation of a wide variety of maps, digital data, and written reports.
\end{abstract}

Maps play a crucial role in supporting DGGS' mission by helping geologists and scientists understand, interpret, and visualize Alaska's diverse geologic resources. Unfortunately, the overall look and feel of DGGS produced small-format maps are often inconsistent, particularly how map marginalia are included or excluded, placed, and designed. Such inconsistencies have the potential to create confusion for the user, leading to difficulties in orienting the map, measuring distances, identifying map symbols, or learning about the topic and important production information about the map. In addition, the overall appearance of some of the marginalia elements used on past DGGS maps do not conform to what is considered good cartographic design. The variation in map marginalia elements also contributes to the lack of cartographic consistency and continuity in the look and feel of the division's maps.

The purpose of this Report of Investigation is to establish recommended designs for map marginalia and present guidelines for their inclusion, design, and placement. An extensive literature review was performed to compile and document accepted cartographic conventions for marginalia inclusion, design, and placement. A qualitative survey was developed and administered to gather user reactions to, and opinions about, DGGS marginalia elements.

Results of the literature review and qualitative survey supported the establishment of recommended designs for map marginalia and guidelines for their inclusion and placement with the purpose of greatly increasing the consistency of DGGS smallformat maps and helping map makers critically think about the purpose, role, and considerations of each element on a map. These guidelines will offer DGGS map makers the flexibility to more easily and consistently create a variety of small-format maps that are recognizable as well-designed, professional, organizational products that have a consistent appearance, while supporting the DGGS' mission and meeting the needs of the map's intended users.

${ }^{1}$ Alaska Division of Geological \& Geophysical Surveys, 3354 College Rd., Fairbanks, Alaska 99709-3707.

2Penn State Department of Geography, 2217 Earth \& Engineering Sciences, University Park, PA 16802 


\section{INTRODUCTION}

The mission of the Alaska Division of Geological \& Geophysical Surveys (DGGS) is to determine the potential of Alaskan land for production of metals, minerals, fuels, and geothermal resources; the locations and supplies of groundwater and construction materials; and the potential geologic hazards to buildings, roads, bridges, and other installations and structures. To help fulfill this mission, DGGS geologists and scientists distribute public information through the creation of a wide variety of maps, digital data, and written reports.

Maps and digital data play a crucial role in understanding, interpreting, and visualizing Alaska's diverse geologic resources. DGGS maps and digital data provide information and interpretation for geology, resource potential, and geologic hazards. These publicly available maps and digital data are used by federal, state, and local governments; communities; natural resource development companies; and Alaska's legislature to make informed decisions necessary for the discovery and commercialization of the state's geologic resources. Maps and digital data are also available to and used by educators, tourists, and the general public to support earth science education and general recreational activities, such as gold panning, rock and fossil collecting, and geologic road tours.

Maps produced by DGGS have two basic components: the map face (which contains the data being visualized) and the map marginalia (which contains information about the map to help the map user effectively use the map for a given purpose). The term marginalia originates from the convention that information about the map was typically drawn in the margins around the map face. Although this convention has largely disappeared (for example, it is very common to see some map information drawn inside the map face), the term persists. Map marginalia often include, but are not limited to, a north arrow, scale bar, title, legend, inset map or location diagram, graticule (network of lines denoting latitude and longitude lines, which area called parallels and meridians, respectively), and metadata information (such as production information, contributor credits, data sources, coordinate system information, and publishing agency). Each of these marginalia elements serves a specific purpose to aid in understanding the map information and context. The north arrow allows the user to orient the map; the scale bar allows the user to measure distances and areas on the map; the title provides essential information about the intent and focus of the map; the legend explains (or defines) symbols used on the map; the inset map and graticule provide additional contextual and locational information; and metadata gives users additional important information about the map.

DGGS produces maps and digital data for a variety of topics. For example, geologic maps, the most common map type produced by the survey, show geologic features at or below the ground surface. DGGS also creates a wide range of thematic and reference maps. Thematic maps show a specific data set or are intended for a specific purpose. DGGS thematic maps include topics such as specific geologic information or features, permafrost, ground conductivity, flood hazard areas, mineral production, volcanic ashfall, and landslide hazards. Reference maps provide important base or background information that show, for example, where geographic features are in relation to each other and include topics such as the geographic extent of study areas, mining regions, locations of samples, locations of volcanoes, measured sections, geomorphic features, and landslide source areas.

In addition to presenting a variety of topics, DGGS maps are produced in different sizes and formats. DGGS maps are typically either smallformat (page sized or smaller) or large-format (larger than page-sized). Large-format maps are rigorously designed and conform to existing cartographic standards. Small-format maps are less formal, show considerable variation in design, and do not necessarily adhere to specific cartographic standards. 
DGGS large-format maps are most often detailed comprehensive geologic maps that are published at larger scales (1:100,000 or greater) and, when printed, require large-sized map sheets. These large-format, large-scale geologic maps use the Federal Geographic Data Committee (FGDC) Digital Cartographic Standard for Geologic Maps (FGDC document number FGDC0STD-013-2006) to guide the map symbology, colors, patterns, and the design of the north arrow, scale bar, inset map, and labels. This standard was created by and is used by the United States Geological Survey (USGS) whose geologic maps are considered well designed with marginalia elements that are consistent between maps. USGS maps are recognizable, especially to those who work in geoscience. DGGS' tradition, and unofficial policy, is to make maps that conform to the USGS design and symbolization standards. DGGS maps are frequently used alongside USGS maps, and consistent symbology and design helps users easily understand, interpret, and use these maps.

DGGS also produces a variety of smaller-scale, small-format maps that are page sized or smaller. Although a few page-sized maps are published as stand-alone products, such as a map of the Historically Active Volcanoes of Alaska (DGGS MP 133v.2), a majority of the small-format maps are published as figures in investigative reports. These small-format maps provide critical locational and contextual information, provide quick data visualization, and serve as a graphic explanation of geologic interpretation. Unlike large-format maps, these small-format maps include unique design opportunities that allow the map to be tailored to best suit the publication or the map's topic, scope, and purpose; however, there is an inconsistency in the overall look of the maps, particularly when it comes to whether map marginalia are included or excluded and how they are placed and designed. For example, some DGGS small-format maps that would benefit from having a scale bar do not include one, while other maps that do not need a scale bar have one present. In other cases, some maps have marginalia elements that are placed in the margins around the main mapped area in a confusing manner or the north arrow that references the main map face is placed in or alongside the inset map, implying it refers to the wrong map frame. These inconsistencies have the potential to create confusion if, for example the reader is unable to properly orient the map, measure distances or areas, identify map symbols, or know the topic and important production information about the map. In addition to marginalia elements causing user confusion, the overall appearance of some of the marginalia elements used on past and current DGGS maps do not conform to what is considered good cartographic design. For example, some of the north arrows are overly ornate nautical compass roses with all the extra frills. As such, the design may hinder the ability of the north arrow to function as intended and detract from the map's appearance as a whole. A north arrow's design should be functional, but not too artistic or visually detractive.

The variation in map marginalia elements also contributes to a lack of cartographic consistency and continuity in the look and feel of DGGS smallformat maps. Cartographic consistency and continuity result in maps that are easy to recognize as a product of a certain organization and help establish positive branding. For example, the United States National Park Service (NPS) maps use a standard design and marginalia elements, such as a distinct black title bar, making them easily recognizable across a broad readership.

There are two overall aims for this project. First, to develop guidelines to help DGGS authors decide which map marginalia should be included in the map, and where individual marginalia elements should be placed. Second, to develop a set of specific cartographic recommendations for the overall design of marginalia elements (i.e., north arrow, scale bar, title, legend, inset map, graticule, and metadata) for DGGS small-format maps. These guidelines will allow authors flexibility in map design but also provide a more consistent and coherent appearance 
and make small-scale maps more useful to the end users. This study used a qualitative analysis survey of map marginalia present on two previously published DGGS small-format maps to help develop these guidelines and recommendations.

This paper is organized into six sections. The first section, Literature Review of Accepted Cartographic Practices, is an overview of cartographic principles and conventions for marginalia elements and overall map design based on a review of the literature. The second, Qualitative Analysis Survey, discusses qualitative analysis methods used in cartography and explains the methodology used by this survey to gather user reactions to, and opinions about, the necessity, functionality, placement, accuracy, and design of DGGS marginalia elements. The survey also was used to test whether the opinions and conclusions differ between DGGS mapmakers and general map users. The third section, Survey Results, describes how results of this survey were compiled, and presents raw data from the survey. The fourth section, Comparison of Survey Results, compares the survey results to the research and practices documented in the literature review. The fifth section, Reflection on Survey Results, identifies common themes between individuals or groups and discusses and reflects on the survey results within the context of DGGS. The sixth section, Guidelines and Design Recommendations for Small-Format Maps, lists and explains the recommended DGGS marginalia designs and guidelines, which are based on, and supported by, the results of this survey, information from the literature review, and the author's expertise as a cartographer for DGGS. 


\section{LITERATURE REVIEW OF ACCEPTED CARTOGRAPHIC PRACTICES}

The literature review presented here summarizes the accepted cartographic principles pertaining to the placement and design of marginalia elements - the purpose of each element, when the element should be included, and considerations for the element's placement on a map. The final marginalia element design recommendations reported in section six are based on, and supported by, this literature review.

Information about the cartographic standards and conventions was compiled from six sources: three of which describe the purpose, design, and use considerations for marginalia elements: Thematic Cartography and Geovisualization (Slocum and others, 2009), Designing Better Maps (Brewer, 2005), and GIS Cartography: A Guide to Effective Map Design (Peterson, 2014). Map Use: Reading, Analysis, and Interpretation (Kimerling and others, 2016) provides insight on the accuracy and utility of scale bars. Cartographic design: Inset map (Buckley, 2008) details on inset map design and Dent's (1998) Cartography: Thematic Map Design provides information about the placement of a graticule in terms of visual hierarchy.

\section{NORTH ARROW \\ Purpose}

A north arrow indicates orientation (the direction of north) on a map. Orienting maps with north at the top is a long-standing tradition in the western world.

A north arrow can represent one or more of the three kinds of north: True north, magnetic north, and grid north. True north, also called geographic north, is the direction along a line of longitude as it converges with other lines of longitude at the North Pole. Magnetic north shows the direction a magnetic compass would point (towards magnetic north). The difference between magnetic north and true north, called magnetic declination, varies both with position on the earth's surface and over time. Grid north is the direction of a plane grid system, usually the grid associated with the map projection. The difference between true north and grid north is an effect of transforming the earth's spherical surface to a plane surface (USGS, n.d.)

Which kind or kinds of north represented by the north arrow on a map depends on the intended purpose of the map. Maps intended for navigation, surveying, orienteering, or collecting field data may require a compound north arrow that shows true, magnetic, and grid north. North arrows for small scale format thematic maps almost always only indicate true north.

\section{Inclusion/Exclusion}

Not every map needs a north arrow. Most map users expect maps to be oriented with north at the top of the page.

\section{Include a north arrow if:}

- The map is oriented with geographic north not at the top of the page.

- Direction is crucial for use of the map, for example, a map intended for navigating, surveying, or orienteering.

- Geographic features are oriented in a way that might confuse the map user, for example, when roads are oriented in a direction other than geographic north.

- Intended map users are not familiar with the mapped area.

\section{Exclude a north arrow if:}

- It is obvious and expected that the map is oriented with geographic north at the top of the page.

- The intended audience is familiar with the area the map depicts.

- Orientation varies across the map. Lines of longitude that are curved or converge over a mapped area indicate that the direction of north is variable. In such cases, a north arrow would only indicate north for a specific location and would be incorrect for portions of the map. Where the direction of north varies, a graticule may be more appropriate to show orientation. 


\section{Placement}

The placement of a north arrow in a map layout depends on available space and the needs of the map user. An inconspicuous location, ideally near the scale bar, is preferable.

A north arrow may sometimes create visual balance with another element or may be grouped with other elements such as the scale bar and legend. In a small layout, such as in an in-line graphic or a page-sized map, the north arrow can be placed inside the map face. Larger layouts typically place the north arrow outside of the map face grouped with the scale bar and other supporting information.

\section{Design}

A north arrow should never be so large or elaborate that it draws attention away from the map's content. Bulky or complex arrow designs should be avoided. The design should be simple and subtle with fine line weights and text that is amongst the smallest on the map. Only the direction of north should be indicated-a user can infer the other cardinal directions.

\section{SCALE BAR \\ Purpose}

Map scale can be represented three ways - as a graphic scale bar, a verbal scale, or a representative fraction. A graphic scale bar communicates map scale and allows the map user to measure distances or areas easily. A scale bar remains accurate even as a map is enlarged or reduced in size, assuming the aspect ratio remains the same. A verbal scale or representative fraction (e.g. 1:63,360) can be easily included in a descriptive figure caption for maps that are included in written reports (P. Kennelly, personal communication).

\section{Inclusion/Exclusion}

An indication of scale is not necessary on every map. The type, theme, purpose, and intended use of a map will affect the decision of whether to include a scale bar.

\section{Include a scale bar if:}

- The map is intended to be used for distance measurement.

- Distance information will enhance the map user's understanding of the map theme. For example, a scale bar on a map showing the number of farms per state could help a map user estimate the number of farms per square mile.

- If scale changes across the map and a scale bar is needed, the standard point, line, or line(s) where scale is accurate (principal scale) should be indicated on the map and the scale bar should be drawn according to the principal scale.

\section{Exclude a scale bar if:}

- Distance information will not enhance the map user's understanding of the map theme. For example, a map showing the type of currency used in each country of South America would not benefit from having a scale bar.

- Scale changes greatly across the mapped area, such as on a map of North America. In these cases, a scale bar is only an accurate representation along certain lines and will be inaccurate for much of the map.

\section{Placement}

A scale bar can be placed in any available space that can accommodate its height and width. Final placement depends on available space and the needs of the map user. If possible, the scale bar should be located below the mapped area, where map users are accustomed to find it.

\section{Design}

A scale bar is intended to be informative without drawing attention away from map content. Its design should be simple and subtle with fine line weights and text that is neither bold nor italic and is amongst the smallest on a map. Include only enough intermediate distance tic marks to allow general measurements to be made.

The length of a scale bar should be long enough to be useful but short enough so that it is not cumbersome or draw unwarranted attention. 
The maximum value represents the length of the scale bar. The appropriate maximum value (and length) depends on the units of measure and the size of the area that is represented. An appropriate maximum distance value is always round, evenly divisible, and easy to use.

Units should be appropriate for the maximum value and decimals and excessively large values should be avoided. Excessively large maximum values can be avoided by choosing the appropriate units. For example, 52,800 feet would be better represented as 10 miles. Units should be appropriate for the intended audience, for example, a map intended for Canadians should show a scale bar in kilometers while a map intended for use in the United States should show a scale bar in miles. Multiple units of measure can be included if the map will be read by a diverse audience.

\section{TITLE}

\section{Purpose}

The title is a statement of the overall map topic that conveys the map's theme and may include additional information such as the region or date. Subtitles, a legend title, and notes can be added to explain the data that are mapped, the purpose of the map, or additional information.

\section{Inclusion/Exclusion}

Slocum and others (2009) states that most thematic maps require a title and recommends using a title in all situations because a title can draw attention to the map. Titles can be omitted on maps that are part of a series when the map theme is discussed in introductory material for that group of maps. Titles are sometimes excluded when a map appears as a figure with a figure caption in a written document.

\section{Placement}

Map users are accustomed to seeing titles at the top of maps, so it is ideal to place and horizontally center titles there. Multiple lines of text in a title should typically be center justified. For large-format maps, titles often are placed directly above the legend so that the map user can easily look back and forth between the title and legend. An additional, separate legend title will accomplish this plus give supplemental information on the data being mapped or how the data are represented. Final placement of the title, and the addition of a subtitle, legend title, or notes depends on available space and the needs of the intended map user.

\section{Design}

The title should be the largest type on a map and generally limited to one line of text. A bold font can emphasize the title but is not usually necessary with an appropriate choice of type size. The style should be plain without italics or ornate type styles. A bounding box is only used if needed to mask underlying mapped areas to improve legibility.

The title, subtitle, and legend title should be succinct and have minimal punctuation. Avoid unnecessary words (like the word "Map") or abbreviations that might be unfamiliar to the map user. A title for a thematic map should succinctly describe the map theme. A title for a reference map is usually a statement about the region being mapped. Slocum and others (2009) recommends that titles use the theme - region - date format.

\section{LEGEND \\ Purpose}

The legend defines map symbols and presents information that helps the map user understand symbols and interpret the map. The legend generally consists of a title and a listing of symbols with a description or explanation for each symbol, and sometimes groupings of symbols.

Professional cartographers disagree about the best name for this important map feature. Slocum and others (2009) and Brewer (2005) prefer the term "legend." In her book GIS Cartography, Peterson (2014) uses both the terms "legend" and "map key." Those who work for the USGS report that the word "legend" is never used on a map, and that the expected term is "explanation." The term legend is used for the purpose of this study and report. 


\section{Inclusion/Exclusion}

Most thematic and reference maps include a legend. Symbols that are obvious and self-explanatory to the intended map user, or those not directly related to the map's theme, can sometimes be omitted from the legend. For example, roads, water, or boundary symbols may be omitted on a map showing population per county. Mimetic symbols, which are often referred to as pictorial symbols, are intended to mimic the feature which the symbol represents (e.g. an airplane icon to represent an airport) (Buckley and others, 2007). Mimetic symbols are desirable on maps when they are unambiguous and easy to understand (Robinson and others, 1995). Some maps include all symbols in the legend even if they are self-explanatory or mimetic. For example, Forest Service Maps include the picnic area symbol in the legend even though the picnic table symbol is self-explanatory. When using a self-explanatory or mimetic symbol, the background and culture of potential map viewers should be considered. For example, a fork and knife symbol would be recognized by most Westerner's as a symbol indicating food; however, the same symbol may cause confusion to others who do not use or have never seen a knife and fork.

\section{Placement}

A legend should be visually centered within a larger area of available space defined by other map elements.

\section{Design}

The style of the legend should be clear and straightforward with a consistent type style used throughout. An effectively designed legend enhances a user's understanding of a map by enabling rapid, effective, and accurate identification of features. The legend should be large enough to be legible and useful, but not so large that it is cumbersome or more visually prominent than the map face or other more important map marginalia. A subtle bounding box is used only when necessary to mask underlying mapped areas to improve legibility.
A legend title may be used to further explain the map's theme. The title "Legend" is not needed for a well-designed legend. The legend title should be placed above the legend symbols and is commonly center justified with the symbols and descriptions to appear visually balanced (neither right- nor left-heavy).

A descriptive label should accompany each symbol represented in the legend. Legend symbols should be identical to those found in the mapped area (including size, color, units, and orientation). Colored boxes, or patches, that identify map features (such as geologic units) should have the same color and outline weight in the legend as the mapped area polygons they represent. If polygons do not use outlines, box outlines may be absent from the legend.

Logically grouping the symbols in the legend into related categories will assist the user to read the map. For example, small swatches containing different lightness of greens can be placed together in the legend representing vegetation. Symbols can be grouped according to many other criteria. For example, symbols can be grouped according to their form (natural or man-made), geometry (point, line, or polygon), or relevance to the maps theme (directly related or base information). This last option is the most appropriate for thematic maps that include base information in the legend.

\section{INSET MAP \\ Purpose}

An inset map is a smaller map within a larger map that serves one or more of the following purposes:

1. Shows the relationship between the primary mapped area and a larger area. For example, if a main mapped area shows a single county, it may be useful to include an inset map showing the location of the county in the state. Maps that fulfill this purpose are often referred to as locator maps. Locator inset maps are the primary inset maps focused on during this study. 
2. Enlarges important or congested areas. Maps that fulfill this purpose are often referred to as enlargement inset maps. The design guidelines for enlargement maps are much different than those for locator maps.

3. Shows areas that cannot fit in their true geographic location on the page due to the map scale of the main map and extent of the page (or computer screen). This is especially true if the areas shown in the inset maps are geographically distant from the main area, as AK and HI are to the conterminous US. During this study, maps that fulfill this purpose are referred to as related area inset maps.

\section{Inclusion/Exclusion}

Whether an inset map should be included on a map depends on available space, the needs of the overall map, and the purpose of the inset map. An inset map should be included on a map if it is necessary to show overall context/geographic location of the mapped area, enlarge important or congested areas, or show important related areas that cannot fit on the page due to map scale and/or page layout.

\section{Placement}

Placement of one or multiple inset maps depends on available space, the needs of the map user, and the layout of the overall map. Inset maps should be placed so that they visually balance other map elements and do not obscure features of the main map.

\section{Design}

The design of an inset map should be relatively minimalistic and complement the main map by using similar colors and fonts (Buckley, 2008). The design of an inset map may vary based on its purpose. For example, if the only purpose of a locator inset map is to help orient the map user, it should be plain and simple in design. The level of generalization of features on an inset map should be appropriate for its scale and purpose. The size of the inset map may vary according the size of the map and the size of other elements. One eighth to one sixteenth the size of the primary map element is customary for the size of the inset (Peterson, 2014). "Zoom lines" connecting the main map and inset map (to make the inset look like it is popping out from the main map) should be omitted because map users are familiar enough with inset maps that zoom lines are not necessary and only add visual clutter (Buckley, 2008).

\section{GRATICULE \\ Purpose}

The graticule is a grid of East-West and NorthSouth lines-those lines are called parallels and meridians, respectively. They are placed on maps at specific locations (in distance from the Equator for parallels and the Prime Meridian for meridians). The measurement of the distances is in degrees latitude for the parallels and degrees longitude for the meridians.

One function of the graticule is to help identify the latitude and longitude of a mapped location (e.g., a location defined in units of decimal degrees). The graticule provides location information (e.g., latitude and longitude) that may be important to the map theme or user. For example, natural vegetation is strongly related to latitude and time zones are closely related to meridians.

The graticule can also serve as background functions in the map's overall design (Dent, 1998). On the one hand, the graticule helps the map viewer visualize how the flat map surface relates to the three-dimensional surface it represents-that is, the type of projection and the associated properties used to represent the area (Peterson, 2014). On the other hand, the orientation of the parallels and meridians of can help show how the direction toward north varies within the mapped area which is important for the map reader to orient the map.

\section{Inclusion/Exclusion}

A graticule should be included on a map if orientation or position information is needed to enhance the map's message or theme. 


\section{Placement}

The placement of the graticule should be considered within the context of its role in a map's design. For this study graticule "placement" refers to the position of the parallels and meridians in the visual hierarchy of the map.

The graticule's placement depends on its function. Options include:

- The graticule visually overlays all elements on the map, which shows all latitude and longitude values across the map.

- Graticule lines are drawn on areas of water and are not shown on land areas to enhance figure-ground relations.

- The graticule appears as small tic marks along the frame-line, or as small crosses on the map marking the intersection of latitude and longitude lines, or both.

\section{Design}

The style of the graticule should be simple and subdued to avoid visually competing with the map's content. Lines, tic marks, crosses, and labels should all be considered when designing the graticule. Labels should be used for the major divisions of latitude and longitude and be clearly associated with their corresponding marks though placement, color, or size. The graticule should have fine line weights and text that is amongst the smallest on the map.

\section{METADATA}

\section{Purpose}

Metadata provide additional information and details about the map or data for a variety of purposes. Examples include author names, acknowledgments, affiliations of contributors, publishing agency, publishing agency logo, contributing agencies, contributing agencies logo, publica- tion number, coordinate system information, and data sources.

\section{Inclusion/Exclusion}

Metadata should be included if it will help the user to better interpret the map. For example, projection and coordinate system information may alert the map user to potential distortions in the mapped area, especially at small map scales. Metadata indicating the source of the data may help the user evaluate whether the data represented on the map are recent or reliable (e.g., ensuring that the map edition used for navigating reflects the most recent magnetic declination data for a given area).

\section{Placement}

Metadata location varies according to available space, but metadata should never attract undue attention. Metadata are often a minor map element and should be placed in an out of the way location at the bottom or sides of the map. If the data sources relate directly to the way the data in the legend is being classified or calculated, the data sources are optimally placed below, and center justified with, the legend.

\section{Design}

Metadata elements (data source, authorship, projection information, etc.) may be arranged as separate blocks of text, and the style should be plain and simple. The type should be amongst the smallest on the map.

Data sources should be labeled "Data Source" or "Source" to avoid being mistaken as map authorship. Format of data sources should be similar to a bibliographic reference or use the data provider's suggested citation but can be simpler. Many map users want to know the date or origin of the data, but not track down the exact data source. 


\section{QUALITATIVE ANALYSIS SURVEY}

\section{QUALITATIVE RESEARCH IN CARTOGRAPHY}

Qualitative research is a method of inquiry, used in many different academic disciplines, that examines the why and how of decision making. Qualitative research involves studying process and meaning (feelings, perceptions, and knowledge) and is particularly useful to capture the patterns of thought across a population. Qualitative research is used by cartographic researchers to bring them "closer to the problem-solving realms of map makers and map users" (Suchan and Brewer, 2000). Suchan and Brewer (2000) also identify a range of methods for obtaining three types of qualitative data. The first type, verbal data, includes information gathered from questionnaires, interviews, focus groups, and think aloud protocols. The second type, direct observation data, includes information gathered by observing and testing participants. The third type, document data, includes information gathered from analysis of maps, images, or written materials.

Verbal assessment, in the form of recording an opinion on what humans have created, is subconsciously encoded in humans and is employed by them in relation to everything they come into contact with. Verbal assessment is an advantageous form of qualitative analysis, because it offers a natural form of evaluation that easily reflects details and names concrete problems. The disadvantage of verbal assessment is that it tends to be subjective and can neglect some characteristics of the assessed object. Questionnaires, which are a form of verbal assessment, offer advantages over other assessment methods, including a lower cost and the ability to easily survey a large number of participants; however, the disadvantage is that participants are more likely to skip a question, misinterpret a question, or not return the questionnaire (Blaha, 2010). Verbal assessment, including questionnaires, uses closed or open questions with responses directly from the subject who is taking the survey. Closed questions can be answered with "yes" or "no" or allow the respondent to choose from a limited menu of set responses, for example, "I am satisfied with the appearance of this map" or choosing from a numerical scale of options where a set scale of numbers represent "strongly agree" to "strongly disagree." Open questions, such as "Explain the purpose of this map" or "Explain your reasoning in answering the question", ask participants to record and explain their opinions, reactions, thoughts, and reasoning in detail (Suchan and Brewer, 2000).

Harrower and others (1997) used a questionnaire, with both closed and open question elements, to gather user reactions to the design and delivery of maps on the Internet. Their study identified key issues in cartography that are related to the Internet and tested whether professional geographers and non-geographers judged Internet maps differently. Based on the approach taken by Harrower and others (1997), the goal of this research on DGGS small-format maps is to collect the reactions and opinions about DGGS marginalia elements and to test whether opinions and conclusions differ between study groups. Harrower's user study methodology will be emulated because of the similarity between their goals of qualitative research and those defined in this study.

\section{DGGS SMALL-FORMAT MAP SURVEY METHODOLOGY}

The Harrower and others (1997) Internet cartography study, hereafter referred to as "the Harrower Study", identified three methodology questions which are appropriate for the cartography user survey: 1) how to select maps to include in the survey, 2) who to survey, and 3) how to design and conduct the survey. The Harrower study answers these questions by using the methodology questions as process steps divided into three partsmap selection, selecting survey participants, and survey design. Similar to the Harrower study, the methodology used for the DGGS small-format 
map study is divided into four steps that address the three methodology questions. The first two steps, which closely follow the Harrower study's methodology, selecting the maps (step 1) and selecting survey participants (step 2), describe how and why the maps and participants were included for this study. Unlike the Harrower study, that discusses survey design in one methodology step, two distinct survey design and analysis steps are identified-developing the questionnaire (step 3) and administrating the survey (step 4). These steps describe how the questions for the survey were developed and how the survey will be administered to the participants.

\section{Step 1: Selecting the Maps}

Similar to the Harrower study, that reduced an initial selection of maps based on specified criteria, an initial set of DGGS maps was reduced based on four criteria - adherence to an existing standard, publication date, map size, and presence of marginalia elements. All DGGS large-format maps were excluded, because they adhere to USGS cartographic standards, are well designed, and demonstrate consistency between maps. Because the majority of DGGS small-format maps are produced in color, only color maps were considered for this study. Every color small-format map published by DGGS in 2015-2017 was initially considered. For this analysis, two maps were chosen: One thematic map and one reference map. These were chosen to represent the two types of maps that the DGGS commonly produces. First, the initial set of 2015-2017 maps were categorized as thematic or reference. Then the maps in each of these categories were grouped into page-sized or smaller than page-size groups. Each map was then examined to determine whether any of the marginalia elements included in this study (north arrow, scale bar, title, legend, locator inset map, graticule, and metadata) appeared on the map. In general, maps printed smaller than page-size had few, if any, marginalia elements, and consequently only page-sized maps were considered for selection. All the marginalia elements were represented on one or both of the maps.
The selected thematic map, which illustrates the bedrock geology of the Cook Inlet region (fig. 1 ), is published as a figure in the written report Energy-related Studies During the 2014 Field Season, Western Cook Inlet, Alaska (DGGS publication PIR 2015-5). The map contains a north arrow, scale bar, legend, and locator inset map. The selected reference map, Historically Active Volcanoes of Alaska (DGGS publication MP 133v.2), was published as a stand-alone version of a larger map, and identifies the locations, names, and eruption dates of the historically active volcanoes of Alaska (fig. 2). The map contains a scale bar, title, locator inset map, graticules, and metadata marginalia elements. See Appendix A for full-sized versions of both maps.

\section{Step 2: Selecting Survey Participants}

Guest and others (2006) state that a sample of 12 participants is sufficient for most research designed to evaluate common perceptions and experiences among a relatively homogeneous group. Patton (1990) argues that there are no specific rules for determining appropriate sample size in qualitative research, and that sample size may be best determined by time allotted, resources available, and study objectives. As in the Harrower study, the limited time frame and lack of financial support for this study make a small, convenient sample from DGGS personnel appropriate. DGGS employees were chosen because of their intimate knowledge of the wide range of topics and data displayed in the two maps used in this study, and their familiarity with how marginalia have been used in the past at DGGS. To recruit participants, all 62 DGGS employees were sent an email that briefly explained the purpose of this project and solicited survey participation. After participant recruitment, 24 DGGS employees volunteered to participate in the study. This is a favorable number because the survey aims to understand common reactions from two relatively homogeneous groups (12 participants in the map maker and 12 in the map user group). 


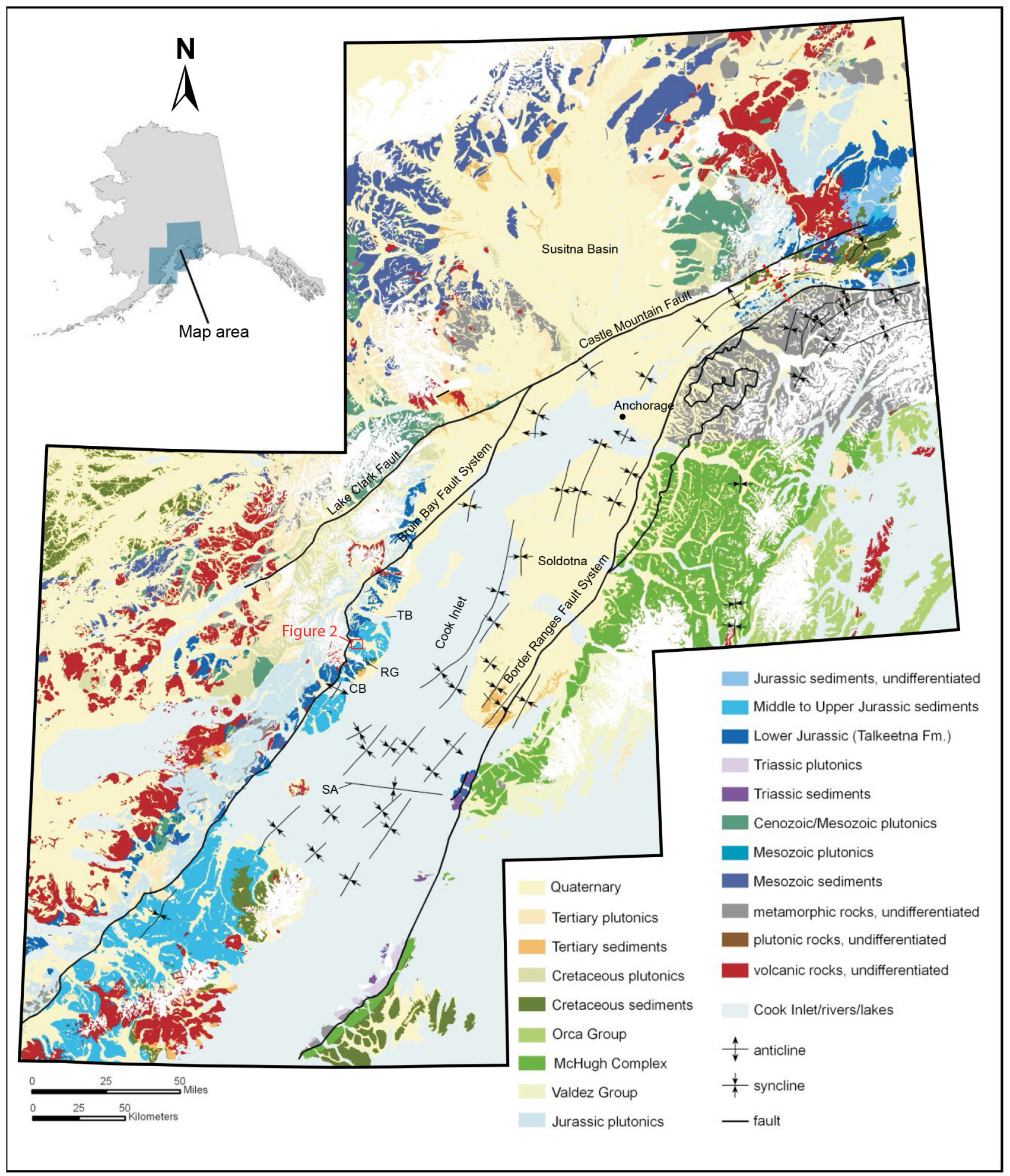

Figure 1. The thematic map selected for inclusion in the user survey shows the bedrock geology of the Cook Inlet region. The full-size version of this map can be found in appendix $A$. 


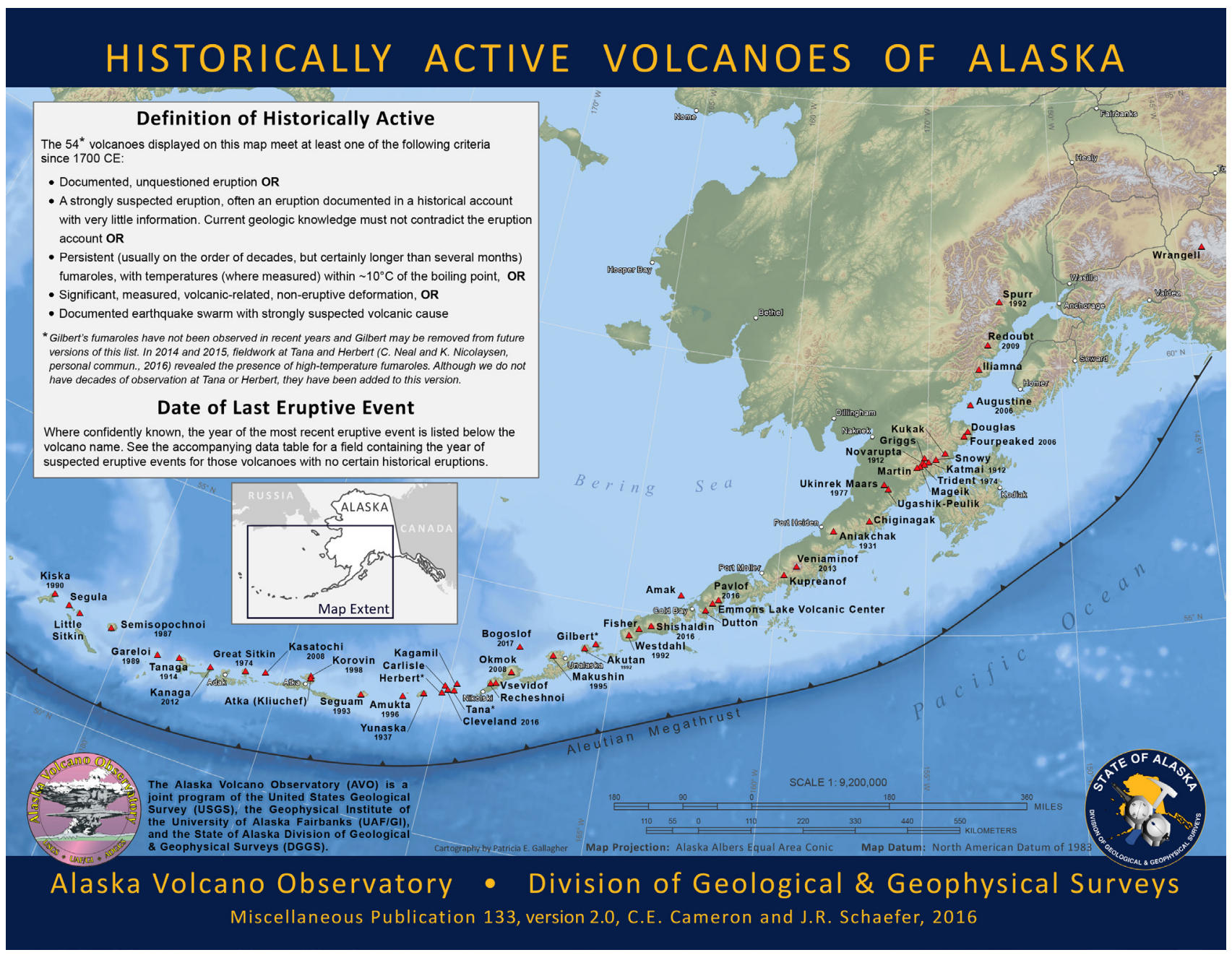

Figure 2. The reference map selected for inclusion in the user survey shows the historically active volcanoes of Alaska. The full-size version of this map can be found in appendix $A$.

Harrower and others (1997) grouped survey participants into professional geographers (faculty, professional staff, and graduate students from a geography department) and non-geographers (people without a geography degree or formal training in cartography). Similarly, DGGS participants were grouped based on cartographic experience and knowledge. Participants were divided into two groups, based on self-identification as a map maker (someone who uses and creates maps regularly, like a geologist), or as a general map user (someone who views and uses maps but does not create them, like a manager, IT person, or HR person). Like Harrower and others (1997), both subgroups are "samples of convenience" (i.e., a group of people who are easy to reach).

\section{Step 3: Developing the questionnaire}

The Harrower study used a combination of open and closed questions for their survey. The questionnaire used for this study also used a combination of these types of questions to determine participants' thoughts on, reactions to, and opinions about DGGS marginalia elements and to test whether the opinions and conclusions differ between DGGS map makers and general map users. Verbal data were gathered using a written questionnaire because they offer many advantages, such as low cost and the ability to record detail and identify problems (Blaha, 2010). Using DGGS coworkers, who have a vested interest in the results 
of this study, will help overcome the disadvantages Blaha (2010) identified for the use of questionnaires, such as skipped questions and low return rate. DGGS coworkers anticipate that the design recommendations and guidelines developed in this study will improve the quality of DGGS' smallformat maps.

For this study, participants were asked to examine one of the two selected maps. Half of the participants viewed the Cook Inlet map and the other half viewed the volcano map. Participants were asked to specifically evaluate the marginalia elements (north arrow, scale bar, title, legend, locator inset map, graticule, and metadata) of the map relative to six criteria: presence (if the object is included on the map), necessity (how important the object is to fulfill the needs of the map user), placement (where the object is placed to be functional and fit into the overall map design), functionality (how well the objects fulfills its intended purpose), accuracy (how accurate the object is at fulfilling its intended purpose), and design (the aesthetic of the object). Figure 3 shows the questions associated with the north arrow element on the Cook Inlet map. A similar set of questions was included for each of the seven map elements. In the questionnaire, the locator inset map is referred to as the "inset map" because both the volcano and Cook Inlet maps include locator insets, which is the inset map type focused on in this study. The full questionnaire can be found in Appendix B. The first five questions ask a closed yes/no question that is immediately followed by an open question that asks the participant to explain their reasoning.

Question \#1 (fig. 3) asks if a marginalia element (for example, the north arrow) exists on the map and tests whether the map user could locate that element on the map. Question \#2 asks the map user to decide if an element is necessary for the map and helped determine if the map user is familiar with traditional cartographic conventions for when it is appropriate to include the element in a map layout. Question \#3 asks if the reader thinks an element is well placed on the map. Questions \#2 and \#3 were used to investigate participant's views on the inclusion and placement of marginalia elements. Question \#4 asks if the map user finds an element functional (e.g., was the map user able to use the marginalia element for its intended purpose?). Question \#5 asks if the map user finds an element accurate. Questions \#4 and \#5 helps to support conclusions about how an element's design affects the element's functionality and map user's ability to accurately use it. In cases where a marginalia element is not shown on the sample map, an alternate question was presented in order to record the participant's opinion about the missing elements necessity, placement, functionality, and accuracy.

After participants reviewed all marginalia elements on the example map, they were presented with a selection of alternative designs for each element, asked to choose the design they found the most visually pleasing for each element, and asked to explain their choice. The term "visually

\section{North Arrow Questionnaire}

1. Is there a north arrow on this map?

2. Does this map need a north arrow? Please explain why or why not.

3. Is this north arrow well placed on this map? If yes, please explain why. If not, please describe where this north arrow should be moved to and why.

4. Does this north arrow help you orient the map? Please explain why or why not.

5. Does this north arrow accurately point toward north for all locations shown in this map? Please explain why or why not.

Figure 3. Survey questions associated with the north arrow on the Cook Inlet map. The full questionnaire can be found in appendix B. 
pleasing" was not defined for participants because what appeals aesthetically to one person may be different for another. For this part of the questionnaire, design alternatives were presented for each marginalia element, except metadata. The sample set of design options included those that exist on previously published DGGS maps or from the list of default designs included in the ESRI ArcMap 10.8 layout options. ArcMap 10.8, rather than ArcGIS Pro, designs were chosen because ArcMap 10.8 is the primary software used by DGGS map makers. Design options were selected to cover a range of shape, simplicity, complexity, compactness, contrast, and elongation of the design. Participants were given the option to draw their own design if none of the design alternatives appealed to them.

The last question evaluated metadata inclusion. It listed ten important metadata elements (author names, acknowledgments, affiliations of contributors, publishing agency, publishing agency logo, contributing agencies, contributing agencies logo, publication number, coordinate system information, and data sources) and asked users to indicate the level of importance of including each element on a small-format map, from 1 (should always be included on the map) to 10 (never has to be included on the map). This question solicited participants' opinion of metadata importance in general, rather than within the context of a specific map.

\section{Step 4: Administrating the Survey}

To keep the completion time of the questionnaire under one hour, and because of the number of people who volunteered to participate in the study, each participant examined only one of the example maps. To ensure a non-biased response, half of the participants were randomly assigned to review the thematic map of Cook Inlet and the other half reviewed the reference map of the volcanoes of Alaska. The questionnaire, in the form of a Microsoft Word form, was sent to participants via email. Immediately following the receipt of the questionnaire, each participant was handed a folder that contained printed copies of one of the example maps and a packet of the element design alternatives.

Participants had the option to complete the questionnaire using a computer and the Word form or to print out the questionnaire and write in their responses by hand. Participants were asked to complete and return the questionnaire within one week. 


\section{SURVEY RESULTS}

\section{COMPILING THE SURVEY RESULTS}

While 24 people volunteered to participate in the study, only 23 questionnaires were completed and returned. Twelve people examined the Cook Inlet geology map and 11 people examined the Volcanoes of Alaska map. Results for each map were copied into an EXCEL spreadsheet and grouped by the participant's self-identified role (map maker or map user). Separate tabs (sheets) were used for to each of the seven marginalia elements, for design alternatives, and for metadata importance. For all sheets, the first two columns identify which map the participant examined and whether or not they considered themselves to be a map maker or map user. The remaining columns contain responses to both closed ("yes" or "no") and open (long explanation) questions. These columns are organized in the same order as in the questionnaire and are labeled according to the theme of each question. Answers to closed questions were entered and totaled in a separate column from corresponding responses to open questions. Responses to open questions, which asked participants to explain their reasoning for each closed question, were entered exactly as the participant recorded. Figure 4 presents the responses from one participant concerning the inset map on the Cook Inlet map.

\section{SUMMARY OF SURVEY RESULTS}

This section presents the overall results and general comments of the survey responses for each map. The following results are organized according to which map the participant examined (Cook Inlet or volcano map) and further arranged by the marginalia element under consideration (north arrow, scale bar, title, legend, inset map, graticule, and metadata) and the reason for asking of each question (to determine an element's existence, necessity, placement utility, functionality, and accuracy). If an element was not present on the map, only the comments regarding the existence and necessity are reported. Commentary for each element begins with a count of the total number of comments, followed by the unique answers or summaries of shared general ideas. Direct quotations from participant responses are also included.

Responses to closed questions (yes/no questions) are reported numerically. In some cases, a participant recorded both "yes" and "no" as their answer to a closed question. In such cases a definitive answer was inferred based on the comments or explanations for that question. When one or more participants did not answer a question, the response total reported does not equal the total

\begin{tabular}{|c|c|c|c|c|c|c|c|c|c|c|}
\hline \multirow[b]{2}{*}{ Map } & \multirow[b]{2}{*}{ Role } & Exist & \multicolumn{2}{|r|}{ Necessary } & \multicolumn{2}{|r|}{ Well Placed } & \multicolumn{2}{|r|}{ Functional } & \multicolumn{2}{|c|}{ Accurate } \\
\hline & & $\begin{array}{c}\text { Inset } \\
\text { map } \\
\text { present? }\end{array}$ & \multicolumn{2}{|c|}{$\begin{array}{l}\text { Does this map } \\
\text { need an inset? }\end{array}$} & \multicolumn{2}{|c|}{$\begin{array}{c}\text { Does the inset well placed } \\
\text { on this map? }\end{array}$} & \multicolumn{2}{|c|}{$\begin{array}{c}\text { Does the inset help you } \\
\text { know where on earth this } \\
\text { map is? }\end{array}$} & \multicolumn{2}{|c|}{$\begin{array}{l}\text { Does the inset accurately } \\
\text { represent the location of } \\
\text { the map area? }\end{array}$} \\
\hline $\begin{array}{l}\text { Cook } \\
\text { Inlet }\end{array}$ & User & $\mathrm{Y}$ & $Y$ & $\begin{array}{l}\text { Since the } \\
\text { map only } \\
\text { covers a } \\
\text { small } \\
\text { portion of } \\
\text { Alaska, I } \\
\text { think it is } \\
\text { important to } \\
\text { include an } \\
\text { inset map to } \\
\text { orient users. }\end{array}$ & $Y$ & $\begin{array}{l}\text { I think the irregular } \\
\text { boundary of the map } \\
\text { is well-used by placing } \\
\text { the inset in the blank } \\
\text { space on the upper } \\
\text { left. If that area is } \\
\text { actually map, though, I } \\
\text { think the inset map is } \\
\text { poorly placed as it } \\
\text { covers up a large } \\
\text { portion of the map. }\end{array}$ & . & $\begin{array}{l}\text { It helps you to know } \\
\text { where on Alaska, but } \\
\text { not where on earth. } \\
\text { If there were some } \\
\text { coordinate indicators } \\
\text { on the map, that } \\
\text { would help to } \\
\text { indicate where on } \\
\text { earth the map is. }\end{array}$ & $Y$ & $\begin{array}{l}\text { Seems that the } \\
\text { outline on the inset } \\
\text { matches the map. }\end{array}$ \\
\hline
\end{tabular}

Figure 4. Example of participant's responses as recorded in the survey results Excel spreadsheet. 
number of participants in each map group. Explanatory or descriptive answers, such as responses to open questions, where given, are summarized as general sentiments rather than numerically.

\section{SURVEY RESULTS FOR THE COOK INLET BEDROCK GEOLOGY MAP}

Of the 12 people who examined the Cook Inlet map, six self-identified as primarily map makers and six self-identified as map users.

\section{North Arrow}

Necessary - All participants located and identified the north arrow on this map. Only one participant suggested that the map did not need a north arrow. Most participants commented that "all maps need a north arrow" or "at this scale, the map needs a north arrow;" however, one participant indicated that the inset map of Alaska was sufficient to show orientation, while another stated that "the inset map doesn't need a north arrow since you can see the whole state of Alaska, whereas the main map should have a north arrow since it's more zoomed in."

Well Placed - Five participants indicated that the north arrow was well placed, while the remaining seven participants indicated that the placement of the north arrow nearest to the inset map of Alaska made it unclear whether it referred to the inset or main map. To improve the placement of the north arrow, half of the participants suggested that the north arrow be moved on top of the main map or near the scale bar.

Functional - Seven participants thought the north arrow helped them orient the map, because it verified that the map was oriented with north at the top of the page. Five participants did not find the north arrow very functional, because they already knew the direction of north based on the orientation of the inset map and the shape of the mapped area.

Accurate - Four participants identified the north arrow's accuracy (pointing north for all locations on the map) as "close enough for the purpose of the map," while eight participants indicated that the north arrow at this scale was inaccurate, because the direction of north changed from the left to the right side of the map due to the chosen map projection.

\section{Scale Bar}

Necessary - All participants identified that the Cook Inlet map had a scale bar and indicated that it was necessary. Most commented that "all maps require a scale bar" or that a scale bar was necessary to show the sizes, proportions, and relationships of features on the map.

Well Placed - Eleven participants indicated that the scale bar was well placed, because it was easy to find, close to the main mapped area, near the bottom of the map, not distracting, and appropriately used white-space. The participant who indicated that the scale bar was not well placed commented that a better placement would be on top of the mapped area to which it refers.

Functional - Nine participants responded that the scale bar was functional and helped them measure distances on the map. Most participants noted that the scale bar was only functional for general measurements and not very precise, because of the map scale. Two participants did not record a response.

Accurate - Although most participants reported that the scale bar was not accurate for all locations shown on the map because "the scale will change with latitude," many commented that, for the size and purpose of the map, the change in scale was probably minimal and the scale bar could be used to estimate distance fairly well.

\section{Title}

Necessary - All participants indicated that the Cook Inlet map did not have a title but did include a figure caption. Most agreed that a title was not necessary for the map, if it was included as a figure in a publication and had a descriptive figure caption. When asked to create a title for the map, ten participants chose "Bedrock Geologic Map of the Cook Inlet Region.” This exact wording was written in the figure caption. Other titles offered 
contained similar wording and included "Cook Inlet Bedrock Geology" and "Regional Geologic Context of the Study Area."

Well Placed - Because the Cook Inlet map did not have a title, participants were asked where they would place a title if one were included. Five participants indicated that the top of the map was the best location. Three chose the bottom of the map, below the scale bar and legend and two said either the top or the bottom would be appropriate. One participant did not record a response.

Functional - All participants thought that the title they created was functional because it identified "what information was being displayed on the map."

Accurate - Eight participants stated that their titles accurately represented the information shown on the map, while three participants said the titles they created did not include all of the information about the map. These participants elaborated that their title did not describe that the map is significantly generalized, contains quaternary geologic units, and is also the index map for an additional figure in the same report. Those who specifically identified their title as inaccurate also noted that "titles can't be too long" or "not all the information is absolutely necessary" in a map's title.

\section{Legend}

Necessary - All participants indicated that the Cook Inlet map had a legend and stated that one was necessary to identify the colors and symbols used on the map.

Well Placed - All participants agreed that the legend was placed in an appropriate location, where it utilized white space and did not obstruct map features.

Functional - Six participants stated that the legend was functional because it helped them understand the important symbols on the map. These participants further commented that the legend was functional for the purposes of a figure in a report, even though not every symbol on the map appears in the legend. The remaining participants indicated that the legend was not functional because it does not contain all the map symbols, and the colors presented were difficult to differentiate.

Accurate - Six participants described the legend as accurate because most of the colors and lines used on the map were identified accurately on the legend. The remaining participants described the legend as inaccurate because it does not contain all of the map symbols and the colors presented on the map.

\section{Inset Map}

Necessary - Eleven participants identified that the Cook Inlet map had an inset map. These participants noted that an inset map was necessary to show the relative size of the mapped area and its location within Alaska. One participant did not record a response to any of the inset map questions.

Well Placed - Eleven participants agreed that the inset map was well placed and used available space effectively; however, a few people, commented that because the inset map is not the main focus of the map, its placement in the lower right area of the page would be more appropriate.

Functional - Eleven participants agreed that the inset map was functional because it helped them know where on the earth the mapped area was located; however, many participants commented that the inset map was functional only if the map user already knew where Alaska is located in the world.

Accurate - Eleven participants stated that the mapped area shown on the inset map accurately matched the geographic extent of the main mapped area; however, many noted that it was challenging to determine the accuracy of an inset map.

\section{Graticule}

Necessary - All participants indicated that the Cook Inlet map did not have a graticule. Six participants indicated that the map needed a graticule to give additional location information. Five participants thought a graticule was not necessary 
because it would add too much complexity and was not required for the purpose of the map. One participant did not record a response.

\section{Metadata}

Necessary - Seven participants identified that metadata was present on the Cook Inlet map and stated that some metadata was necessary to give users additional map information; however, four participants disagreed and indicated that metadata was not present on the map. They reasoned that the omission was acceptable, because the map was a figure in a report which likely contained additional map information. One participant did not record a response. Participants commented that the data sources, authors, data modification details, projection, scale, data collection date, publication date, publication agency, Digital Object Identifier (DOI) link, and intended purpose of the map would be useful metadata information to have when interpreting the map.

\section{SURVEY RESULTS FOR THE VOLCANOES OF ALASKA MAP}

Of the 11 people who examined the Volcanoes of Alaska map, six self-identified as primarily map makers and five self-identified as map users.

\section{North Arrow}

Necessary - All participants recognized that the volcano map did not have a north arrow. Nine participants stated that a north arrow is not necessary because "the mapped area is so large that the direction of north changes across the extent of the map." Many commented that the graticule indicated the direction of north. Two participants offered that the map "needs a north arrow to be consistent with other maps" and "because all maps should have north arrows."

Well Placed -Most participants reiterated that a north arrow was not appropriate for this map. Some continued and said that, if one were appropriate, they would place it in the lower right corner or near the scale bar.
Functional - Most participants reiterated that a north arrow would not help them orient this map, because the direction of north changes across the map. A few commented that a north arrow would help someone unfamiliar with Alaska orient the map.

Accurate-All participants stated that a north arrow would not accurately point toward north for all locations on the map, because the direction of north changes across the map due to its conic projection.

\section{Scale Bar}

Necessary - All participants identified that a scale bar was present on the volcano map. Four participants reported that the map did not need a scale bar because the graticule indicated the scale, but agreed that a scale bar would be useful to "get a general sense of how far apart things are." The remaining participants reported that the map needed a scale bar to give users an idea of the size of Alaska and the distance between features on the map.

Well Placed - All participants thought that the scale bar was well placed, because it did not obstruct underlying map features, was legible, and in a location that was out of the way and easy to find.

Functional - Six participants indicated that the scale bar was functional because they could easily use it to roughly measure distances on the map. The remaining participants did not find the scale bar functional because the scale and projection of the map caused distance to vary slightly from the top to the bottom of the map. Some users also commented that the scale bar was not functional because it did not contain increments of 50 or 100.

Accurate - Three participants thought that the scale bar accurately represented distance for all locations shown on the map, while eight participants indicated otherwise; the scale bar was not accurate because of distortions caused by the map's scale and projection. Many commented that a scale 
bar may be useful to get a general sense of distance, but that it would not be accurate for all locations on the map.

\section{Title}

Necessary - All participants indicated that the volcano map included a title and stated that one was necessary to "convey the main point of the map." Three of the five participants who identified as map users reported that "all maps need a title."

Well Placed - All participants agreed that the top center of the map was the best location for the title to be placed, because it is "the first place people typically look for a title."

Functional - All participants agreed that the title was functional, because it "highlights the main point of the map."

Accurate - All participants agreed that the title provided an accurate, generalized short summary of the map topic.

\section{Legend}

Necessary - All participants indicated that the volcano map did not have a legend. Five participants commented that a legend was necessary to clearly explain the symbols used for volcanoes, cities, and roads. The remaining participants thought that a legend was not necessary, because the red triangle and white circle symbols used for volcanoes and towns, respectively, are labeled on the map, and commonly found on other maps.

Most participants commented that the symbols that represent volcanoes, towns, roads, and the Aleutian Megathrust should be included in a legend, if the map were to include one. Participants reported that the best location for a legend would be in "an area that doesn't impede important map features," such as in, or under, the gray box with the text information, or within the area of the Pacific Ocean.

\section{Inset Map}

Necessary - All participants indicated that the volcano map had an inset map. Eight participants indicated that an inset map was necessary to orient the map, provide context about Alaska's location in a global context, and show what portion of Alaska is displayed in the main map. Three participants thought an inset map was not necessary because the title, graticule, and scale made the overall locational context of the map obvious.

Well Placed - Four participants indicated that the inset map is well placed, because it occupies empty space and "does not interfere with the main features on the map," while the remaining participants reported that the inset map was poorly placed, because "it is too big and has a too-prominent position." Many commented that the inset map was grabbing attention away from the main map features. These participants suggested that a smaller, more subtle, inset map, placed in the lower right corner (near the scale bar and DGGS logo), would be more appropriate.

Functional - Ten participants thought that the inset map helped them know where the geographic area was in relation to Alaska, Canada, and Russia, which are well-known and easily-recognized features. One participant claimed that the inset map would be more functional if it showed more of North America and Asia, especially for users who do not have knowledge of Russia's and Canada's locations.

Accurate - All participants agreed that the extent of the area shown in the inset map accurately matched the actual extent of the main mapped area.

\section{Graticule}

Necessary - Ten participants identified that the volcano map had a graticule and said that the map needed a graticule to give important location and orientation information and to help indicate scale and projection.

Well Placed - Ten participants recorded that the graticule is well placed because "it is where it is" and questioned "how could it be placed anywhere else?" Most participants also commented on the design of the graticule by offering that the color 
choice and simple design of the graticule "look fine" and that the labels were correctly placed. One participant did not record a response.

Functional - Ten participants indicated that the graticule helped them mentally place the mapped area in a global context. One person commented that "unless users have an inherent knowledge of latitude and longitude, the inset map is a better way to portray global location." One participant did not record a response.

Accurate - Ten participants agreed that the graticule accurately represented the location of the map but commented that it was challenging to identify the accuracy of the graticule just by looking at the printed map. One participant did not record a response.

\section{Metadata}

Necessary - All participants indicated that metadata were present on the volcano map and commented that metadata are important to give users additional information about how and why the map was made.

Well Placed - Most users commented that the amount of metadata on the map was sufficient for the map's purpose and that it was well placed in areas that did not interfere with the main map features. One participant commented that "Authorship and date should be prominent. The other items do not need to be front-and-center but should be present and findable by users who want this information." Suggestions for additional metadata included the publication date, data collection date, volcano eruption frequency, volcano eruption index, agency websites, and a Quick Response (QR) code.

Functional - Nine participants indicated that the metadata on the map gave them important production information about the map. One participant commented that, for their general use of the map, it was helpful to know who authored and published the map, but that the information about projection and datum was less useful. One participant was unsure how to define "important produc- tion information" and did not record a response.

Accurate - All participants indicated that the metadata accurately represented the map production details, but many remarked that determining the accuracy of metadata from viewing the map was difficult if not impossible.

\section{SURVEY RESULTS FOR DESIGN ALTERNATIVES}

For each marginalia element, all 23 participants viewed a collection of design alternatives and were asked to identify which design they found the most visually pleasing. Appendix $\mathrm{C}$ contains the full collection of design alternatives included in the questionnaire. For the north arrow, scale bar, title, legend, and inset map, participants viewed eight alternative designs for each element, labeled with a letter identifier (A through $\mathrm{H}$ ). Alternative graticule designs were shown to the participants for two maps: a small-scale map showing Alaska and the surrounding continents and oceans and for a large-scale map showing the area around Fairbanks, Alaska). Seven graticule designs (labeled A through $\mathrm{G})$ that differed in overall design and placement in the layer hierarchy were considered for the smallscale map, and six graticule designs (labeled A through F) were evaluated for the large- scale map. Figures 5, and 7-11, show the top three design alternatives chosen for each element.

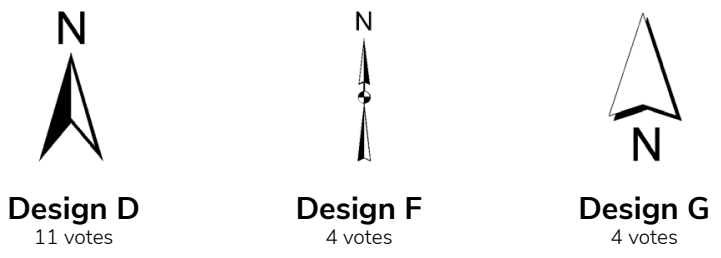

Figure 5. The top design alternatives participants chose for the north arrow.

\section{North Arrow}

Eleven of 23 participants indicated that design $\mathrm{D}$ (fig. 5) was the most visually pleasing north arrow, commenting that it was a clear, clean, and simple design that would provide good contrast on a variety of backgrounds. Designs F and G each received four votes. In addition to indicating their 
design choice, three participants chose to draw one or two north arrows of their own design. Figure 5 shows the top three design alternatives participants chose for the north arrow. Figure 6 contains the four custom north arrows illustrated by participants.

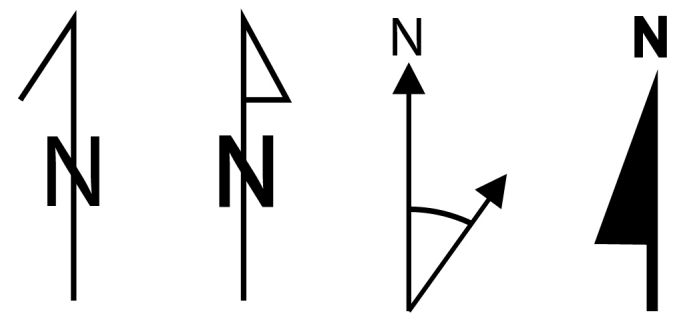

Figure 6. Custom north arrows drawn by participants.

\section{Scale Bar}

Sixteen participants indicated design E (fig. 7) was the most visually pleasing scale bar with a simple, bold, unambiguous, and useful design that would be legible at any size, and is similar to scale bars they see regularly. A few participants reported that the alternating dark and light segments of the scale bar made it easy to distinguish distances and were appropriate for a variety of backgrounds. Designs A, B, and F (fig. 7) all tied for second place with two votes each.
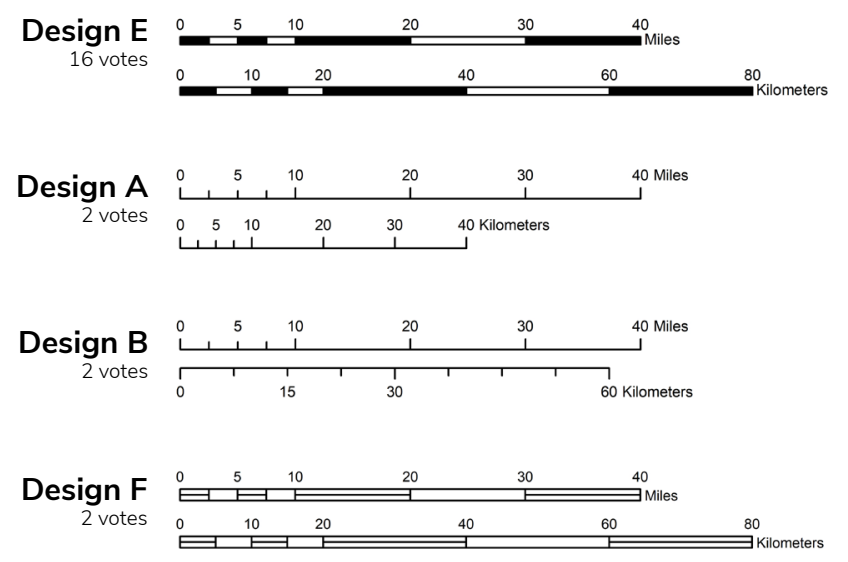

Figure 7. The design alternatives participants chose most often for the scale bar.

\section{Title}

Title designs C and D (fig. 8) each received six votes as the most visually pleasing title. Participants who chose design $C$ stated that the sans serif type face was clean, simple, and easy to read; and that the bold typeface and all-capital letters indicated the importance of the title. Participants who chose design $\mathrm{D}$ agreed that the sans serif type face was the most appealing. They noted that bold letters imply importance but thought title case was most appropriate for a title. Designs A, B, and E (fig. 8) tied for second place with three votes each.

\section{$\underset{6 \text { votes }}{\operatorname{Design} \mathrm{C}}$ BEDROCK GEOLOGY OF COOK INLET

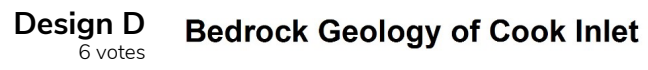 \\ $\underset{3 \text { votes }}{\text { Design A BEDROCK GEOLOGY OF COOK INLET }}$ \\ $\underset{3 \text { votes }}{\text { Design }} \quad$ Bedrock Geology of Cook Inlet \\ $\underset{3 \text { votes }}{\text { Design E }}$ BEDROCK GEOLOGY OF COOK INLET}

Figure 8. The design alternatives participants chose most often for the title.

\section{Legend}

Eleven participants indicated design A (fig. 9) was the most visually pleasing legend. Designs $B$ and E (fig. 9) each received 5 votes each. Participants reported that the simple and streamlined look of design A was the easiest to read and would also take up the least amount of space on a map. Many participants commented that the simple geometric symbols of design A were more appropriate than the complicated pictographic symbols of legend design B. Many participants also commented that the symbol groupings of design $\mathrm{E}$ would be preferable for a map with many symbols or layers. 


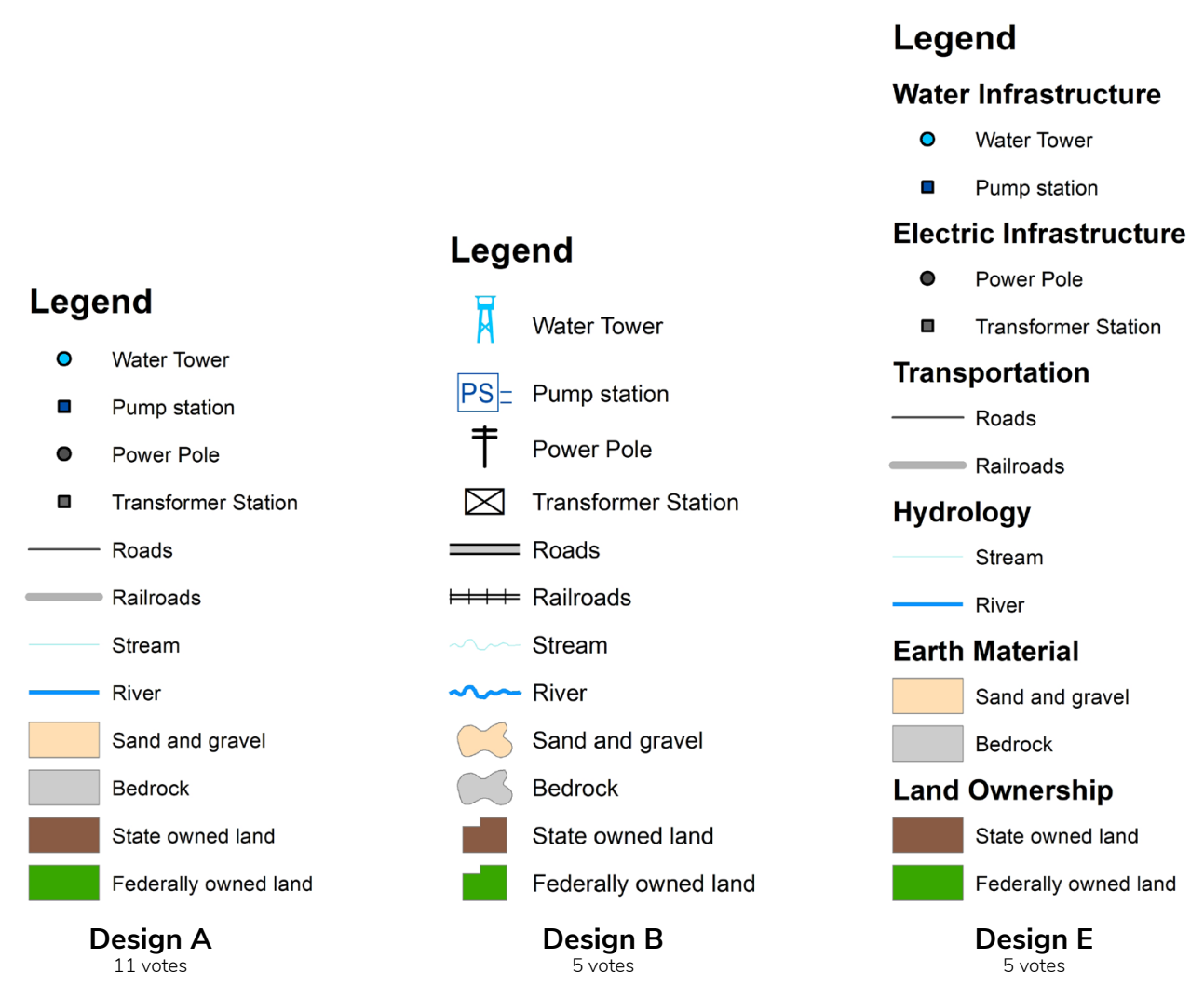

Figure 9. The design alternatives participants chose most often for the legend.

\section{Inset Map}

Twelve participants indicated design C (fig. 10) was the most visually pleasing locator inset map. Design A came in second and design $E$ was third, with seven and four votes, respectively (fig. 10). All participants chose inset map design alternatives that included a box outline, as opposed to a dot, to indicate a mapped area. All participants who preferred design $\mathrm{C}$ liked that Canada and Russia gave locational context and that the bounding box anchored the inset map so that "Alaska did not appear to be an island floating in space." Participants who chose design A preferred its extremely simple and straightforward design, without the distractions of additional lines and colors. Participants who selected design $\mathrm{E}$ were drawn to the additional regional, textural, and topographic information provided by the shaded relief. A few participants commented that adding shaded relief to design $\mathrm{C}$ would make it even more appealing; however, most other participants found the shaded relief to be overly distracting.

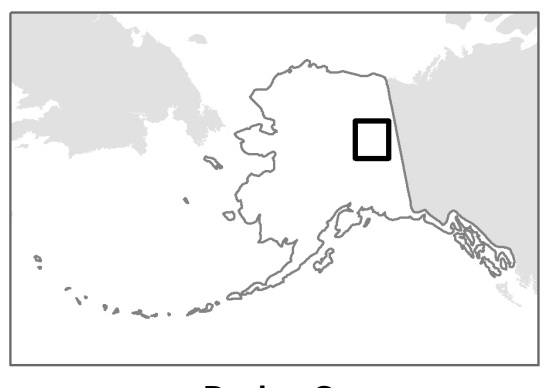

$\underset{12 \text { votes }}{\text { Design C }}$

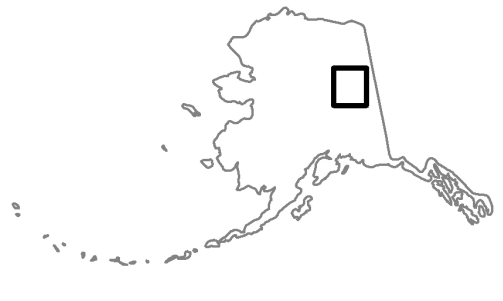

$\underset{7 \text { votes }}{\text { Design } A}$

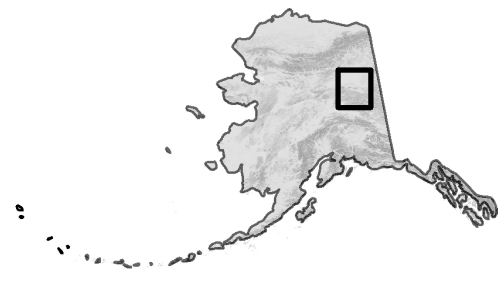

$\underset{4 \text { votes }}{\operatorname{Design}} \mathbf{E}$

Figure 10. The design alternatives participants chose most often for the inset map. 


\section{Graticule for maps that show both land and ocean areas}

Fourteen participants recorded that design A (fig. 11) was the most visually pleasing graticule for a map that shows both land and ocean areas. Participants commented that design A was the easiest to quickly read and understand and would provide reference for both land and ocean areas. Three participants preferred graticule design D (fig. 11), because the graticule "doesn't overwhelm the map as much" as other designs and commented that "the graticule for this small-scale map is mostly for looks, so it is best in the background." Designs B, C, and F ranked third with two participant votes each.

\section{Graticule for maps of land areas}

Eleven participants thought that design A (fig. 12) was the most visually pleasing graticule for a map that shows only land features. Participants preferred labels on all four sides of the map and the full grid of lines to provide balance and complete coverage without ambiguity. Many of the participants who chose design A commented that design E (fig. 12) would be a good choice if the map shows many features or is very busy. Six participants selected design E for similar reasons. Graticule designs B and C (fig. 12) tied for third place, with two votes each.

\section{SURVEY RESULTS FOR METADATA ELEMENT INCLUSION}

To address metadata design and how it should be considered for inclusion on a map, participants were given a list of important metadata components and asked to indicate each element's level of importance on a small-format map. The potential score for each element ranged from a minimum of 1 (always include) to a maximum of 10 (never include). Table 1 shows the summaries of the scores from the ten metadata elements, listed in accordance with their order in the questionnaire, and it includes both mean and modal scores derived from the 10-point continuum.

The mean score reflects the average scoring value by all participants, where the values ranged from one to ten. The mode is the score that was
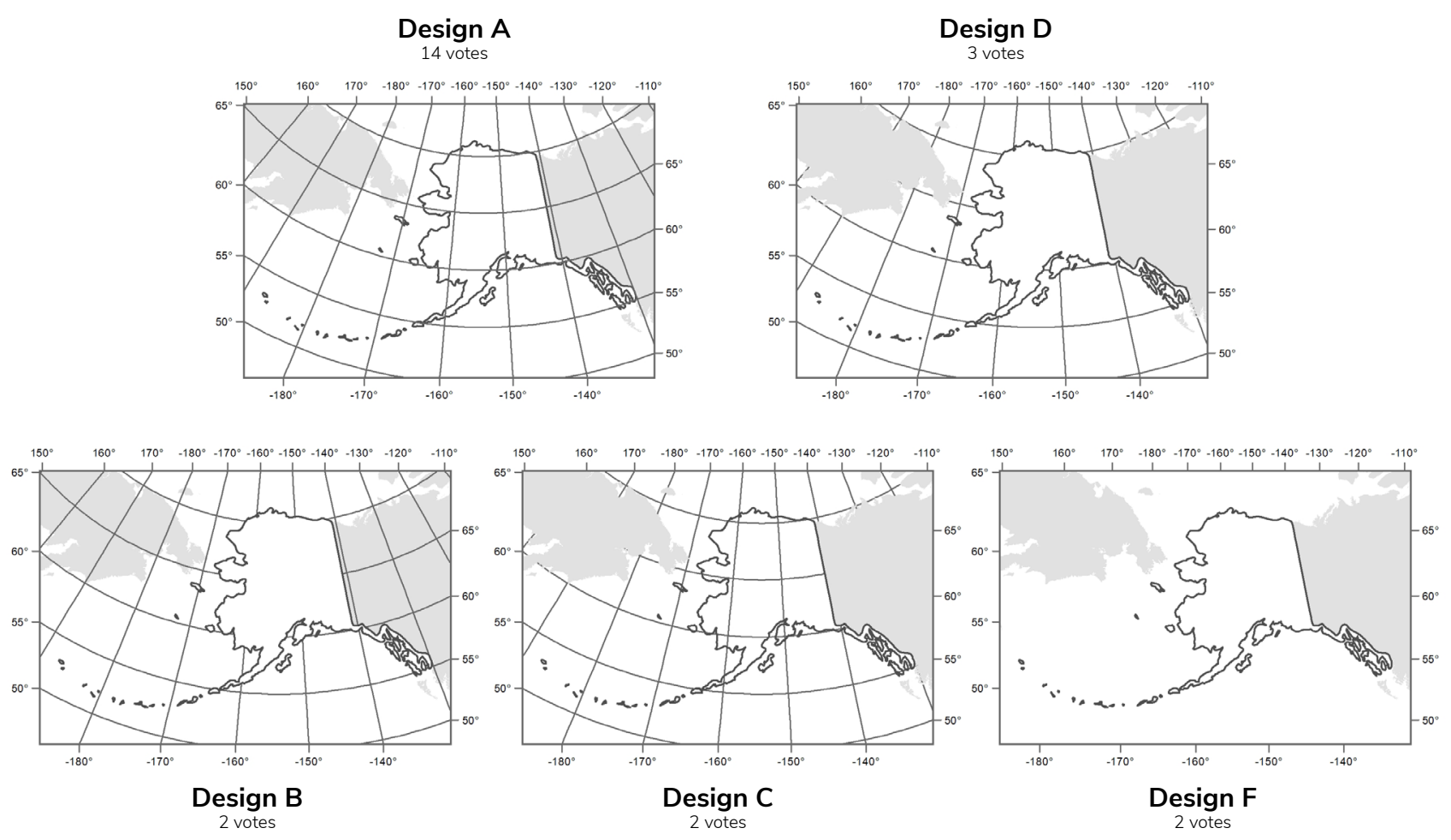

Figure 11. The design alternatives participants chose most often for the graticule for land and ocean areas. 
reported by participants more often than any other. A mode of one indicates the associated element was deemed the most important by a significant number of participants. When an equal number of participants chose two different scores the most frequently, two mode values are reported.
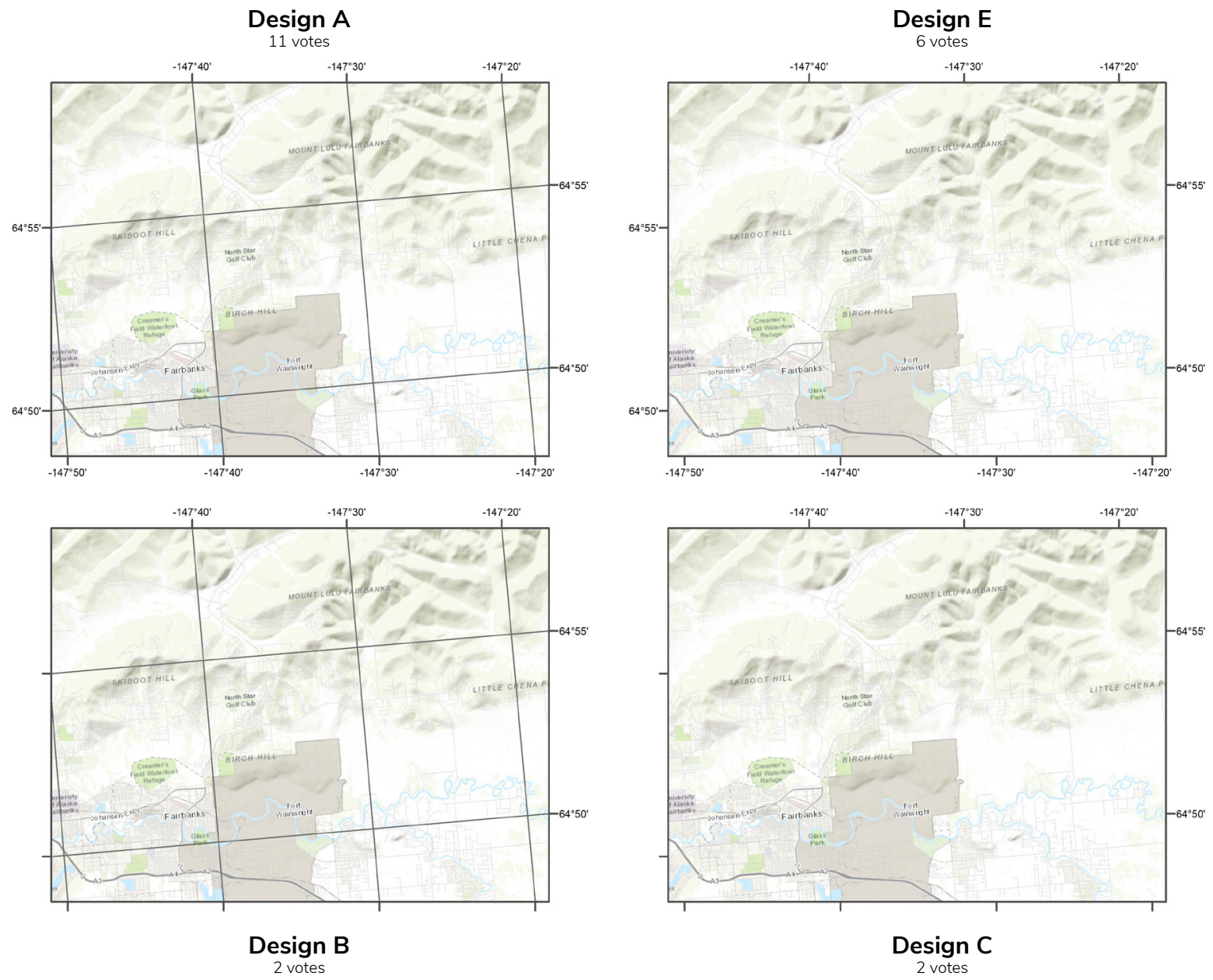

Figure 12. The top design alternatives participants chose most often for the graticule for land areas.

Table 1. Scores of metadata element importance.

\begin{tabular}{ccc} 
Metadata Element & Mean Score & Mode \\
\hline Names of the author(s) & 3.5 & 1 \\
\hline Credits or Acknowledgements & 6 & 7 \\
\hline Affiliations of the author or contributors & 5 & 1 \\
\hline Name of the publishing agency & 3 & 1 \\
\hline Logo of the publishing agency & 4.8 & 5 \\
\hline Name(s) of contributing agencies & 4.1 & 1 and 3 \\
\hline Logo(s) of contributing agencies & 6.2 & 1 \\
\hline Publication number & 3 & 1 \\
\hline Coordinate System Information & 2.9 & 1
\end{tabular}




\section{COMPARISON OF SURVEY RESULTS TO ACCEPTED CARTOGRAPHIC PRACTICES}

This section compares the survey results to the research and practices documented in the literature review.

\section{NORTH ARROW Inclusion/Exclusion}

Many participants who examined the Cook Inlet map, and a few who examined the volcano example, stated that "all maps need a north arrow." This is divergent from the Slocum and others (2009) statement that not all maps need north arrows, because most map users expect north to align with the top of the page.

Most participants who viewed the volcano map indicated that a north arrow should be included on a map only if it is functional. These participants considered a north arrow functional if it was accurate (indicated north for all points shown on the map) or, in cases where the direction of north varied across a map, solely intended to give users a general sense of orientation. This agrees with the description that the purpose of a north arrow is to indicate orientation or the direction of north (Slocum and others, 2009 and Brewer, 2005).

The participants' general conclusions about the inclusion or exclusion of a north arrow on a map are supported by Slocum and others (2009) and Brewer (2005) who concluded that a north arrow should not be included on a map if its orientation varies, such as on a map using a projection with curved meridians.

\section{Placement}

Participants from both groups preferred that the north arrow be placed near the scale bar. This is in agreement with Slocum and others (2009) and Brewer (2005) who state that the preferred placement of the north arrow is out of the way and near the scale bar. Many participants, who viewed the Cook Inlet map, concluded that the north arrow can confuse the user if it is placed too far away from the map face to which it refers. This is consistent the suggestion that, for small-format maps, the north arrow should be placed directly on the map face (Peterson, 2014).

\section{Design}

Most participants shared the preference that a north arrow should be simple and only show the direction of north. This is in agreement with Slocum and others (2009) who state that a north arrow should be simple and subtle, with only the north direction indicated.

\section{SCALE BAR \\ Inclusion/Exclusion}

Almost all participants stated that a scale bar is necessary to show the sizes, proportions, and spatial relationships of features on the map, even if the scale bar gives only a general sense of scale. This aligns with the recommendation that a scale bar should be included if distance information enhances the user's understanding of the map theme (Slocum and others, 2009 and Brewer, 2005). A few participants thought that all maps require a scale bar, which doesn't align with the recommendation that a scale bar may be excluded from a map if it does not enhance the map user's understanding of the map theme or if scale changes greatly across the mapped area (Slocum and others, 2009 and Brewer, 2005).

Participants noted that, depending on a map's scale and projection, the scale bar may not be accurate for all areas of the map, but may still be used to get a general sense of distance. This aligns with the consensus that a scale bar should be omitted in cases where scale changes greatly across the mapped area, unless the standard point, line, or lines on the map where the scale bar is accurate (principal scale) is clearly noted (Slocum and others, 2009). 


\section{Placement}

All participants indicated that the scale bar should be placed in a location that is easy to find and close to the mapped area, preferably near the bottom of the map. This conclusion is supported by the guideline that the scale bar should be placed below the mapped area when possible because map users are accustomed to finding it there (Slocum and others, 2009 and Brewer, 2005). Participants also elaborated that the scale bar should be placed in a location where it is legible and does not obstruct underlying map features. This is similar to suggestions in the literature that the scale bar may be placed in any available space that can accommodate its height and width (Slocum and others, 2009 and Brewer, 2005).

\section{Design}

Most participants shared the preference that a scale bar should be simple and subtle. This is in agreement with Slocum and others (2009) who state that a scale bar should be simple, subtle, and legible.

\section{TITLE}

\section{Inclusion/Exclusion}

All participants concluded that the purpose of a title is to convey the main point of the map. Most participants agreed that all maps should have a title-except in situations when the map is a figure in a larger report and is accompanied by a descriptive figure caption. This is in agreement with Slocum and others (2009) who state that "most maps require a title, although a title is sometimes omitted when a map is used as a figure in a written document, assuming that the theme is clearly expressed in the figure caption."

\section{Placement}

Most participants preferred the top center of the map for the title. This agrees with the assertion that the top center of the map is the best location for the title because map users are accustomed to seeing it there (Slocum and others, 2009 and Brewer, 2005). A few participants preferred that the title be located at the bottom of the map near the legend and scale bar. This is also consistent with the idea that a title may be placed near the legend, allowing a user to easily look back and forth between the title and legend; however, this arrangement is more commonly used on large-format maps (Slocum and others, 2009 and Brewer, 2005).

\section{Design}

A small majority of participants, who preferred a title in bold typeface to further emphasize the importance of the title or map, don't share Slocum and others' (2009) opinion that a bold typeface is not usually necessary to emphasize a title if an appropriately sized type is used. Most participants agreed with Slocum and others (2009) that a title should be simple, clean, and easy to read.

\section{LEGEND}

\section{Inclusion/Exclusion}

Three quarters of participants stated that all maps need a legend to clearly explain the colors and symbols on the map, while the remaining participants commented that a legend is not necessary for symbols that are clearly labeled or commonly found on other maps. Both opinions are supported by conclusions of Slocum and others (2009) and Brewer (2005) that, although most thematic and reference maps should include a legend, omitting one is acceptable if the symbols do not enhance the user's understanding of the map or are self-explanatory. Therefore, the intended audience should be considered when making the decision of whether to include a legend (Slocum and others, 2009 and Brewer, 2005).

\section{Placement}

All participants thought that a legend should be placed in a location where it utilizes white-space and does not obstruct other map features. This agrees with the statement that the legend should be placed within a larger area of available space defined by other features (Slocum and others, 2009 and Brewer, 2005). 


\section{Design}

Most participants agreed that the legend design should be simple and subtle (Slocum and others, 2009 and Brewer, 2005). Roughly two thirds of participants chose a design with simple geometric (rather than mimetic) symbols. None of the participants commented whether the label "Legend" is required-Slocum and others (2009) assert that a legend need not be labeled as such because the fact that it is a legend is obvious.

All participants chose legend designs that contained a symbol description, which supports the idea that a descriptive label should accompany each symbol represented in the legend (Slocum and others, 2009 and Brewer, 2005).

Many participants preferred that symbols representing similar features be grouped in the legend if a map has many symbols or layers. This is consistent with the conclusion that logically grouping the symbols in the legend into related categories will assist the user in reading the map (Slocum and others, 2009 and Brewer, 2005).

\section{INSET MAP \\ Inclusion/Exclusion}

All participants agreed that a locator inset map should be included on a map to help orient the user and indicate the location of the mapped area. This is in agreement with Slocum and others (2009) and Brewer (2005) who recommend an inset map be included if one is necessary to show overall context or geographic location of the mapped area.

\section{Placement}

Participants from both groups agreed that an inset map should be located so that it occupies vacant space and does not cover up map data. This is in agreement with Slocum and others (2009) and Brewer (2005) who conclude that an inset map should be placed so that it does not interfere with main map features. Many participants' commented that an inset map should be placed so that it avoids drawing attention away from the main map. This is supported by Slocum and others (2009) and Brewer (2005) statement that the use and placement of inset maps depend on the available space and needs of the map user.

\section{Design}

Most participants shared the preference for a simple inset map. This is in agreement with Slocum and others' (2009) and Brewer's (2005) guideline that a simple and subtle inset map is preferable when possible, but that more complexity might be appropriate depending on its intended purpose.

\section{GRATICULE}

\section{Inclusion/Exclusion}

Participants indicated that a graticule should be included on a map to give the map user location and orientation information. This is in agreement with Slocum and others' (2009) and Brewer's (2005) statement that a graticule should be included on a map if orientation or position information are needed to enhance the map's message, theme, or the user's understanding.

\section{Design}

\section{Graticule for maps that show both land and ocean areas}

Over half of the participants preferred a design where the graticule visually overlaid all mapped features. This is contrary to Dent (1998), who advocates that a graticule should usually be treated as a background element.

\section{Graticule for maps of land areas}

Slightly less than half of the participants preferred a design where the graticule fully overlaid all mapped features and includes labeled tic marks on all sides of the frame line, while almost a quarter of participants chose a design where the graticule was indicated only by labeled tic marks on all sides of the frame line. According to Slocum and others (2009), either option would be acceptable if the graticule is simple and subdued so that it does not visually compete with the other map content. 


\section{METADATA Inclusion/Exclusion}

All participants recognized that metadata should be included on the map when it is necessary to provide additional map information, such as how and why it was created. This is supported by the guideline that metadata should be included on the map if it will help the user interpret the map more accurately (Slocum and others, 2009).

For this survey, the coordinate system metadata element had the lowest mean score and mode, which indicates participants viewed this element as being the most important metadata on a map. Slocum and others (2009) asserts that coordinate system information is important to include on a map because it can be used to alert the map user to potential distortions in the mapped area, especially at small scales.

The name of the publishing agency and publication number metadata elements had the second lowest mean score and mode, indicating that participants viewed publisher information as more important than authorship information. This contrasts Peterson's (2014) statement that a map of serious scholarly consequence needs real people standing behind it. In his book, Beautiful Evidence,
Edward Tufte (2006) goes further- stating, "We should remember that people do things, not agencies, bureaus, departments, or divisions. People may do better work when they receive public acknowledgment and take public responsibility for their work."

Slocum and others (2009) also describes the importance of data source metadata, which may help the user determine if the data being represented are recent or reliable. Supporting Slocum and others (2009) statement, as seen in table 1, the data source metadata element has a mode value of 1 , which indicates that a significant number of participants deemed it the most important. Slightly contrary to this idea, the mean score of the data source metadata element is 4.1 , which indicates that a majority of participants thought this element was less important and assigned it a larger number that resulted in a higher mean score.

\section{Placement}

Participants commented that well-placed metadata should not interfere with the main map features. This is in agreement with Slocum and others' (2009) conclusion that metadata location may vary due to available space and the needs of the map user but should never attract undue attention. 


\section{REFLECTION ON SURVEY RESULTS}

The purpose of this study is to establish recommended designs for map marginalia and present guidelines for their inclusion, design, and placement. These guidelines and recommendations will enhance users' ability to find and understand information illustrated on DGGS maps. This section identifies common themes and discusses and reflects on the survey results within the context of DGGS. The authors of this paper considered preferences revealed by this study and the requirements of DGGS authors and publications. Drawing on their experience as cartographers and their extensive knowledge of cartographic standards and design, they discuss their conclusions in this section and offer their perspectives on cartographic design at DGGS.

\section{NORTH ARROW}

Six participants from the group who examined the Cook Inlet map (three map makers and three map users) stated that "all maps need a north arrow"; however, when the same participants were asked if the north arrow shown on the map accurately pointed toward north for all locations on the map, they responded that it did not or that it was "close enough". Elaborating on their ideas, they considered the purpose of the north arrow to be an indicator of general, rather than accurate, orientation.

It is common for novice map makers to think that all maps need a north arrow. Although not specifically intended for this study, the survey questions about the north arrow guided participants through a critical examination of the utility and accuracy of the north arrow. It can be inferred from participant comments that the first question, about the need for a north arrow on the specific map, inspired people to consider whether "all maps need a north arrow." The next questions may have helped people think about why the map would or would not need a north arrow based on its utility and accuracy. The wording of these questions indicate that a north arrow is considered functional if it helps the user orient the map and is considered accurate if it points to the north for all locations shown in the map (in other words, if orientation does not vary greatly across the mapped area). One participant, who viewed the volcano map, first stated that the map needed a north arrow, then, when answering the question regarding accuracy, stated "Well, now that you mention it...this is a trick question! No, I would say it's not exact since it's a small-scale map; however, I still think there should be one for the general purpose of orientation." Such a statement reflects this participant's general desire for a directional indicator even in cases when a north arrow would not be necessarily accurate across the entire mapped area. The statement also reveals the participant's recognition of a north arrow's utility considering the map scale.

\section{North Arrow Accuracy as a Function of Scale and Projection}

DGGS authors make thematic maps at many scales and with a variety of projections. Both scale and projection impact the accuracy of a north arrow and appropriateness of including a north arrow on a map. Many participants, from both survey groups, confirmed their familiarity with this concept by responding that the accuracy of the north arrow was influenced by the map scale and projection; however, many participants also advocated for inclusion of a north arrow on most maps.

The amount of variation in orientation across a map and how it is affected by scale and projection can be visualized by viewing the map's graticule. For example, the graticule on a large-scale map, regardless of the projection used, will likely look like a grid of parallels and meridians. If the meridians do not appear to converge toward the poles, then the direction of north does not vary greatly over the mapped area. In such situations, a single north arrow is accurate for all locations on the map. On the other hand, the graticule on a small-scale map in the northern hemisphere, depending on 
the projection used, may appear to have meridians that are curved or start to converge to the north. This indicates that the direction of north varies over the mapped area. In such situations, a single north arrow would not be accurate at all locations on the map, and the map maker might consider using the graticule to indicate orientation rather than including a north arrow on the map.

As the scale of the map becomes smaller, the map projection greatly influences the direction of "north" across a map, which can be visualized by the arrangement of the graticule. For example, meridians on a small-scale map with a conic projection will converge to either the North or South Pole, indicating that north/south orientation varies across the map. A map of the same area at the same scale using a cylindrical projection (like the very popular Mercator projection) will have meridians that remain parallel. When a cylindrical projection is used, even at a small scale, north orientation will not vary across the mapped area suggesting that a north arrow would be accurate over the entire map.

The effect of scale and projection on maps of Alaska is often exaggerated, because Alaska is located so far north. This effect is amplified when the map covers a significant area of this large state. At DGGS, the Alaska Albers Equal Area Conic projection is commonly used to illustrate statewide datasets or data that span multiple UTM zones. Because the Albers is a conic projection, the direction of north will vary across a small-scale map and a single north arrow would not be accurate. In such cases, if an accurate indication of north is necessary for the use and interpretation of the map, a graticule should be used to indicate orientation. Doing so provides a clear indication of orientation, informs map users of the variation in the north direction across the map, and can help indicate any distortion due to the projection.

\section{Inclusion and Accuracy of the North Arrow}

When map users say, "all maps need a north arrow", they generally are not commenting on the appropriateness of the north arrow inclusion, but rather mean that all maps should include some way to indicate their general orientation. Many of the people who examined the Cook Inlet map responded that "all maps need north arrows" but upon reflection, stated that although the north arrow on the Cook Inlet map was not necessarily accurate it provided a general sense of orientation. This suggests that map users desire a general indication of map orientation and do not necessarily expect the orientation of the north arrow on such a map to be exact. Many small-format maps produced at DGGS do not conform to the "north up" standard-which may help explain participants' desire for a general indication of orientation.

Participants generally recognized that a map should not display a north arrow that is neither accurate nor functional. As discussed earlier, the accuracy of a north arrow can be determined by considering the scale and projection of the map. The functionality of the north arrow can be subject to some individual interpretation, but it is crucial to the decision of whether to include a north arrow on the map. Only functional north arrows (associated with both its accuracy and intended purpose) should be included on a map.

The north arrow on a map could be both accurate and functional (table 2). For example, a large-scale topographic map intended for navigating and field data collection would require an accurate north arrow or other indication of orientation. In this case, a north arrow on such a map would be considered both accurate and functional.

The north arrow on a map could be accurate and non-functional (table 2). A large-scale map that conforms to the "north up" standard may include an accurate north arrow; however, if orientation is not necessary for the interpretation or use of the map, the north arrow cannot be considered functional. For example, a large-scale map of the University of Alaska Fairbanks's ski trails conforms to the "north up" standard and is intended for locals who are likely familiar with the area and the orientation of the 
Table 2. Examples of maps where a north arrow would be considered functional, non-functional, accurate, and inaccurate. A north arrow should be included or excluded based on its functionality for use by the intended audience based on the map's intended purpose.

\begin{tabular}{cll} 
& \multicolumn{1}{c}{ Functional } & \multicolumn{1}{c}{ Non-Functional } \\
\cline { 2 - 3 } Accurate & $\begin{array}{l}\text { Large-scale topographic map intended for } \\
\text { navigating (include a north arrow) }\end{array}$ & $\begin{array}{l}\text { Large-scale map of ski trails intended for local } \\
\text { users familiar with the area (exclude a north arrow) }\end{array}$ \\
\hline Inaccurate & $\begin{array}{l}\text { Small-scale reference map of southeast Alaska } \\
\text { cruise ship routes intended to provide locational } \\
\text { context for an audience unfamiliar with the area } \\
\text { (include a north arrow) }\end{array}$
\end{tabular}

surrounding streets and landmarks. On such a map, if a north arrow was included it would be accurate, but it is unlikely that map users would find it useful. In such cases where the north arrow is non-functional, it should not be included on the map.

The north arrow on a map could also be inaccurate and functional (table 2). For example, a smallscale map of Southeast Alaska, that is intended to provide locational route and context for cruise ship passengers, may include a north arrow that is not accurate for all points on the map. If a general sense of orientation is necessary for map users to orient the map (if they are unfamiliar with southeast Alaska, find the northwest to southeast trending waterways confusing, or if the map does not have north at the top of the page), then the north arrow can be considered functional. In such cases, and in those where overall contextual information is required, a north arrow or some other indication of orientation (such as a graticule) should be included.

The north arrow on a map could also be inaccurate and not functional (Table 2). For example, if a north arrow were included on small scale map of bird migration routes across North and South America, it would be considered neither accurate nor functional. Such a north arrow would be inaccurate because of the scale and projection of the map and would be non-functional, because most users are familiar with the general orientation of the continents. In such cases, the north arrow should not be included on the map.

As supported by participants' comments, the decision to include a north arrow on a map should be influenced by the north arrow's accuracy and functionality. When making a map, omit the north arrow if it is neither accurate nor functional for the intended audience or purpose.

\section{Design of the North Arrow}

The north arrow that was preferred by most participants (design D; fig. 5) is used on many DGGS maps. Preference for this design may be influenced by participants' familiarity with it from viewing and using DGGS maps that employ design D. Participant preference for this design, at least among the map makers, may also be influenced by its easy availability in the ESRI ArcMap 10.8 North Arrow Selector window. The design's position in the top row and right-hand side of the North Arrow Selector window (fig. 13) makes it very visible and easy to immediately click on.

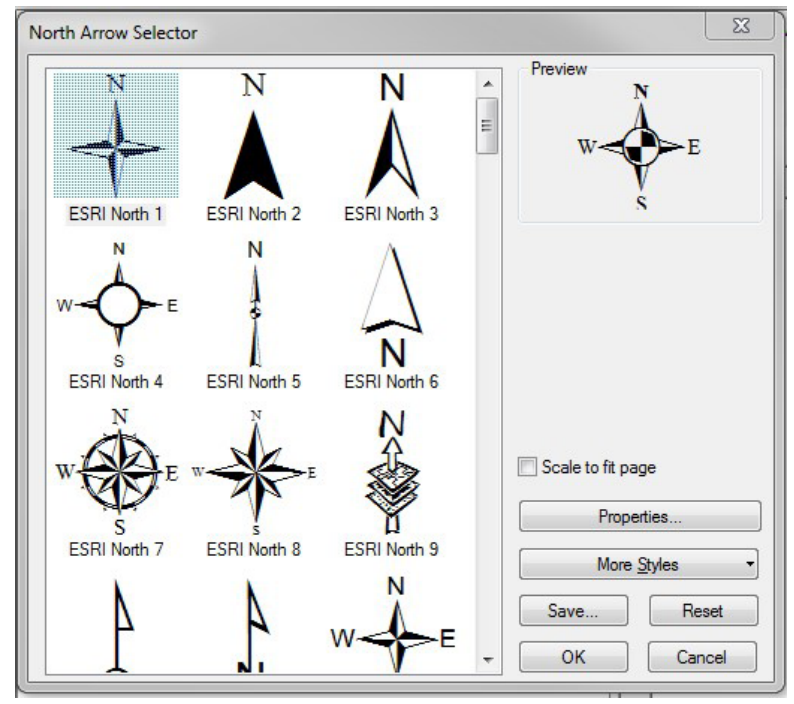

Figure 13. The north arrow designs shown in the ESRI ArcMap 10.8 North Arrow Selector window. 
Design C (ESRI North 1), the ESRI default north arrow is not the ideal north arrow for a small-format map, because it is overly decorative and complex - a four-pointed star is not needed to indicate north on most maps. The two north arrow choices that received the second highest number of votes, design F (ESRI North 5) and design G (ESRI North 6) are in the second row of the North Arrow selector. It is possible that map makers think that these north arrows are listed in order of their cartographic suitability or, perhaps, they just do not want to have to scroll through a large list. The top three selected designs in the survey (fig. 5) are all relatively simple north arrows, which may indicate that participants prefer simple but functional designs.

Some participants commented that a north arrow design with good contrast would be appropriate for a variety of backgrounds. This is logical, as DGGS maps often contain a wide range of backgrounds, including hillshade relief, hypsometric tinted elevation combined with a hillshade, topographic and bathymetric contours, air photo, satellite imagery, or bright and/or complex colored geologic map units. In such cases, the north arrow must have sufficient contrast against the background to be clearly seen, which makes the ESRI North 3 design an ideal choice.

As seen earlier in the Survey Results for Design Alternatives section of this report, four participants chose to illustrate their own alternative north arrows designs (fig. 6). These designs are relatively simple, depicting a line arrow with only the letter $\mathrm{N}$, which reflects participant's stated preference for simple designs. In two of the participant's illustrated designs the letter $\mathrm{N}$ is overlaid by the north arrow, which is surprising because the stem of the arrow interferes with the letter. One participant drew a north arrow that included a second, smaller arrow to represent magnetic declination (the difference between true north and magnetic north). Geologists and scientists who gather field data are very aware of magnetic declination and its effect on field data collected with a compass, especially in Alaska where declination is significant. Many large-format DGGS maps, which show geologic structure points which reference the azimuth and inclination of a plane, include a compound north arrow that indicates true north, magnetic north, and magnetic declination. In such cases, declination is very important; however, magnetic declination is often not relevant on small-format maps, and such a complex north arrow would rarely be functional or necessary.

One participant who examined the volcano map stated that the map "needs a north arrow to be consistent with other maps". This comment, along with the numerous comments that all maps should have north arrows, brings up the idea of consistency regarding overall map design. By conducting this survey and summarizing the findings, it is hoped that map users become more aware that maps coming from a single organization should have a consistent overall design and that DGGS small-format maps would benefit from increased consistency.

\section{SCALE BAR}

Most participants stated that knowing the map scale and having the ability to measure or estimate distances is important for many map purposes. Some participants stated that all maps need scale bars; however, the inclusion of a scale bar should be considered based on its accuracy and utility.

\section{Inclusion and Accuracy of the Scale Bar}

Although not extremely practical for measurement tasks, a globe is the only small-scale way to represent Earth with constant scale across its surface in all directions. On globes, one "scale" applies equally across the globe's surface. On a map, a scale bar is used to measure distances with varying degrees of accuracy. The accuracy of the scale bar will impact its utility and help determine whether or not to include it on a map. Depending on the map theme, purpose, and intended audience, the scale bar on a map may be expected to be relatively accurate in order to measure distances or areas on 
the map. According to Slocum and others (2009), "All bar scales loose much of their utility when used on maps in which scale changes greatly from one location to another" (p. 199). Participants hinted at their familiarity with this concept when they noted that, depending on a map's scale and projection, the scale bar may not be accurate for all map locations.

The accuracy of the scale bar is influenced by how much the scale is distorted across the mapped area which is determined by the map's scale and projection. For example, smaller-scale maps that depict large geographic areas, will have greater scale distortion across the mapped surface than larger-scale maps that cover smaller geographic areas. The amount of scale distortion across a map is also impacted by the projection property. For example, on conformal projections scale is constant at every point in all directions along a given line of latitude but scale changes according to latitude, while scale on equal area projections changes constantly across the map.

Area and distance distortion are also affected by the scale and projection of the map. At small map scales, the projection of the map greatly impacts the magnitude and pattern of the area and distance distortion. At large scales, area and distance distortion will not vary greatly over the mapped area regardless of projection. Therefore, as the map scale becomes larger (e.g., 1:250,000, $1: 100,000,1: 24,000)$, one can expect the scale bar to be more accurate for all features on the map.

How quickly distortion changes across a map can be controlled by specific lines called "standard lines". Many projections include standard lines along which there is no distortion. On projections that include standard lines, area or distance measurements will be accurate near standard lines but those measurements will become increasingly inaccurate the further away from the standard lines. This concept can be visualized by comparing distortion found in the two common projections - the Mercator cylindrical (fig. 14) and the Albers equal area conic (fig. 15).

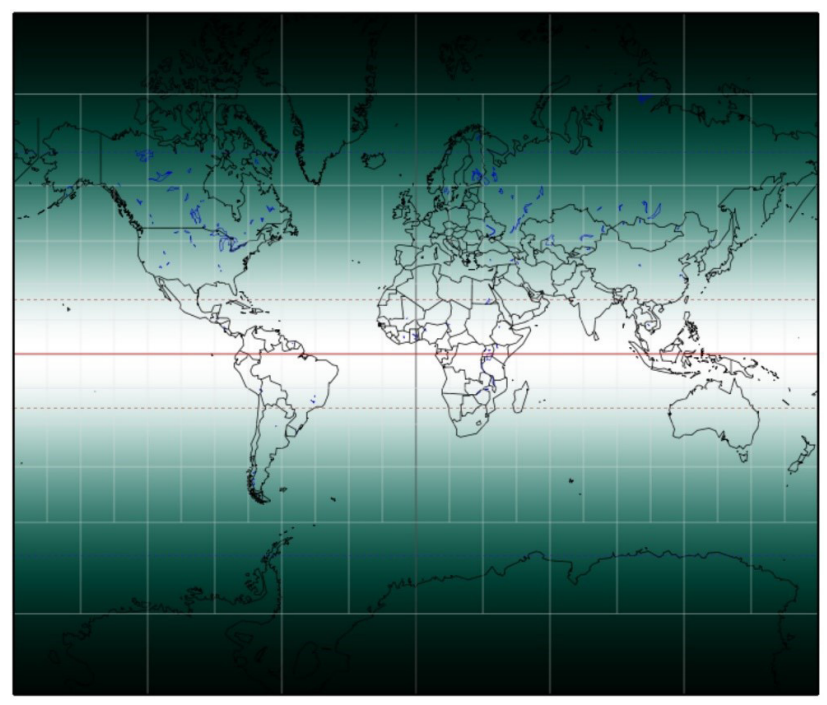

Figure 14. The Mercator cylindrical projection with the equator (solid red line) as the standard line. Darker green color values correspond to an increasing amount of areal distortion. There is no magenta appearing on this map since the projection preserves angular relations. (Image created by Fritz Kessler using Geocart v3.0.1).

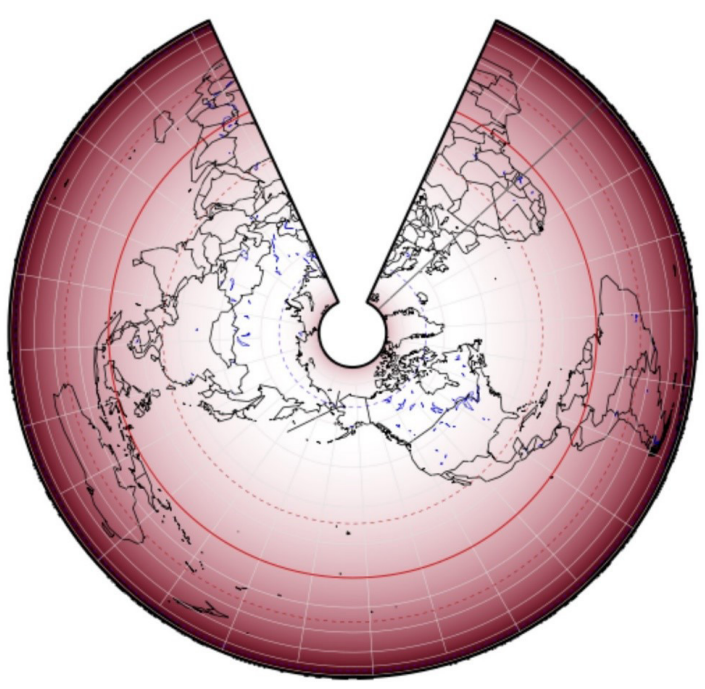

Figure 15. The Albers equal area conic projection with standard lines at $55^{\circ}$ and $65^{\circ}$ north. Darker magenta color values correspond to an increasing amount of angular distortion. There is no green appearing on this map since the projection preserves areal relations. (Image created by Fritz Kessler using Geocart v3.0.1).

Figures 14 and 15 use color gradations to show distortion across the image where green represents areal distortion, magenta represents angular distortion, and gray represents scale distortion. Light 
colors indicate low distortion while darker colors indicate more distortion. White indicates no distortion of any type and black indicates a lot of distortion combing all three types.

Figure 14 shows the Mercator cylindrical projection that uses the equator as the standard line. On this projection, in the upper latitudes, there is considerable distortion of all three properties - areal, angular, and scale- - (as indicated by the black coloring) while at the equator, no distortion is found (as indicated by the white color). Note that the green color values darken from the equator poleward suggesting an greater amounts of areal distortion on this projection. Therefore, when using the Mercator projection, only areas or distance measurements close to the equator will be accurate. Area and distance measurements more distant from the equator will become less accurate unless a specialized scale bar on this projection is shown (i.e., a scale bar that is sized differently according to the latitude at which the distance is measured).

Figure 15 shows the Albers equal area conic projection that is optimized for Alaska by using lines of latitude at $55^{\circ} \mathrm{N}$ and $65^{\circ} \mathrm{N}$ as standard lines. This projection shows light magenta color values near the standard parallels. The magenta color values become increasingly dark toward the poles, especially the South Pole, indicating greater amounts of angular distortion. Unlike the Mercator, it is only near the South Pole on the Albers projection that we see black-indicating maximum levels of areal, angular, and scale distortion. When using the Albers projection, area and distance measurements taken close to the standard lines are more accurate than measurements that are more distant from these lines.

At larger map scales, the scale bar is more accurate for a given mapped area than on a smaller map scale. On small-scale maps, the accuracy of the scale bar decreases as measurements are taken further from the projection's standard line or lines; however, as implied by many study participants, a scale bar may still give the user of a small-scale map a general sense of distance and allow measurements that approximate distance across the map.

\section{Inclusion and Utility of the Scale Bar}

The utility of the scale bar is often a function of the map's theme, purpose, and intended audience. If a scale bar will not be useful to the map user or enhance the readers understanding of the maps theme, then it should not be included on the map. For example, a scale bar could serve a purpose on a map of major highways of Alaska intended for tourists. On such a map, the reader could use a scale bar to estimate the road length (and therefore driving time) between two cities. In another instance, a scale bar on a geologic map of Alaska also intended for tourists would be less useful. Although a reader could attempt to calculate the area of a geologic unit using the scale bar, the irregular shape of the areas would make the task cumbersome. Regardless, when designing the map, the cartographer would need to carefully select an appropriate map projection and choose the standard line placement to ensure that the distortion allows the scale bar to be used, for example, for accurate distance measurements.

A scale bar can also be useful to give the map user a general sense of scale, such as a sense of how much of the earth's surface is being displayed in the map frame. By saying that a scale bar is necessary on all maps, it can be surmised that the participants were expressing the general utility of a scale bar. Using the earlier example, a scale bar might be included on a geologic map of Interior Alaska that is intended for tourists. Although the scale bar wouldn't be useful to make accurate area measurements of the geologic units, it may give the reader (who is unfamiliar with Alaska) an idea of how large Interior Alaska is (it is about the same size as Colorado). In such cases, an inset map may be a better option to show the general size and geographic context of Interior Alaska. 
Survey, participants favored the inclusion of a scale bar on the example small-format maps. While it seems unlikely that the scale bars would be used to make accurate or detailed measurements on these maps, survey participants who are scientists are generally accustomed to being able to make accurate measurements on large-scale maps, so they likely prefer maps that include a scale bar - even if the scale bar is not useful for accurate measurements.

One participant commented that "the volcano map did not need a scale bar because the graticule indicated scale". If the graticule has latitude lines labeled with the appropriate degree values, then one could make an approximation of scale at that latitude. Although knowing the scale at a given latitude would be accurate, this approach seems cumbersome and it is doubtful that most map users would be capable of such calculations. A well-designed scale bar would be a much simpler tool for the map user to estimate areas or distances on the map.

\section{Design of the Scale Bar}

The participants preferred that a scale bar design be simple, subtle, and legible. Participants commented that they also preferred a scale bar that is unambiguous, bold, and appropriate for both dark and light backgrounds; similar to scale bars seen regularly on DGGS maps. In the design alternatives portion of the questionnaire, design $\mathrm{E}$ (fig. 7) was the overwhelming favorite. Although design $\mathrm{E}$ is a simple and legible scale bar, it is not subtle and could easily overwhelm simple maps with its darkness and boldness; however, this scale bar is frequently included in DGGS small-format maps because it is bold and has high contrast that would work for the various backgrounds.

Design $\mathrm{E}$ is the scale bar shown on the Cook Inlet Map. Of the 12 participants who viewed the Cook Inlet map, eight of them chose design $\mathrm{E}$ as their favorite. The presence of this scale bar on the Cook Inlet map probably did not influence participants' choices, because 67 percent of the participants in the Cook Inlet group also chose design E- approximately the same as the 73 percent of participants in the volcano group who chose that design.

It is surprising that design $\mathrm{F}$ did not get more votes (although it was tied with designs $\mathrm{A}$ and $\mathrm{B}$ for second place), because it is the style of scale bar used on the DGGS large format maps; however, design $\mathrm{F}$ is rather busy, especially if it were to be small in size (as it would need to be on a smallformat map), which may explain why participants did not favor it. Design $\mathrm{F}$ is the scale bar used in the volcano map, and both people who chose it as their preferred design were from the volcano map group. The presence of this scale bar design on the volcano map could have influenced their choices.

Scale bar designs A and B are very similar and are the simplest of the design alternatives. Given participants' stated preference for simple and subtle designs, it is incongruous that more people did not choose one of these two designs. Participants may have been concerned that the simple lines of designs A and B would not show up adequately on a busy background like satellite imagery or a lidar hillshade. It is possible that participants found this simple design less scientific, credible, or official looking, when compared to designs $\mathrm{E}$ and $\mathrm{F}$.

\section{TITLE}

\section{Inclusion of the title}

All participants concluded that a title should be included on most thematic maps-except in situations where the map is a figure in a larger report and is accompanied by a descriptive figure caption. This conclusion reflects that DGGS map makers frequently produce small-format maps that are included in a written report. During the initial map selection process of this project, it became apparent that more small-format maps were published as part of written reports than as individual stand-alone publications. As a result of frequently including maps as figures in written reports, DGGS staff are accustomed to writing and including descriptive figure captions to be viewed alongside such maps. In those cases, the recommendation, that a map title should be included on small-format maps can be relaxed. 
It is important to note, however, that often a map figure is copied out of the report and used without the caption - for example in a PowerPoint presentation. In these cases, a title can help to reduce any potential confusion or ambiguity. For this reason, it is often advisable to always include a title (A. Buckley, personal communication, May 28th, 2020).

\section{Placement of the title}

For those maps requiring a title, most participants preferred to locate the title at the top center of the map. Most users expect to see the title in that position, and it is often placed there. Top center placement is ideal because it is important to clearly and quickly convey the main point of the map to the map user. A title at the top of the map is more visible and draws more attention than other placements.

A few participants preferred the title to be located at the bottom of the map. This response may have been influenced by the DGGS largeformat map standard, which mandates the title be placed at the bottom center of the page just above the scale bar. Participants also noted their preference for the title to be located at the bottom of the map, near the legend and scale bar, which may indicate that they prefer to look back and forth between the title and the legend; however, few small-format maps require users to look back and forth between the title and legend because these maps usually have simple legends that do not require additional thematic clarification from the title. If a user did need to look back and forth between the legend and title, it would be better to have a short, clear title at the top center of the page to explain the main theme of the map and a subtitle near the legend to explain further details about the legend items or map theme. If the overall layout or available space precludes a top-centered title, the title may be placed at the bottom center of the map. Titles at the bottom of the map can still be seen easily, though they are often not as prominent as titles at the top of the map, because people typically read from the top of the page to the bottom.

\section{Design of the title}

Participants were roughly split on whether titles should use all capital letters or title case, with 57 percent of participants preferring all capital letters (fig. 8). Those who preferred all capital letters may have been influenced by the DGGS large-format map standard, which requires titles be displayed in all capital letters. Some consider this standard to be simpler because it does not require them to decide which words should be capitalized. It was a bit surprising that more people did not prefer titlecase. Indeed, the very name "title-case" implies that it is associated with title design. In typography circles, the general rule of thumb is that mixedcase letters (such as those in title case) are easier to read because the ascenders and descenders give more visual clues and increase the recognizability of words (Typedecon.com, n.d.); however, title case can sometimes introduce mistakes, especially when proper names or words from foreign languages are present. When using title case, more effort must go into identifying which letters should be capitalized, but the result is a title that is much easier to read than if all capital letters were used.

Most participants (78 percent) preferred titles that use a sans serif type face (fig. 8). This preference could be influenced by the slight majority of people who preferred all capital letters because sans serif fonts are more legible in all-capital letters than serif ones (Butterick, 2020). Serifs (the small lines attached to the ends of each stroke in a letter) make text appear blurry, especially in smaller type sizes. This blurring effect is especially obvious in text that is in all capital letters or viewed at a small size (Butterick, 2020). In general, sans serif fonts are cleaner and easier to read than serif fonts and are a more modern, relaxed, and approachable choice for type design.

\section{LEGEND}

\section{Inclusion of the legend}

In the questionnaire, participants were asked whether a legend should be included on the specific map they examined. All participants who exam- 
ined the Cook Inlet map, which included a legend, indicated that a legend was necessary to identify and explain the colors and symbols on the map. In contrast, only about half of the participants who examined the volcano map, which does not include a legend, indicated that one was necessary. This interesting dichotomy of responses suggests that the decision to include a legend is dependent on the map's theme, purpose, and the specific symbols used on the map. In general, most thematic and reference maps require a legend; however, a legend may be omitted if none of the map symbols requires explanation. Which symbols require explanation depends on whether the intended map user would find each symbol to be self-explanatory or obvious. If the map user will not intuitively know what a symbol represents, map makers should consider whether the symbol is directly related to the map's theme, how an explanation of the symbol would impact the reader's understanding of the map, and whether there is a method-such as a label-that could be used to define the symbol without requiring a legend.

The volcano map illustrates a good approach to decisions regarding inclusion of a legend and legend items. For example, the volcano map does not require a legend because none of the symbols on the map requires additional explanation. The red triangle and white circle symbols that represent volcanoes are labeled on this map and are commonly found on other DGGS maps. Note that the triangle shape, which mimics the cone shape of a volcano, and red color, which mimics the red and orange colors of lava, help a map user interpret that these symbols represent volcanoes. Also, in our culture red is associated with danger or hazards, which certainly holds true for active volcanoes. In other words, these volcanic symbols can be considered self-explanatory and do not need to be included in a legend. Furthermore, the title of the map, "Historically Active Volcanoes of Alaska," sufficiently identifies the single theme and its symbols.

When considering other symbols on the volcano map, the white circles also are commonly used on many DGGS maps to represent popula- tion centers. Both the symbols for volcanoes and cities are accompanied by labels that further help identify them. With this in mind, including these symbols in a legend would likely not enhance a user's understanding of the map. Therefore, it is not necessary to include them in a legend.

The roads, which appear as thin black lines, are considered background features because they are not directly related to the map's theme, and, therefore, do not require additional explanation in the legend. The map is a reference map whose purpose is to show the location and eruption year of Alaska's historically active volcanoes. The major highways of Alaska are included as helpful landmarks for geographic context. If the purpose of the map were to illustrate possible evacuation routes for volcanic eruptions, the roads would be an important feature and should be identified in a legend.

\section{Functionality and Accuracy of the legend}

Survey participants who examined the Cook Inlet map disagreed about whether the legend was functional. Half stated that the legend was functional for the purposes of a figure in a report because it included the main map symbols shown in the figure. The other half said that the legend was not functional because it did not contain all the map symbols, and the colors were difficult to differentiate. This difference of opinion may indicate that the utility of a legend is related to its accuracy and completeness. In the strictest sense, a complete legend would include all of the symbols that appear on the map, while an accurate legend would show symbols exactly as they appear on the map. During the survey, participants were only asked if they considered the legend accurate, not if they considered it complete. Participants' opinion of what they considered an accurate legend varied greatly; however, their comments focused solely on legend completeness. Some participants considered the legend as accurate only if it was complete, meaning that it contained all the symbols and colors shown on the map. Others considered an incomplete 
legend accurate if it contained the symbols relating to the theme and purpose of the map. Expanding the survey question to address both legend accuracy and legend completeness might have prompted participants to think about both aspects of a legend and may have altered the results.

None of the participants mentioned that the accuracy of a legend depends on whether the symbols in the legend exactly match (in size, color, shape, etc.) the symbols shown on the map, which is advocated consistently in cartography reference books.

The Cook Inlet map legend contains all symbols that are on the map (completeness) and the symbols exactly match (accuracy). Therefore, the legend may be considered both complete and accurate; however, some participants commented that the colors on the Cook Inlet map and legend are difficult to distinguish from each other, which certainly impacts the utility of the legend. If a map user cannot easily use the legend to determine which areas of the map represent a single geologic unit, adjustments need to be made to the underlying color design of the map. The general suggestion regarding color choice, set forth by the USGS, is that colors should have CMYK values that differ by at least 20 to 30 percent. For example, if 20 percent magenta is chosen for one map unit, another map unit should be at least 40 or 50 percent magenta.

\section{Design of the legend}

There are many possible designs, styles, and formats for a legend. The best legend design for an individual map will depend on the map's theme, symbology, and available layout space. It was a challenge to select eight design options for inclusion in the survey, each of which differed from the others in only one aspect.

The most obvious variation between the sample legends in the survey (appendix C) is the use of geometric versus mimetic (pictographic) symbols. Seventy percent of participants chose a design that showed geometric symbols (fig. 9), which may have been influenced by the fact that most maps, including other DGGS maps, use geometric symbols. For example, all large-format DGGS geologic maps use a colored rectangle to represent a single geologic unit, while specialized symbology for points and lines contain both geometric and mimetic components. For example, the symbol for a thrust fault (as seen on the volcano map) is a combination of two geometric symbols - a solid line and a triangle - but is also slightly pictographic in nature, because it illustrates the motion of one side of the fault relative to the other. Depending on what is being represented, mimetic symbols are sometimes preferable over geometric ones. Six participants chose legends designs with mimetic symbols. This inclination may have been because the mimetic symbols are preferable for hydrology and land ownership features. For example, representing streams and rivers with sinuous, rather than straight, lines helps a user interpret the symbols, determine what they represent, and to easily differentiate hydrologic features from other linear features, such as roads, fault traces, or geologic folds. Mimetic symbols for state and federally owned land may be preferred because irregular polygons visually resemble the blocky forms typical of mapped land parcels and federally designated areas, such as national parks.

Seventy percent of participants chose a legend design that did not group symbols into categories based on the similarity of the features they represent (fig. 9). The choice of a legend without logical groupings may have been influenced by participants' preference for a simple and subtle legend. Text headings for groups (especially in a bold font) adds both length and visual weight to the legend and may not be appropriate for a legend with simple or few symbols; however, as many participants noted, grouping symbols into categories will assist the user in reading the map if it has many symbols or layers. Participants are likely aware of the benefits of grouping symbols on more complex maps because most DGGS 
large-format maps have legends that are grouped by symbol categories.

Only two participants chose a legend with a horizontal format. The sample legends with horizontal formatting may have been a less appealing choice because they are less clear or less easy to read; however, in some cases, a horizontally formatted legend is more easily accommodated in the available space on a map.

The results for the legend design could have been different if participants were asked to choose the best legend design within the context of a given example map. Had they been given a sample map with many symbols, participants could have been asked to design their own legend, which may have revealed more about their individual preferences. The best legend design for a map depends strongly on the requirements for an individual map and the knowledge or experience of the map user. Asking participants to choose a legend without a specific map in mind may have skewed the results towards the simplest, most basic design that would be useful to the map user.

No participants commented on the presence of the word "Legend" serving as the legend title, which is unsurprising because it appears frequently on many DGGS maps and figures. It is unnecessary to identify the legend with "Legend", and it should be removed from the map or changed to a more descriptive title that supports the map theme. This rule is consistently stated in cartography textbooks. The absence of comments about the "Legend" label in the examples is discordant with responses from the title section of the questionnaire, where a few participants mentioned that a subtitle near the legend can be used to give readers more information about what is being presented on the map. This further suggests that asking participants to choose a legend design out of context influenced the survey results. The only comment regarding the "Legend" label came from one participant who stated that he would prefer the term "Explanation."

\section{INSET MAP \\ Inclusion of the Inset Map}

All the participants who examined the Cook Inlet map stated that an inset map was necessary to show the relative size of the mapped area and its location within Alaska. In contrast, only 73 percent of the participants who examined the volcano map thought that an inset map was necessary to orient the map, provide context about Alaska's location, and show what portion of Alaska is displayed on the main map. The variety of responses likely reflects the Cook Inlet map showing a much smaller portion of Alaska and not having a title or graticule to provide overall locational context, in which cases a locator inset map might be necessary. The size and scale of the mapped area, the presence of additional contextual information (such as graticule or title), and the intended function of the inset map should all be considered when deciding whether to include an inset map. For example, if the Cook Inlet map did not include a locator inset map, a map user would have no way of knowing where in a larger geographic context of Alaska the main mapped area is located.

The small-scale volcano map shows the entire state and uses a descriptive title to inform readers that it is a map of Alaska. A graticule is also included to help provide locational context. Map users who are familiar with Alaska will likely already know its geographic context and a locator inset map would not be necessary. On the other hand, if the map is likely to be viewed by map users who are unfamiliar with the location and geographic context of Alaska (such as school students in Florida), a locator inset map would be useful to inform map users about the general location of the mapped area. The decision to include a locator inset map should depend on the familiarity of the intended map viewer with the mapped area. For example, a map of Fairbanks, Alaska, intended for its citizens would not require a locator inset map because city residents are likely to be very familiar with the geographic location of 
the city in which they live. If the same map were intended for visitors and tourists, a locator inset map could be beneficial.

\section{Function of the Inset Map}

An inset map can indicate geographic location (in a local, regional or world context), enlarge congested areas, or show important related areas. The Cook Inlet and volcano maps include locator inset maps, which are the primary type of inset map discussed in this study. Many participants commented on the utility of an inset map to show geographic location and context in two different, yet related ways. Unlike the volcano map, which displays outlines of Russia and Canada in the inset map, the Cook Inlet inset map displays only a simple outline of Alaska. Some participants, from both map groups, considered the inset map functional because it showed the location of the mapped area within the context of Alaska. Some participants who viewed the Cook Inlet map, suggested the inset map would be more useful if it showed the map location in a larger context (Alaska, Canada, and Russia). One participant, who viewed the volcano map stated that an inset map showing more of North America and Asia would make the inset map more useful to users who are unfamiliar with Alaska in relation to Russia's and Canada's locations. The wide range of feedback on inset maps may reflect the national origins and experiences of DGGS map makers and users, as they come from all over the world and are accustomed to making and seeing maps with inset maps that show different levels of geographic context and are intended for a diverse audience.

While many participants commented that an inset map could show the relative size of the study area or be used to orient the map, no participants suggested that an inset map could be used to enlarge congested areas or show important related areas. Undoubtedly these responses were influenced by the wording of the question regarding inset map functionality, which only asked if the inset map helped them know were on the earth this map is. Participants presumably did not offer additional comment on enlargement inset maps, because the maps they examined did not contain areas that would benefit from this type of inset. Additionally, large-format geologic maps rarely have enlargement inset maps, despite their propensity for many small, clustered symbols, because they are better understood when viewed in a regional context, rather than in small pieces. The need to see overall patterns across an area is also desirable for small-format maps, and therefore, enlargement inset maps remain rare on DGGS small-format maps.

\section{Design}

Participants generally preferred a simple and subtle inset map design, but some mentioned that more complexity might be necessary depending on the needs of the map and the purpose of the inset map. This is evident in the even split between participants who chose a simple inset map and those who chose a more complex one (fig. 10). Half of the participants chose an inset design that included a Canada, Russia, and a bounding box, while only thirty percent of participants chose the simplest design that shows only Alaska. That half of participants chose an inset design with Canada, Russia and a bounding box is slightly unexpected given participants' preference for a simple and subtle inset map, and that the inset map standard on DGGS large-format maps is to show only Alaska.

Those who chose the design that shows only Alaska reasoned that the inset map was only intended to show the location of the mapped area within the state. Participants who chose a more complex inset map design that showed Alaska, Canada, and Russia reasoned that it was necessary to show the spatial context of Alaska at a more global scale. When designing an inset map, the simplest and most subtle inset map design should be used unless the intended audience will need to see Canada and Russia to correctly place Alaska in its geographic context. 
A few participants thought that adding shaded relief to the inset map would be appealing, though most found it distracting. Keeping the purpose of the inset map in mind, including shaded relief may be appropriate if regional topographic information is pertinent-such as the mapped area is in an important geographic location (e.g., between two mountain ranges).

To show the extent of the mapped area, all participants chose a design that outlined the area on the main map with a box, rather than a simple dot. This preference likely reflects participants' desire to have the spatial extent shown on the inset map to exactly match the extent of the main map. Many DGGS large-format maps have large or irregular mapped areas, so the participants' preference for an accurate bounding box extent is understandable.

\section{GRATICULE Inclusion of the Graticule}

Participants who examined the Cook Inlet map were approximately evenly split on whether it was necessary to include a graticule on the mapsix participants were in favor of including it and five participants were against it. Those in favor of including a graticule argued that its presence would give additional locational information. Although a graticule can provide users with absolute locational information, most map users would not be able to use the latitude and longitude information from the graticule to place the mapped area correctly according to its coordinate values. If the only intended purpose of including a graticule is to provide locational context, a locator inset map would be more appropriate.

Participants who argued against the inclusion of a graticule on the Cook Inlet map stated that it would add more visual complexity than was required for the map's purpose. This reasoning is likely influenced by geologic maps and figures, which almost always have a wide variety of elaborate symbols, colors, lines, and labels. As a result, there are many times when DGGS map users and makers think that including a graticule would add too much complexity and visual clutter to the map. Adding graticule indicators as small tic marks along the map frame line would not significantly obstruct or distract from map features, but the question remains whether their addition would enhance the message or utility of the map, especially since the inset map is a better way to provide locational context. Additionally, at the scale of the Cook Inlet map, a graticule probably would not help a user know which map projection was used, but it might help users orient the map.

Many DGGS maps and figures include graticule lines or tic marks, even when their presence does not enhance the map's theme. The rationale for this practice, as one participant noted during the survey, is that graticule or corner coordinate values are crucial for georeferencing purposes (which is a common occurrence at the DGGS), even on pagesized maps.

All participants who examined the volcano map, which is at a much smaller scale and shows a larger area than the Cook Inlet map, concluded that a graticule was necessary, but did not specify their reasoning. Graticule lines on this map clearly indicate orientation and show that the direction of north varies across the mapped area. The curved lines of latitude and straight meridians converging toward the North Pole may also help map users identify that this is a conic projection. If a map user is familiar with the distortion associated with a conic projection, they can assess the potential distortion on the map.

Overall, most participants indicated that including a graticule can provide important location and orientation information and, depending on the map scale, may help users identify the projection used for the map; however, participants elaborated that, depending on the map's purpose, a graticule is not necessary for inclusion when its display would add too much complexity or distract from important mapped features. A graticule should be omitted if it does not help indicate the maps projection or orientation or enhance the users' understanding of the map. The addition of 
graticule tic marks may be appropriate if there is a possibility that the map will need to be scanned and georeferenced.

\section{Placement of the graticule}

None of the participants commented on the placement of the graticule in the visual hierarchy of the map layers and overall design. During the survey, most participants offered that the graticule in the example map was well placed but did not explain their reasoning. This indicates to me that participants may not have completely understood survey question 6c, which asks; "Is the graticule well placed on this map? If yes, please explain why. If not, please describe where the graticule should be moved and why." The intent of the question was to have the participants determine how the graticule was ordered in the visual hierarchy. In other words, the intended definition of "placement of the graticule" is related to the position of the graticule symbols (lines, tic marks, and labels) within the visual hierarchy of the map. This form of "placement" is different than what was stated in question $6 c$ for the other elements. In question $6 c$, the other marginalia elements are placed according to the elements' physical location on the map, not the level in the visual hierarchy. Rephrasing question $6 c$ to be more specific about placement in terms of the visual hierarchy of the graticule symbols may have produced different, more conclusive results, assuming that the participants have some background knowledge related to the visual hierarchy.

\section{Graticule design for maps that show both land and ocean areas}

Rather than consider the size, style, or color of the lines used to represent a graticule, the design choices of a graticule differed according to how it was placed in the visual hierarchy. Sixty percent of the participants preferred a design where a simple solid gray graticule visually overlaid all elements on the map (fig. 11). This design is the most useful because the parallels and meridians extend from one side of the map to the other allowing a user to estimate the latitude and longitude of a point anywhere on the map, even in situations where the map projection results in curved lines of latitude or longitude. This design is also the default configuration for the graticule in ArcMap 10.8. It is important to note that when using the ArcMap 10.8 dataframe and grid properties dialogue windows, it is very difficult to place the graticule elsewhere in the hierarchy of map layers. The difficulty of adjusting the graticule hierarchy may have contributed to participant confusion regarding placement. Some participants might not even know it is possible to change the placement of the graticule using ArcMap 10.8 by using a feature class that includes the lines of the graticule so that it can be moved above or below other layers in the map's contents.

Three participants voted for the design which displays the graticule as only small tic marks along the frame line (fig. 11). This "tick mark only" design is not a good choice for small scale maps that use a conic or azimuthal class of projection because there is no way to visualize how meridians and parallels curve from one side of the map to the other; therefore this design will not allow the map user to accurately estimate latitude and longitude positions.

This shortcoming of the "tic mark only" graticule design is illustrated in figure 16 by comparing maps $A$ and F, which use the Albers equal area conic projection. In figure 16, straight red lines have been drawn between corresponding latitude tic marks, to illustrate how a map user might visually connect the tick marks or sketch a latitude line with the aid of a ruler. By comparing this result to the graticule in figure 16A, it is evident that a straight line from one tic mark to its corresponding tic mark on the other side of the map does not accurately represent the curvature of the parallel. Thus, using the tic mark only design for a graticule in this situation may give a map user a completely inaccurate impression of the position of the unseen line of latitude or longitude.

Three participants likely choose this "tick mark only" design because labeled tic marks are 

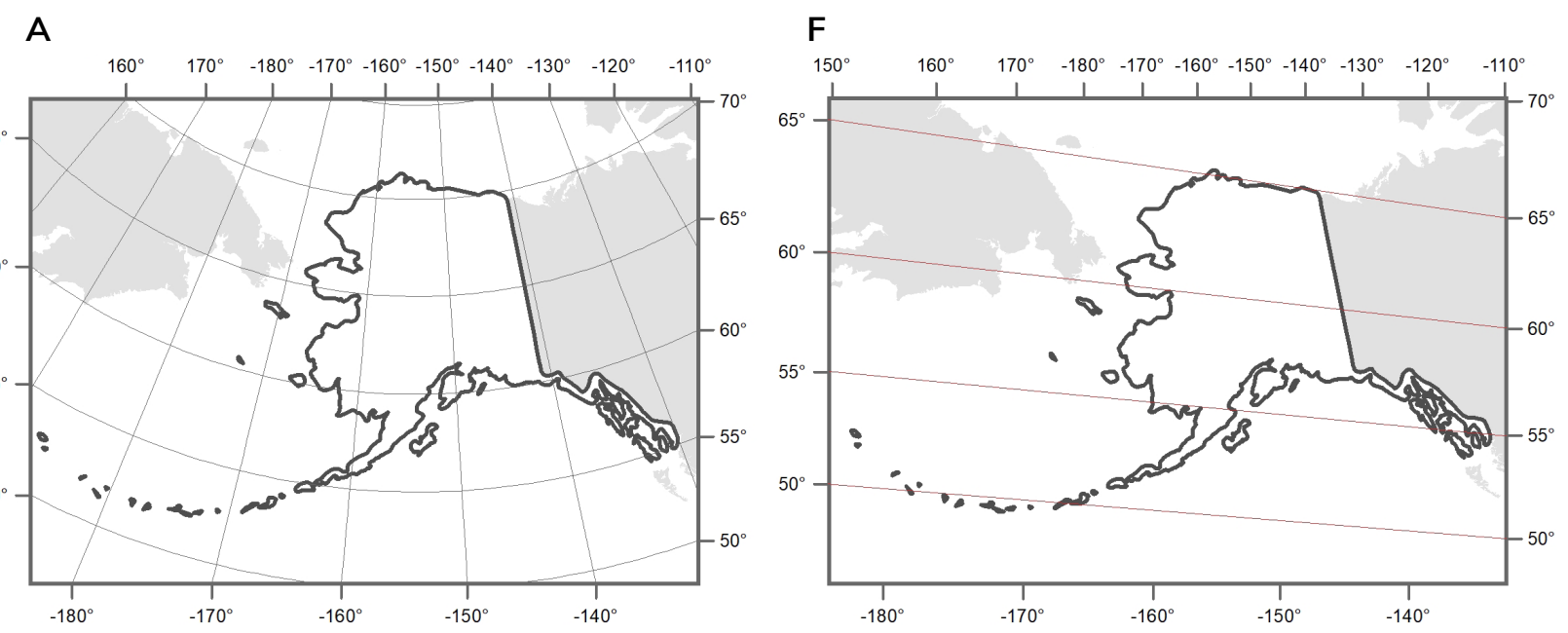

Figure 16. Comparison between an accurate representation of a graticule (as illustrated in design choice A during the survey) and how a map user may incorrectly visualize the graticule if only tic marks are provided (shown on design choice F).

a familiar and common graticule representation found on most maps, including DGGS largeformat maps and USGS topographic maps. This preference might also be related to the fact that it is easy to create a "tic mark only" design in ArcMap 10.8 by simply turning off the graticule lines using the layout grid properties.

The "tic mark only" graticule design would be appropriate if the map is displayed with a cylindrical projection that has straight lines for the graticule. Cylindrical projections preserve parallels and meridians as straight lines, therefore, connecting corresponding tic marks with a straight line would give an accurate representation of the graticule and would allow the map user to better estimate latitude and longitude of a point.

\section{Graticule design for maps that show land areas}

Almost a quarter of participants chose a design where the graticule was indicated only by labeled tic marks on all sides of the frame-line (fig. 12). Many people preferred only the tic marks, because of the simplicity and ability to show location information on maps with a lot of features. Geologic and non-geologic maps typically have many different symbols, colors, and lines, so a simpler graticule avoids unnecessary visual clutter and does not obscure important map features. The example maps used to illustrate graticule designs for only the land areas can be considered large scale maps because they show only the area immediately around Fairbanks. As a result, the tic mark only design of the graticule works well because a user can imagine (or draw with a ruler) a straight line from tic mark to tic mark and get a good approximation of the meridian or parallel tracing; however, it is important to note that when using this graticule arrangement, all tic marks must be labeled, because the user needs to know which marks correspond to each other; locations of tic marks can vary when using different projections or if the map is oriented with north not oriented to the top of the page.

\section{METADATA}

\section{Inclusion of Metadata}

All participants commented that some form of metadata should be included on a map. Some participants elaborated that, in cases where the map is a figure in a larger report, less metadata on the map is acceptable, because additional information likely appears in the report or figure caption. From these comments, it is clear that DGGS map makers and users are familiar with the importance and function of metadata. As scientific authors, DGGS staff are well-acquainted with the kinds of 
Table 3. Metadata elements listed by the mean and mode score of inclusion importance.

\begin{tabular}{|c|c|c|}
\hline Metadata Element & Mean Score & Mode \\
\hline Coordinate system information & 2.9 & 1 \\
\hline Name of the publishing agency & 3 & 1 \\
\hline Publication number & 3 & 1 \\
\hline Names of the author(s) & 3.5 & 1 \\
\hline Name(s) of contributing agencies & 4.1 & 1 and 3 \\
\hline Data sources & 4.1 & 1 \\
\hline Logo of the publishing agency & 4.8 & 5 \\
\hline Affiliations of the author or contributors & 5 & 1 \\
\hline Credits or acknowledgements & 6 & 7 \\
\hline Logo(s) of contributing agency or agencies & 6.2 & 5 \\
\hline
\end{tabular}

metadata that are included with maps and reports. Additionally, metadata is a required component of every DGGS project, though it is not required to be placed on the map.

During the survey, participants were given a list of important metadata elements that could appear on a small-format map and asked to indicate each element's level of importance on a smallformat map. In their scoring, 1 was most desirable and 10 was least desirable. Table 3 shows all ten metadata elements listed in order by their mean and mode scores. Table 3 shows the same information as table 1, seen earlier in the Survey Results section, which shows the metadata elements listed in the order they appeared in the questionnaire.

For this survey, the coordinate system metadata element had the lowest mean score and mode, which indicates participants viewed it as being the most important metadata element on a map. Due to Alaska's large size, irregular shape, and high latitude location, the coordinate system can greatly affect the accuracy and appearance of the map. DGGS map makers have experience using a wide variety of coordinate systems to display scientific data and, therefore, are quite aware of the mapping complexities and potential distortions caused by coordinate systems. In addition to alerting a user of potential map distortions, coordinate system information is vital if the map is georeferenced. Coordinate system information also allows the data to be ingested into a GIS and registered with other data layers. With these reasons in mind, it is understandable why the coordinate system metadata element was viewed as the most important.

The next lowest scores were associated with the name of the publishing agency and the publication number. These results reflect the high priority that DGGS assigns to publishing information. The publishing agency's name gives DGGS credit and identifies the map as a scientific product that has been thoroughly reviewed and vetted, while the publication number identifies all publications and allows for it to be tracked, located, and archived. All DGGS publications, including large-format geologic maps, clearly indicate and prominently place metadata about the publishing agency and publication number. On a large-format map, the publication number is always located in the 
upper right corner of the map and the publishing agency (DGGS) is stated in at least three places the upper left corner, the lower right corner near the Division's legal disclaimer, and near the title as an author affiliation. For DGGS reports, the publishing agency and publication number are included on the front and back cover.

Author names ranked lower than the element for publication agency and number, which implies that participants consider it more important to credit the publishing agency than the individuals who accomplished the work. The result is a bit surprising, since many of the survey participants are authors and map makers. This response may reflect the loyalty that DGGS authors feel toward the division as an organization and that they consider the reputation of and respect for DGGS as more important than being given individual credit.

As shown in table 3 and discussed above, participants thought coordinate system information, name of the publishing agency, publication number, and name of the author(s) are very important to include on a map. Although these four metadata elements will likely be important on most maps, metadata elements included will vary from one map to another. Deciding what metadata elements to include must balance the needs of the map (what information will help the reader interpret the map) with its overall design (what amount of metadata will result in an overly complex or cluttered map). How many metadata elements and which ones to include on a map will depend on the map's intended audience, purpose, theme, and type (for example, standalone map versus figure in a report).

A modal score of 1 was recorded for seven of the ten metadata elements, which indicates that more participants chose a score of 1 for these elements than any other score. This result illustrates that a substantial number of participants believe that metadata elements for the coordinate system, publishing agency, publication number, author names, contributing agencies, data sources, and author/contributor affiliation should always be included on the map. Despite these elements conveying important information to the map user, a small-format map could become very crowded and cluttered if it included all seven of these elements.

Although it is useful to know which metadata elements a participant thinks should always be included on a map, it could also have been enlightening to know which single element was viewed as most important. The phrasing of the metadata design survey question may have also contributed to the frequent appearance of a mode score of 1. Participants were prompted to "indicate how important it is" for each element to be included on a small-format map, which implied that multiple metadata elements, even all of them, could receive a score of 1 . Rephrasing the question so that it asked participants to rank the metadata elements in order of importance may have dramatically altered the results. If participants ordered elements based on their importance, only one metadata element could have a score of 1 . This rephrasing of the question would have prevented a mode score of 1 from occurring so often.

A few participants provided additional comments and explanation for their scoring choices. Most commented on whether they were considering the importance of the map's metadata elements as a figure in a report or as a stand-alone map. Scores varied widely depending on whether the participant considered the question to refer to a map as a figure in a report or as a stand-alone product. It is logical that a stand-alone map would require more metadata information than a map in a report, which could include metadata information in the figure caption or report text.

\section{Placement and Design of Metadata}

When making a map, metadata design and placement should support the purpose of metadata- to inform the map user without drawing attention away from the map content. One participant clearly agreed by stating that the most useful design and placement of a metadata element can 
vary based on its content, importance, or utility, as in the case of authorship or date.

Unlike the other survey questions regarding placement, which asked participants whether an element shown on the map was well placed, the metadata placement question asked participants to describe where on the map metadata elements should be placed and to explain their reasoning. This allowed all participants to indicate which metadata they thought would be useful when interpreting the map. It also gave participants who examined the Cook Inlet map, which has no metadata other than the figure caption, a chance to comment on metadata placement.

During the survey, participants were not asked to directly comment on the design specifics (style, typeface, size, etc.) of metadata elements, though a few participants alluded to design when discussing an element's placement. Most participants commented that metadata should have a subdued design (such as a small font) and be placed in a position that does not interfere with map features, with a strong preference that metadata be located along the bottom or other edges of the map.

The design and placement of metadata should be based on the map's theme, purpose and type. On large-format geologic maps, authorship is traditionally shown in a large font and placed in a prominent location just under the title. On some maps, the date is part of the title, subtitle, or legend title, and may be sized and placed prominently so that a map user can quickly identify how current the data portrayed on the map is. For example, a map showing yearly rainfall would benefit from a prominently displayed date. 


\section{GUIDELINES AND DESIGN RECOMMENDATIONS FOR SMALL-FORMAT MAPS}

The following guidelines and recommendations provide direction on the inclusion, placement, and cartographic design of marginalia elements for small-format maps. Recommendations are supported by this author's experience as a cartographer at DGGS, review of the current literature, and analysis of the survey results described here. These guidelines are intended to offer flexibility for small-format maps with a range of topics purposes, and scales. Use of these recommended guidelines and designs should be considered the default option when designing a small-format map. Deviation from these recommendations is acceptable in certain situations, giving DGGS staff some degree of flexibility when creating maps.

\section{NORTH ARROW}

\section{Purpose}

The north arrow indicates the direction of north (orientation) on a map. The kind or kinds of north indicated (true north, magnetic north, or grid north) will depend on the intended purpose of the map. North arrows on small format thematic maps usually only need to indicate true north.

\section{Inclusion/Exclusion General guidelines:}

A north arrow is not required for every map (e.g., if north is at the top of the page and the map readers are assumed to understand this). Smallformat thematic maps usually only require a north arrow that indicates true north.

\section{Include a north arrow if:}

- The map is NOT oriented with geographic north at the top of the page.

- Direction is crucial for use of the map, for example, if the map is intended for navigating, surveying, orienteering, or collecting and displaying orientated field data. In such cases, a north arrow that indicates true north, magnetic north, and grid north may be necessary.

- Geographic features are oriented in a way that might confuse the map user.

\section{Exclude a north arrow if:}

- The mapped area is familiar to the intended audience.

- The map is oriented with geographic north at the top and direction is not crucial for map use (i.e., navigating, surveying, or orienteering).

- The direction of north varies across the map due to map projection or scale. Meridians converge toward the north pole over the mapped area indicating that the direction of north varies. In such cases, a north arrow would only indicate north for a particular location and would therefore be incorrect for the majority of the map. In such situations, a north arrow may be replaced with a graticule to indicate orientation.

\section{Placement}

- The placement of the north arrow should consider available space and the needs of the map user.

- Place the north arrow in an inconspicuous location. The north arrow is intended to inform, not divert the user's attention away from map features.

- Visually balance the north arrow with other elements on a map layout.

- Place the north arrow inside the map face if possible, preferably in a corner.

- If possible, position the north arrow near the scale bar so that direction and distance are adjacent.

- Avoid placing the north arrow in a location that could confuse the map user. For example, the north arrow should not be placed closer to the inset map than to the map face to which it refers.

\section{Design}

\section{General considerations:}

- The design of the north arrow should be simple and subtle (fig. 17).

- The north arrow should be large enough to be legible and easily located visually, but not 
so large that it obstructs map features or adds visual clutter to the map. Generally, no larger than half an inch tall on page-sized maps.

- Indicate only the north direction using the letter " $N$ " placed at the top of the arrow. "North" can be spelled out if the intended audience may not be familiar with the designation " $N$ ".

- The color of the north arrow should contrast with the background of the map. White, light gray, dark gray, or black are acceptable. Gray color will reduce the north arrows' visual impact and is a more subtle option than white or black, especially on very dark or very light backgrounds.

\section{Recommended north arrow design:}

The design recommended for DGGS smallformat maps (fig. 17) is simple, clear, legible at a small size, and provides good contrast on a variety of backgrounds, including aerial photography. Deviation from this recommendation is acceptable for maps intended for navigating, surveying, or orienteering where true north, magnetic north, and grid north are required.

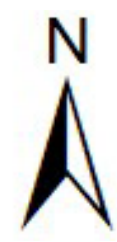

Figure 17. The recommended north arrow design (ESRI North Arrow 3) for DGGS small-format maps.

\section{SCALE BAR}

\section{Purpose}

A scale bar communicates map scale and allows the map user to measure distances and areas.

\section{Inclusion/Exclusion General guidelines:}

- A scale bar is not necessary on every map.

- The decision of whether to include or exclude a scale bar is influenced by the map type, theme, and purpose.

\section{Include a scale bar if:}

- The map's intended use includes measuring distance or area.

- Distance or area information will enhance the map user's understanding of the map theme.

- If scale varies across the map and a scale bar is needed, indicate the standard point or line(s) where scale is accurate (principal scale). Scale bar should be drawn according to the principal scale.

\section{Exclude a scale bar if:}

- Distance or area information will not enhance the map user's understanding of the map theme.

- Scale varies greatly across the mapped area due to the geographic area mapped or the map projection. In such cases, a scale bar is only accurate along certain lines and will be inaccurate for much of the map.

\section{Placement}

- Preferred placement of the scale bar is below or near the bottom of the mapped area, where map users are accustomed to finding it.

- If placement below the mapped area is not possible, the scale bar may be placed in any available space that can accommodate it; however, be sure the scale bar is placed in an area out of the way where it is easy to find, preserves the map's visual balance, and does not obstruct or distract from other map features.

\section{Design}

\section{Length:}

- A scale bar should be long enough to be useful, but short enough so that it is not difficult to use.

- The appropriate length of a scale bar (maximum value) depends on the units of measure and the size of mapped area.

- The maximum value should always be round, evenly divisible, and easy to use. Avoid decimals and excessively large values.

\section{Units:}

- A scale bar should include sufficient intermediate distance tics to suit the map's intended purpose. 
- A single line with labeled end points will suffice for a scale bar intended to give only a general sense of scale.

- More complex maps or those requiring greater precision in measurement may require a more detailed scale bar that shows subdivisions and their associated measurements (Peterson, 2014).

- Units should be appropriate for the maximum value. Avoid excessively large maximum values by choosing the appropriate units. For example, a scale bar with a maximum value of 20 kilometers may be easier to work with than one with a maximum value of 20,000 meters. Also, as a design consideration, the " 20 " number of digits may fit the dimensions of the scale bar better than " 20,000 " number of digits.

- Metric or English units should be chosen according to the map's purpose and intended audience.

- Include multi-unit scale bars when the map purpose dictates so that map users do not have to perform mental unit conversions.

\section{General design considerations:}

- Scale bar design should be simple, subtle, and legible. A scale bar is intended to be utilitarian without drawing attention away from the map content.

- Line weights should be fine and text among the smallest on the map.

- Show scale bars in white, light gray, dark gray, or black for sufficient contrast with backgrounds. Gray shades will reduce visual impact.

- Scale bars should have a visually balanced appearance.

- If using two or more stacked scale bars place the longest on the bottom and shortest on the top.

- Two or more stacked scale bars should have the zero division aligned with each other.

- Always include a 0 value and always indicate units.

\section{Recommended scale bar design:}

- The scale bars shown in figure 18 are the preferred design for most DGGS small-format maps. With an appropriate choice of line width and color, these scale bars are the best choice for most small-format maps.

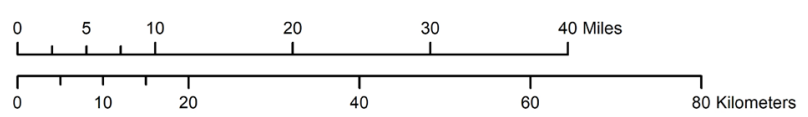

Figure 18. The recommended scale bar design (ESRI Scale Line 1 and ESRI Scale Line 3) proposed for DGGS small-format maps.

The design shown in figure 19 is too bold for many small-format maps, but provides good contrast and may be a better choice for a colorful or visually busy map face, such as aerial photography base maps. Dark gray, very light gray, or white (depending on whether the background is primarily light or dark) are the better color choices for this design.

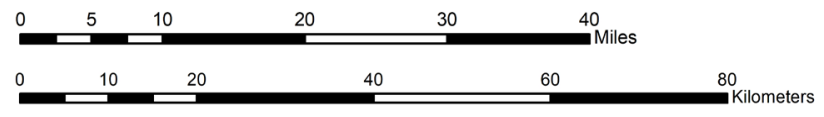

Figure 19. The alternate scale bar design (ESRI Alternating Scale Bar 1) for DGGS small-format maps.

\section{TITLE}

\section{Purpose}

A map title clearly and quickly conveys the main point or purpose of the map. A title may describe the what, when, and/or where of a map.

\section{Inclusion/Exclusion General guidelines:}

- Most thematic maps require a title.

- A title can be used to draw attention to the map.

- The title may also include additional information, such as the region or date.

- Subtitles, a legend title, or notes can be added to explain the data that is mapped, the purpose of the map, or additional information. 
- Including a title on maps included in written reports will reduce potential ambiguity and confusion if the map is copied and used without a descriptive figure caption.

\section{Exclude a title if:}

- The map is part of a series AND the theme is discussed in the introductory material for that group of maps.

- The map is a figure in a written document, has a descriptive figure caption, and is unlikely to be copied and used apart from its caption.

\section{Placement}

- The title should be centered horizontally at the top (preferred) or bottom of the map.

- Center-justify subtitles or multiple lines of text under the title.

- Additional subtitles or headings can be placed above, and center-justified with the legend or other map elements.

\section{Design}

\section{General design considerations:}

- The title should use title case and be the largest type on the map.

- Limit the title to one line of text, in most cases.

- The style should be simple in style, easy to read, and without underline or italics.

- Bold font is acceptable but is not usually necessary if the appropriate type size is chosen.

- A bounding box around the title is only necessary if it masks underlying mapped areas and improve legibility.

\section{Title content:}

- The title should be concise and contain minimal punctuation.

- For thematic maps, the title should succinctly describe the map theme.

- For reference maps, the title usually states the region being mapped.

- Use the what, where, when format when possible.

- Avoid abbreviations and the word "Map."

\section{Title design recommendations:}

- Sans-serif type face

- Regular typeface, not bold

- Title case

- Basic title case rules (Lowe, n.d.)

- Capitalize the first and last word in the title.

- Capitalize all nouns, pronouns, verbs, adjectives, adverbs, and subordinating conjunctions (e.g., because, although).

- Lowercase for "to" as part of an infinitive, articles (a, the), prepositions (to, at, in, with), and coordinating conjunctions (and, or).

- Figure 20 illustrates examples of titles that conform to the above guidelines and design recommendations.

Bedrock Geology of Cook Inlet

Historically Active Volcanoes of Alaska

\section{Slopes Susceptible to Movement Sitka, Alaska}

\section{Geothermal Resources \\ Fairbanks Region}

\section{Coastal Communities Experiencing Erosion 2008}

Figure 20. Examples of titles that follow the title guidelines and design recommendations.

\section{LEGEND}

\section{Purpose}

The legend defines the map's symbols and presents information that helps the map viewer understand symbols and interpret the map.

\section{Inclusion/Exclusion}

\section{General guidelines:}

- Most thematic and reference maps should include a legend. 
- Not all map symbols must be included in the legend.

\section{Include a legend if:}

- Map users would be unfamiliar with any of the symbols or colors on the map or any of the symbols on the map are not clearly labeled or are not fairly obvious.

\section{Exclude a legend if:}

- All the symbols on the map are clearly labeled, obvious, or self-explanatory to the intended map viewer.

\section{Include a specific symbol in the legend if:}

- The symbol or color on the map requires explanation.

\section{Exclude a specific symbol in the legend if:}

- The symbol is fairly obvious or self-explanatory to the intended map viewer.

- The symbol is not directly related to the map's theme.

\section{Placement}

- Center the legend in a larger area of available space that does not obstruct important map features. This can include placement on the map face, such as in an ocean area on a terrestrial-focused map.

- The legend may be used to visually balance other map elements in a layout.

\section{Design}

\section{General design considerations:}

- The legend's design should be simple and subtle so that it does not distract from important map features.

- The legend should be large enough to easily use, but not so large that it draws attention away from other map features.

- The legend may include a descriptive title if necessary. Neither "Legend" nor "Key" are suitable legend titles.

- Legend titles should be placed above, and center-justified with, the legend.

- To maintain a cohesive style, legend fonts should be consistent throughout and match the other marginalia fonts on the map.
- A subtle bounding box, bounding lines, or legend background color should be used sparingly and only when it is necessary to mask underlying mapped areas to improve legibility.

\section{Symbol design considerations:}

- Simple geometric symbols (circles, squares, etc.) are often preferred to mimetic symbols, except when mimetic symbols are easily recognized because they have a standard usage (e.g. airplane or picnic table icons).

- Symbols in the legend should exactly match (shape, size, color, orientation, etc.) the symbols shown on the map.

- Colored box symbols should use the same outline color and weight as the polygons they represent.

- If the polygons do not use outlines, box outlines may be omitted. White, black, or very light-colored fill symbols, may require an outline. In such cases, a thin gray outline will help differentiate the symbol from the background.

- In cases where the represented polygons do not use outlines and are a very light color (such as yellow), the color box on a white legend background may be hard to see. In such situations, the color box should have a subtle, thin, gray, outline to differentiate it from the background.

- Each symbol in the legend should be accompanied by a descriptive label.

\section{Legend Organization considerations:}

- Group legend symbols into logical categories to improve the map's readability and support the map's theme.

- Common grouping strategies are:

- Thematic relevance (directly related to the map theme or base information).

- Categorical (i.e. all land use colors placed separately from all land ownership colors).

- Geometric (points, lines, or polygons).

- Form (natural or man-made).

- Each group should have a short descriptive heading. 


\section{Spacing considerations:}

- Default legends produced in GIS software usually contain appropriate spacing between letters and words.

\section{Alignment considerations:}

- Default legends produced in GIS software usually contain appropriate spacing between letters and words.

- Symbols should be placed on the left and defined to the right.

- Symbols should be vertically distributed and horizontally centered with one another.

- Symbols should be vertically centered with their descriptions.

- Descriptions should be vertically aligned to the left.

\section{Continuous Legend considerations:}

- If the legend describes a continuous gradient of values (such as a temperature gradient color scheme), then the items should be touching each other rather than separated by space. If there is a break in values, it is appropriate to include a break in the legend in the corresponding place.

- Continuous legends can be oriented vertically or horizontally depending on the orientation of the map page and the available space. If the continuous legend represents a vertical subject, such as elevation, a vertical orientation is preferred.

- Maximum and minimum values should always be labeled.

- Assign intermediate labels that are appropriate for clarity and support the map theme.

\section{Legend design recommendations:}

- DGGS legends should conform to as many of the above recommendations as possible; however, legend design varies greatly according to a map's purpose, theme, and content. Figure 21 illustrates examples of a discrete legend and a continuous legend that comply with the above recommendations. 
- Adds too much visual clutter to the map and is not absolutely necessary. For example, an overview inset is not necessary if the intended audience is familiar with the location of the mapped area.

\section{Placement}

- Place the locator inset in a space that does not obstruct important map features. This can include placement on the map face, such as in an ocean area or other unimportant area of the map.

- The locator inset should be placed in an inconspicuous location that does not divert the user's attention away from main map features.

- Placing the locator inset near the bottom of the map will help make it less prominent.

- Locator inset map placement depends on the available space, needs of the map user, and layout of the overall map.

\section{Design}

\section{General inset map design considerations:}

- An inset map should be large enough to easily use, but not so large that it distracts from important map features.

- Multiple inset maps are acceptable depending on the needs of the map but use as few insets as possible to avoid an overly cluttered layout.

\section{Locator inset map design considerations:}

- The inset design should be simple, subtle, and plain.

- Display the extent of the mapped area on the

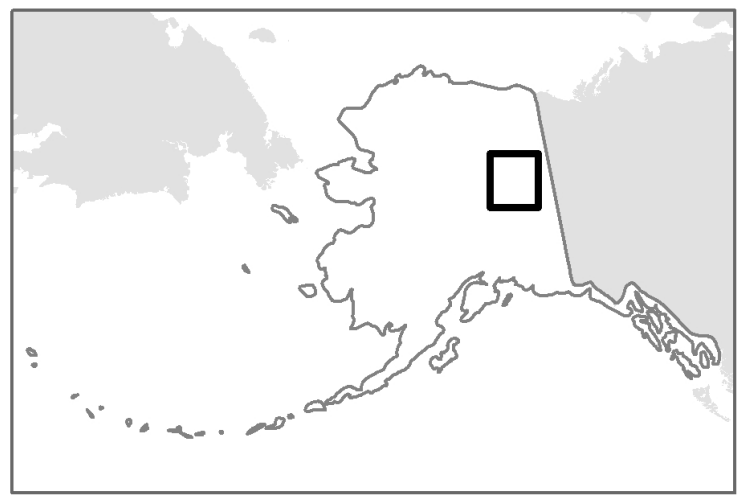

overview inset. If the extent of the main map is displayed, it should match the extent of the main map.

- A bounding box around the inset map is only necessary when features that overrun the inset extent are present. As illustrated in figure 22, the inset on the left requires a bounding box because Russia and Canada are present, and the bounding box helps anchor and contain all of the features. The inset map on the right does not require a bounding box. Its absence results in a simpler, more subdued inset.

\section{Recommended locator inset map design:}

- For small-format maps, the locator inset map should be no larger than roughly $21 / 2$ inches wide and 1 5/8 inches tall.

- Locator inset maps should display the generalized outline of Alaska.

- The scale of the locator inset map should be between 1:50,000,000 and 1:55,000,000.

- The outline of Alaska should be a thin line (0.5 points) cast in a medium gray.

- The main map extent indicator should be dark gray.

- Display and label adjacent areas (e.g., Canada and Russia) only when the intended audience is not familiar with the geographic location of the main mapped area (e.g., Alaska).

- Display and label the surrounding seas and oceans only when they are necessary for the interpretation and use of the map.

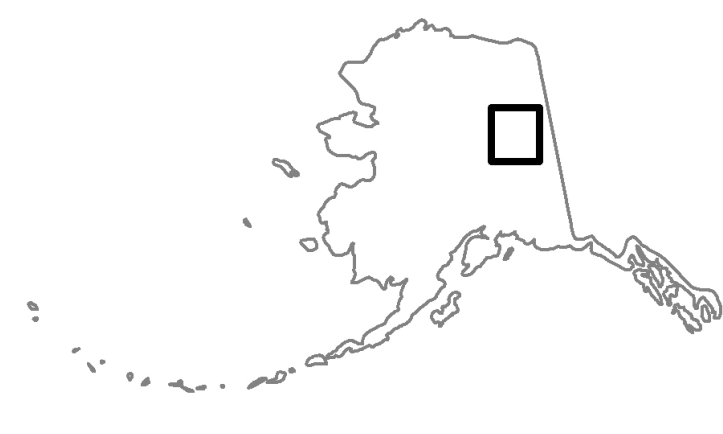

Figure 22. Two examples of recommended overview inset map designs for DGGS small-format maps. 
- Adjacent areas (e.g., Canada and Russia) should be light gray (when included).

- Include an inset bounding box only when adjacent areas (e.g., Canada and Russia) are also displayed.

\section{GRATICULE}

\section{Purpose}

The purpose of the graticule is to indicate orientation and direction by displaying parallels and meridians within a mapped area, which can be important depending on the map's extent and theme. The graticule's secondary functions include indicating orientation and the projection of the map. The graticule also illustrates when the orientation (direction of north) varies across the mapped area. If meridians converge towards a pole, the direction of north within the mapped area is variable and the north arrow is of limited utility. Additionally, the graticule can be crucial if the map is ever georeferenced in the future.

\section{Inclusion/Exclusion}

\section{Include a graticule if:}

- Orientation, position, or direction information are needed to enhance the map's message, theme, or the user's understanding.

- The viewer needs to visualize how the flat map surface relates to the Earth's three- dimensional surface.

- The direction of north varies across the map.

- The direction of north does not adhere to the "north up" convention.

- The map might need to be georeferenced and digitized in the future.

\section{Exclude a graticule if:}

- Orientation and direction information is not necessary and does not support the map's theme or increase the user's understanding of the map.

- It adds unnecessary clutter, complexity, or visual distraction or obscures more important map features.

\section{Placement}

- The physical location of a meridian or parallel cannot be changed.

- Graticule placement should be considered as its visual order in the hierarchy of a map's design.

- The visual placement of the graticule can take on one of three functions:

- The graticule visually overlays all elements on the map, which allows the graticule to identify absolute positions in latitude and longitude on the map.

- The graticule is visually juxtaposed between the land and water, so that the lines are only visible on top of water features, which enhances figure-ground relations.

- The graticule can appear as small tic marks along the frame-line or as small crosses in the interior of the map marking the intersection of parallels and meridians on the land, water, or both.

- The visual placement of the graticule is dependent on the map's extent, scale, and displayed features.

\section{Design}

\section{General graticule design considerations:}

- The style of the graticule should be simple and subdued.

- The graticule should not obscure or visually compete with the map content.

- Use fine, gray line weights and small, subdued, black or gray text.

- Include labels at the top, bottom, left, and right ends of the graticule lines.

- The graticule interval should be appropriate for the extent and scale of the map. An appropriate number of parallels and meridians will conveniently represent location, orientation, and direction, while too many lines would be overwhelming and distract from viewing other map features. 


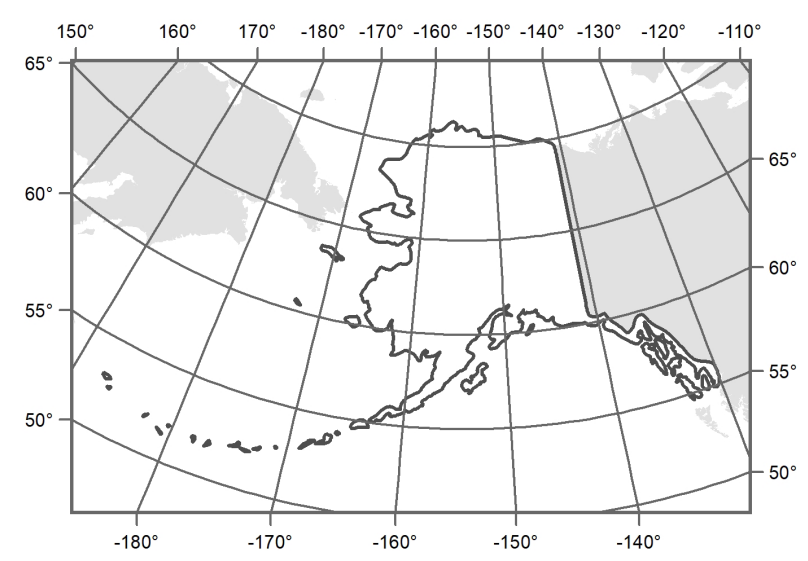

Figure 23. The recommended graticule design when the graticule is placed over all map features.

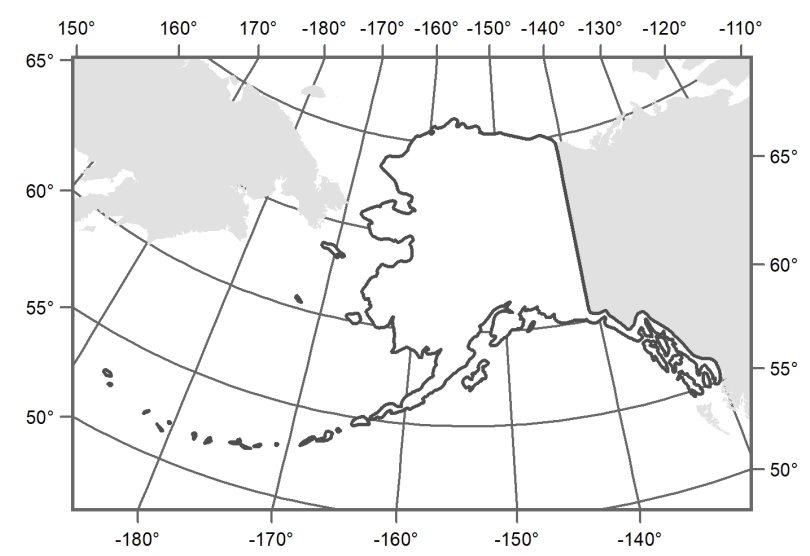

Figure 24. The recommended graticule design when the graticule is placed over just the water features.

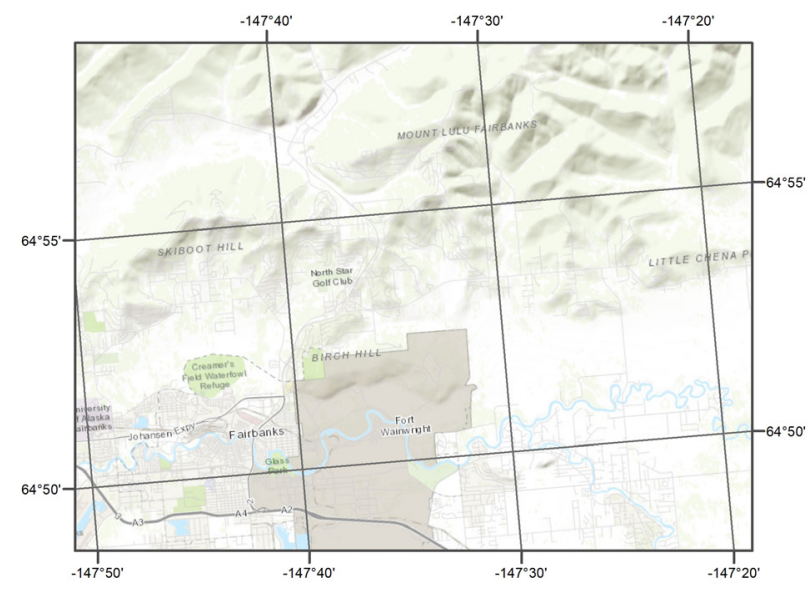

Figure 25. The recommended graticule design when the graticule is placed over land areas.

\section{Recommended graticule designs for maps that show land and ocean areas:}

The graticule overlays all elements on the map (fig. 23).

Use this design when:

- The graticule serves a primary function.

- The user needs to reference the location of a feature displayed on the land or ocean.

- Location information is important to the map's theme.

- The map is intended for navigating, orienteering, or surveying.

The graticule overlays only the water areas of the map (fig. 24).

Use this design when:

- The graticule serves a primary or secondary function.

- The full graticule design overwhelms the map or interferes with viewing important map features.

- The map is very small (such as an overview map) and graticule lines are necessary.

\section{Recommended graticule designs for maps that show only land areas: \\ The graticule overlays all elements on the map (fig. 25).}

Use this design when:

- The graticule serves a primary or secondary function.

- A user needs to reference the location of a feature.

- Location information is important to the map's theme.

- The map is intended for navigating, surveying, or orienteering. 


\section{The graticule is shown as tic marks} around the map frame-line (fig. 26).

\section{Use this design when:}

- Full graticule lines overwhelm the map or interfere with viewing important map features.

- The map shows many features or is visually cluttered.

This design is not ideal to indicate position, orientation, projection, or directional variability because the map user must "connect the tic marks" in their head to visualize the lines of longitude and latitude. Graticule lines may curve between tic marks (especially on a small-scale map) and therefore a straight line drawn between tic marks would be inaccurate. This design would also make georeferencing the map prohibitively difficult. This design is appropriate only when a general sense of latitude and longitude is required.

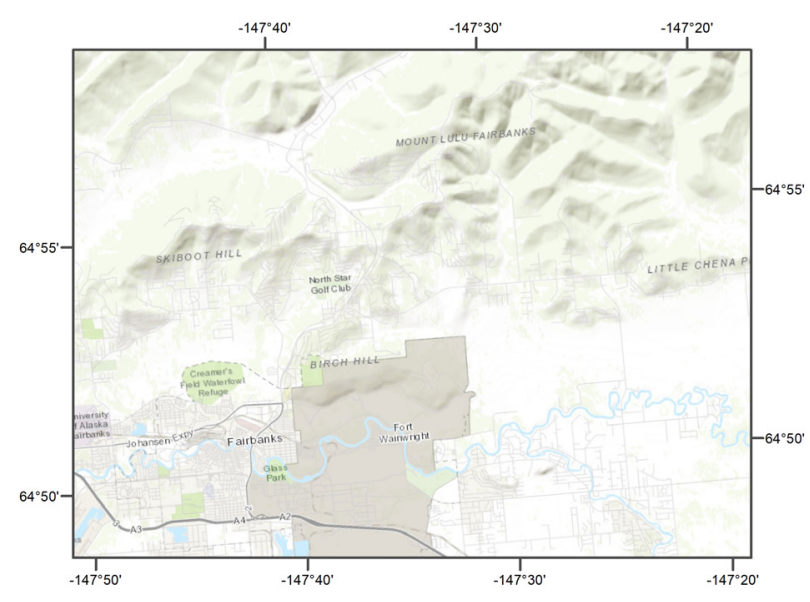

Figure 26. The recommended graticule design when only tic marks appear on the map.

\section{METADATA}

\section{Purpose}

Metadata provides additional information and details about the map or data.

\section{Inclusion/Exclusion}

- Metadata should be included if it will help the user interpret the map more accurately.

- Maps that are figures in a report typically need fewer metadata elements because the figure caption or report will likely contain the required information.

- The following categories should be reviewed when considering the inclusion of metadata for DGGS small-format maps:

\section{Most important Metadata Elements}

Always include the following metadata on the map or in the figure caption:

- Coordinate system information (datum and projection)

- Coordinate system information may alert the viewer to potential distortions in the mapped area, especially at small map scales.

- Name(s) of the author(s)

- Authorship information makes it possible to reference or cite the map in any derivative works. The author's name is important as a way to ask follow-up questions, signal reputation (or lack thereof), and signify that someone is taking responsibility for the work (Tufte, 2006).

\section{Data sources}

Metadata about the data's source may help the user determine if it is recent or reliable.

\section{Moderately important Metadata Elements}

Attempt to place this metadata on the map:

- Name of the publishing agency

- Publication number

- Name of contributing agencies

- Credits or acknowledgments

- Date(s)

- Date refers to data collection or map publication

\section{Least important Metadata Elements:}

Place this metadata on the map only if it is necessary, there is available space, and it does not overly clutter the map:

- Affiliations of the author or contributors

- Logo of the publishing agency

- Logo(s) of the contributing agencies 


\section{Other metadata Elements:}

These items may be necessary depending on the map's purpose, intended audience, and available space:

- Agency website(s)

- DOI link to the publication or a QR code

- Agency disclaimer

- Intended purpose or use of the map or data

- Potential limitations of the map or data

\section{Placement}

Metadata location may vary according to the available space.

- Place metadata elements in an inconspicuous area of the map.

- Metadata should never attract undue attention or interfere with the main map features.

- Metadata elements should be placed near each other or grouped together.

- Data sources are optimally placed below, and center-justified with, the legend.

- Metadata is commonly placed at the bottom or right side of the map.

\section{Design}

General metadata design considerations:

- The type should be amongst the smallest on the map and have a plain and simple style.

- Using gray, rather than black, text is a good way to reduce the visual impact of metadata content.

- Metadata elements may be arranged as separate blocks of text or as a larger group of text with differentiating (bold, for example) headings.

- Data sources should be identified by a "Data Source" or "Source" label to avoid being mistaken as map authorship. Data sources should be formatted similar to a bibliographic reference and not use abbreviations.

\section{CONCLUSION}

Maps play a crucial role in understanding, interpreting, and visualizing Alaska's diverse geologic resources. The overall look and theme of small-format maps produced at DGGS are often inconsistent, particularly in how map marginalia are included or excluded, placed, and designed. Such inconsistencies have the potential to create confusion for the user, leading to difficulties in orienting the map, measuring distances, identifying map symbols, or knowing the topic and important production information about the map. In addition, the overall appearance of some of the marginalia elements used on past DGGS maps do not conform to what is considered good cartographic design. The variation in map marginalia elements also contributes to the lack of cartographic consistency and continuity in the look and feel of the division's maps.

The purpose of this Report of Investigation is to establish recommended designs for map marginalia and present guidelines for their inclusion and placement. During this project, accepted cartographic conventions for marginalia inclusion, placement, and design were compiled from an extensive literature review. A qualitative survey was designed and administered to gather user reactions to and opinions about DGGS marginalia elements and to test whether the opinions and conclusions differ between DGGS map makers and users.

The survey results indicated that almost all the survey participants, including both map makers and users, are familiar with the basics of common cartographic conventions which are also outlined in the literature. It was clear that all participants were familiar with the marginalia elements and their intended purpose, which speaks very highly of the mapping education and experience of DGGS personnel; however, there were a few instances where survey participants didn't agree with 
common cartographic conventions. This disagreement likely stems from the unique characteristics of and requirements for mapping in Alaska and the individual experiences of DGGS staff. The guidelines and recommended designs developed during this project are specifically tailored to address the preferences of DGGS map makers and users. For example, survey participants showed a strong preference that the title be placed at the bottom center of a map, while common cartographic conventions state it is most often placed at the top center. As a result of this preference, the DGGS guideline is that the title may be placed at either the top or bottom center, depending on the space available, the needs of the map, and the personal preference of the cartographer.

At the beginning of this study, the initial expectation was that there would be a clear difference between the cartographic knowledge of map users versus map makers, with map users presumably being less familiar with advanced cartographic principals and conventions. This assumption was not supported by the survey results. Both map makers and users showed a remarkably similar familiarity with advanced cartographic concepts. For example, roughly the same number of map users and map makers indicated that the accuracy of a scale bar depends on the scale and projection of the map, which can be considered a fairly advanced cartographic concept. It is plausible that the DGGS participants have more experience with maps than they reported and these "map users" have the knowledge and skills of map makers, but simply do not make maps as part of their current job duties. Considering the fairly high level of cartographic knowledge among the map users in the survey group, the results from this study may have been different if conducted with the true "end-users" of DGGS small-format maps. DGGS maps and reports are available to all members of the public, including persons from federal, state, and local governments; local communities; and natural resource development companies; as well as educators, tourists, and the general public. There- fore, identifying and defining the true end-users, let alone soliciting their participation in a survey, would be a challenge. Nonetheless, it would be very interesting to survey these types of end users to see if they shared similar knowledge, opinions, or preferences with the DGGS survey group.

The survey results suggest that both groups of map makers and users possess a fairly high level of familiarity with cartographic principals and conventions; however, there is a lack of consistent design standards for DGGS designed smallformat maps. This suggests that the inconsistency of DGGS small-format maps is not a result of map maker's cartographic knowledge, but rather likely related to other factors, such as the lack of consistent guidance regarding cartography, which is addressed in this study. Other factors may also be at play, for example, the amount of time allotted for small-format map design and production. An intriguing follow-up study would explore whether DGGS map makers have, or make, the time to carefully consider the details and decisions based on more advanced cartography.

The small-format maps produced by DGGS cover a broad spectrum of topics and purposes, as well as provide critical locational and contextual information, support effective data visualization, and serve as a graphic explanation of geologic interpretation. With maps that must fulfill many diverse purposes and a variety of end users, cartographic guidelines and recommendations for DGGS smallformat maps must strike a balance between consistency and flexibility. The guidelines and recommended designs developed in this project are a solid starting point for the map design process because they provide many industry-accepted conventions and a good overview of cartographic basics. They will offer current map makers reminders of traditional cartographic conventions, and they will provide novice cartographers and new hires with useful training materials. The use of DGGS cartographic guidelines and designs will be highly recommended, rather than strictly mandated, to provide DGGS authors with an additional degree 
of flexibility when creating maps. There will, inevitably, be some need to deviate from these recommendations. In such cases, these recommendations provide a position to deviate from-for example, if an author decides the recommended north arrow design is not acceptable for an individual map, there is a good chance that a similar looking arrow will be appropriate and that many of the other recommended elements may remain unchanged. The practice of deviating from the guidelines and recommended designs only when necessary will result in DGGS maps with a greater consistency in their overall look and feel. In the absence of recommendations, map makers are faced with unlimited choices and the variation in overall look and design of DGGS maps will be much greater.

This project establishes a recommended designs for map marginalia and presents guidelines for their inclusion and placement with the purpose

\section{REFERENCES}

Blaha, J.D., 2010, Various Ways of Assessment of Cartographic Works, in Gartner, G., and Ortag, F., eds., Cartography in Central and Eastern Europe: Berlin, Heidelberg, Springer-Verlag, p. 211-229.

Brewer, C.A., 2005, Designing Better Maps: A Guide for GIS Users: Redlands, California, Esri Press.

Buckley, Aileen, 2008, Cartographic design: Inset maps [blog]. (Last accessed July 24th, 2020) https://www.esri.com/arcgis-blog/products/ product/mapping/cartographic-design-insetmaps/

Buckley, Aileen, Barnes, David, Richards, Jaynya, 2007, Achieving Historical Map Effects with Modern GIS: Cartographic Perspectives, no. 56, p. 63-72.

Butterick, M.atthew, 2020, Practical Typography [website]. (Last accessed January 4, 2020) https://practicaltypography.com/all-caps.html

Dent, B.D., 1998, Cartography: Thematic Map Design (5 ed.): Dubuque, Iowa, William. C. Brown. of greatly increasing the consistency of DGGS small-format maps and helping map makers critically think about the purpose, role, and design of each element on a map. With a single set of recommended designs and a small selection of acceptable alternatives for each element, much of the decision making in finding an appropriate and acceptable element design will be eliminated. These guidelines will offer DGGS map makers the flexibility to more easily and consistently create a variety of small-format maps that are recognizable as well-designed, professional, organizational products that have a consistent appearance, while meeting the needs of the map's intended users.

\section{ACKNOWLEDGMENTS}

The authors acknowledge Dr. Aileen Buckley at ESRI and Dr. Patrick Kennelly at the Central Oregon Community College for reviews that helped to improve the quality of this report.

Guest, Greg, Bunce, Arwen, and Johnson, Laura, 2006, How Many Interviews are Enough? An experiment with Data Saturation and Variability: Field Methods, vol. 18, no. 1, p. 59-82. https:// doi.org/10.1177/1525822X05279903

Harrower, Mark, Keller, C.P., Hocking, Diana, 1997, Cartography of the Internet: Thoughts and a Preliminary User Survey: Cartographic Perspectives, no. 26, p. 27-37. https://doi. org/10.14714/CP26.718

Kimerling, A.J., Buckley, A.R., Muehrcke, P.C., and Muehrcke, J.O., 2016, Map Use: Reading, Analysis, Interpretation (8 ed.): Esri Press.

Lowe, Carla, [n.d.], Rules for Capitalization in Titles [website](Last accessed October 19, 2018) https://www.dailywritingtips.com/rules-forcapitalization-in-titles/

Patton, M.Q., 1990, Qualitative Evaluation and Research Methods (2 ed.): Beverly Hills, California, Sage.

Peterson, G.N., 2014, GIS Cartography: A Guide to Effective Map Design (2 ed.): Boca Raton, Florida, CRC Press. 
Robinson, A.H., Morrison, J.L., Muehrcke, P.C., Kimerling, A.J., and Guptill, S.C, 1995., Elements of Cartography: Wiley \& Sons. 674 p.

Slocum, T.A., McMaster, R.B., Kessler, F.C., Howard, H.H., 2009, Thematic Cartography and Geovisualization (3 ed.): Upper Saddle River, New Jersey, Pearson Prentice Hall.

Suchan, T.A., Brewer, C.A., 2000, Qualitative Methods for Research on Mapmaking and Map Use: Professional Geographer, vol. 52, no. 1, p. 145-154.
Tufte, E.R., 2006, Beautiful Evidence: Graphics Press LLC.

Typedecon.com, [n.d.], Typography Deconstructed-Type Glossary: Ascender [website]. (Last accessed November 25, 2018) https://www. typedecon.com/blogs/type-glossary/ascender/ United States Geological Survey, [n.d], What do the different north arrows on a USGS topographic map mean? [website]. ( Last accessed March 4, 2021) https://www.usgs.gov/faqs/what-dodifferent-north-arrows-a-usgs-topographicmap-mean 
DEVELOPING MAP MARGINALIA DESIGN RECOMMENDATIONS FOR THE ALASKA DIVISION OF GEOLOGICAL \& GEOPHYSICAL SURVEYS

APPENDIX A: FULL-SIZED VERSIONS OF THE MAPS FEATURED IN THE USER SURVEY 


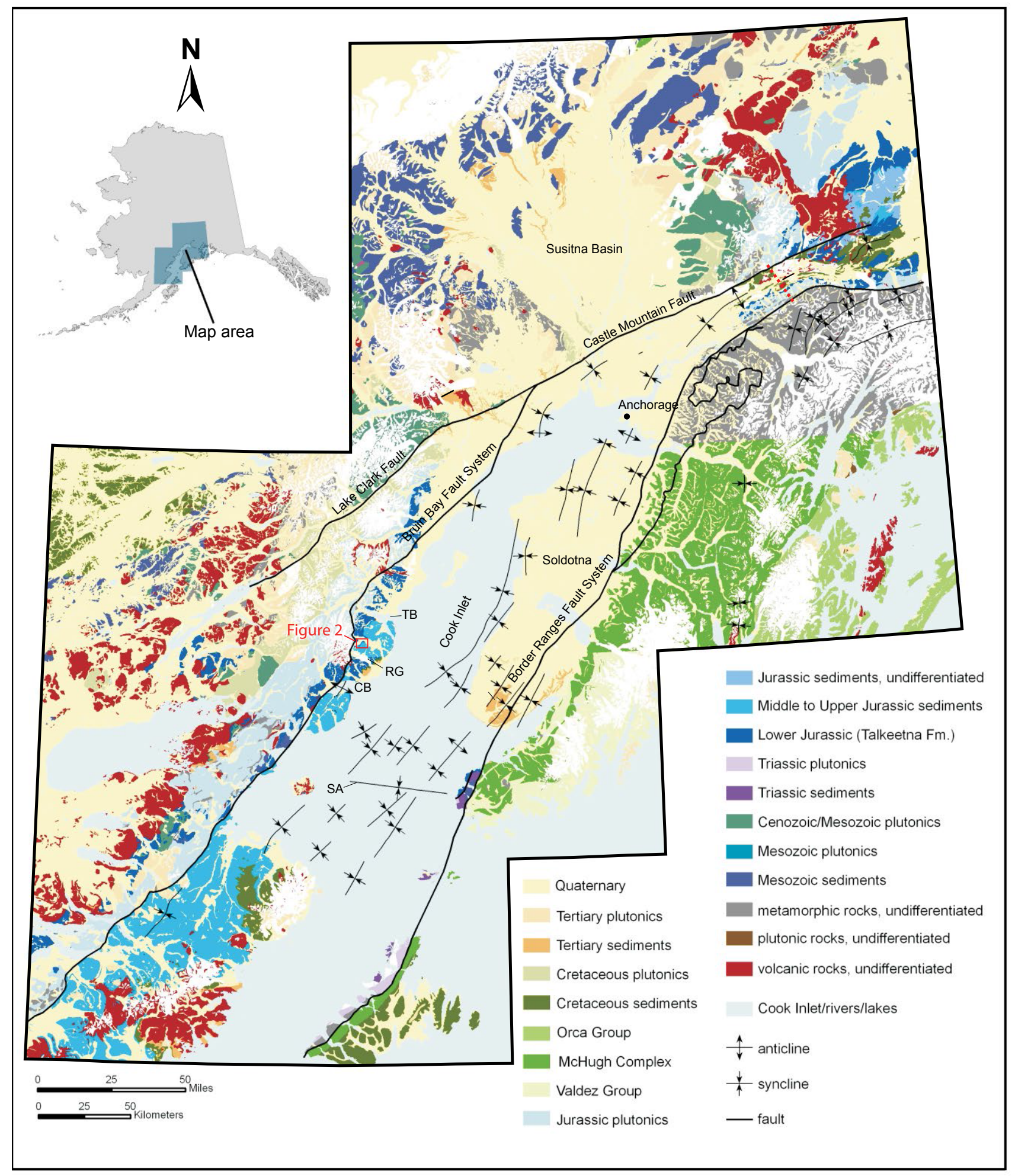

Figure 5-1. Bedrock geologic map of the Cook Inlet region. CB= Chinitna Bay; Sa = Seldovia arch; RG = Red Glacier; $T B=$ Tuxedni Bay. Modified from Wilson and others (2009). 


\title{
HISTORICALLY ACTIVE VOLCANOES OF ALASKA
}

\begin{abstract}
Definition of Historically Active
The $54^{*}$ volcanoes displayed on this map meet at least one of the following criteria since $1700 \mathrm{CE}$ :

- Documented, unquestioned eruption OR

- A strongly suspected eruption, often an eruption documented in a historical account with very little information. Current geologic knowledge must not contradict the eruption account OR

- Persistent (usually on the order of decades, but certainly longer than several months) fumaroles, with temperatures (where measured) within $\sim 10^{\circ} \mathrm{C}$ of the boiling point, OR

- Significant, measured, volcanic-related, non-eruptive deformation, OR

- Documented earthquake swarm with strongly suspected volcanic cause

* Gilbert's fumaroles have not been observed in recent years and Gilbert may be removed from future versions of this list. In 2014 and 2015, fieldwork at Tana and Herbert (C. Neal and K. Nicolaysen

personal commun., 2016) revealed the presence of high-temperature fumaroles. Although we do not have decades of observation at Tana or Herbert, they have been added to this version.
\end{abstract}

\section{Date of Last Eruptive Event}

Where confidently known, the year of the most recent eruptive event is listed below the volcano name. See the accompanying data table for a field containing the year of

suspected eruptive events for those volcanoes with no certain historical eruptions.

(a)

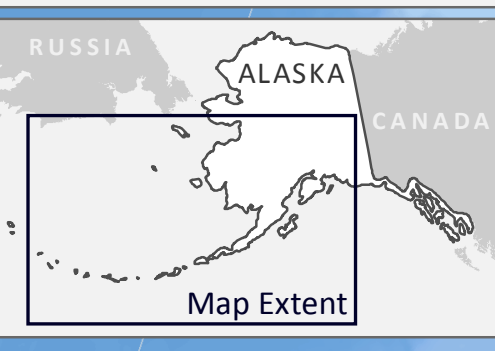

Segula

$\underset{1987}{\text { Little }} \Delta \underset{\text { Semisopochnoi }}{\Delta}$

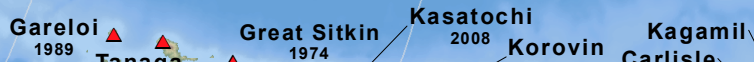

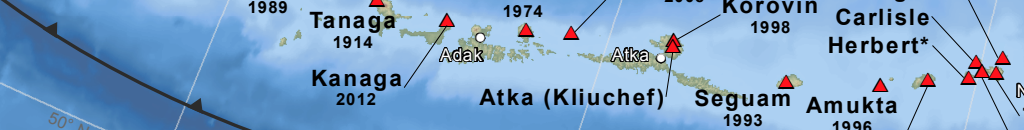

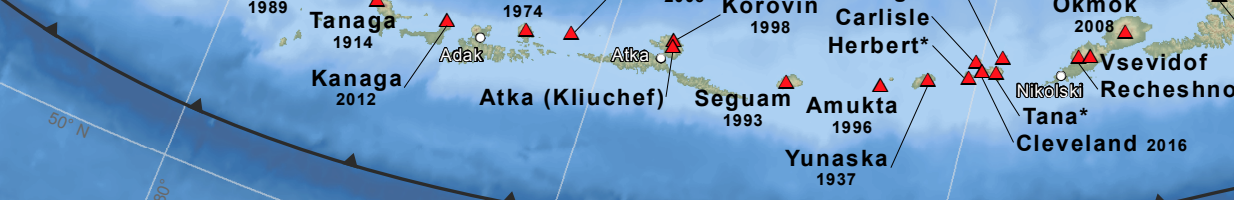

Okmok

$2008 \Delta$
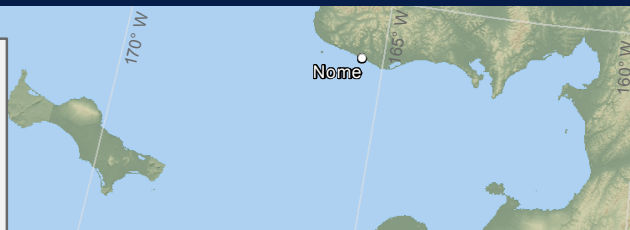

OF ALASA

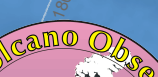

The Alaska Volcano Observatory (AVO) is a
joint program of the United States Geological Survey (USGS), the Geophysical Institute of the University of Alaska Fairbanks (UAF/GI),
and the State of Alaska Division of Geological \& Geophysical Surveys (DGGS).

\section{Alaska Volcano Observatory}


DEVELOPING MAP MARGINALIA DESIGN RECOMMENDATIONS FOR THE ALASKA DIVISION OF GEOLOGICAL \& GEOPHYSICAL SURVEYS

APPENDIX B: DGGS MAP MARGINALIA QUESTIONNAIRE 


\title{
Developing Map Marginalia Design Standards for the Alaska Division of Geological \& Geophysical Surveys
}

\section{DGGS Marginalia Questionnaire}

\author{
Principal Investigator \\ Patricia Ekberg \\ 3354 College Road \\ Fairbanks, AK 997709 \\ 303-588-1147 \\ Advisor \\ Dr. Fritz Kessler \\ 814-863-1508
}

\section{Study Background and Purpose}

There are two basic components of maps. The map face contains the data being visualized. The map marginalia contains the information about the map. Map marginalia often include, but are not limited to, a north arrow, scale bar, title, legend, inset map, graticule, and metadata information. This questionnaire will only focus on map marginalia.

Each marginalia element serves a specific purpose to aid in understanding the map information and context. Because of this, each element should be well designed and appropriately placed on the map.

Here at the Alaska Division of Geological \& Geophysical Surveys (DGGS), there are no clear rules for how marginalia should be included or shown on a small format map - often it is left completely up to the map maker's discretion.

This questionnaire will record your opinions and reactions to marginalia on a recent DGGS small format map. Please consider each question carefully and give your honest opinion. There are no wrong answers. Responses to this questionnaire will be used to support the development of cartographic standards for map marginalia elements to be used on DGGS small format maps.

This survey is anonymous. No personal identifying information will be collected. Your participation is voluntary. You may choose not to participate in the survey, to stop responding at any time, or to skip any questions you do not want to answer. 


\section{Instructions}

1. Decide how and when you would like to complete the questionnaire

- You may print out the questionnaire and write your answers in by hand or you may type your answers directly into this word document

- You may complete the questionnaire at home or in the office

- You may complete and return the questionnaire at any time before the turn-in deadline

2. Read the Consent for Exempt Research (page 3)

3. Select what participant role you consider yourself (page 4)

4. Complete part 1 , and 2 of the questionnaire

- Part 1 of this questionnaire will examine map marginalia in the context of an example map. Use the printed example map to answer the questions.

- Part 2 of this questionnaire will examine potential designs for marginalia elements for small format maps. Use the printed Marginalia Element Design Choices packet to answer the questions.

- Each question is on a separate page.

- Write your answers below each question in the text box provided. Check boxes can be checked or unchecked by clicking on them.

- Please explain your reasoning, but do not feel like you have to write a novel. In most cases 3-4 sentences is sufficient. If you are feeling verbose, text boxes will hold more text than is visible - just keep typing, or change the formatting if you prefer.

5. Return the Questionnaire

- Completed questionnaires should be turned in no later than $10 \mathrm{pm}$ on Wednesday March $14^{\text {th }}$.

- Electronic questionnaires should be saved as a word document file and turned in by email. Files can be emailed to patricia.gallagher@alaska.gov

- Printed questionnaires can be directly handed to Trish Gallagher or may be placed in the tan folder in her mailbox in the DGGS mailroom.

\section{Thank you for participating in this survey!}




\section{Consent for Exempt Research}

The Pennsylvania State University

Title of Project: Developing Map Marginalia Design Standards for the Alaska Division of Geological \& Geophysical Surveys

Principal Investigator: Patricia Gallagher

Telephone Number: 303-588-1147

Advisor: Dr. Fritz Kessler

Advisor Telephone Number: (814) 863-1508

You are being invited to volunteer to participate in a research study. This summary explains information about this research.

- This research is being done to support the development of map marginalia design standards for small format maps made at DGGS.

- You will be asked to examine a marginalia element (north arrow, scale bar, title, legend, inset map, graticule, and metadata) in the context of two example maps. Using a written survey, you will be asked to answer questions about each marginalia element and explain your decisions, reasoning, or opinions. You will not be asked to reveal any personal identifying information.

- No personally identifiable information will be collected.

If you have questions or concerns, you should contact Patricia Gallagher at 303-588-1147. If you have questions regarding your rights as a research subject or concerns regarding your privacy, you may contact the Office for Research Protections at 814-865-1775.

Your participation is voluntary and you may decide to stop at any time. You do not have to answer any questions that you do not want to answer.

Tell the researcher your decision regarding whether or not to participate in the research. [For verbal consent] OR Your participation implies your voluntary consent to participate in the research. [For implied consent] 


\section{Participant Roles}

Map makers use and create maps regularly. This may include geologists, scientists, cartographers, and GIS analysts.

Map users view and use maps but do not create them. This may include managers, editors, and IT or administrative personnel. This may also include scientists who do not create maps regularly but use maps for field work, interpretation, or general purposes.

Would you consider yourself a map maker or a map user? Please select one answer below.
I'm a map maker!
I'm a map user! 


\section{Marginalia Element Questionnaire for Cook Inlet Geology Map}

The following questions ask you to examine each marginalia element within the context of the bedrock geology of the Cook Inlet region map. This map was published as a page-sized figure in a larger report.

\section{North arrow}

1a. Is there a north arrow on this map?

1b. Does this map need a north arrow? Please explain why or why not.

$\square$ YES $\square$ NO

Type or write your response in this box

1c. Is this north arrow well placed on this map? If yes, please explain why. If not, please describe where this north arrow should be moved to and why.

$\square$ YES $\square$ NO

1d. Does this north arrow help you orient the map? Please explain why or why not.

$\square$ YES $\square$ NO

1e. Does this north arrow accurately point toward north for all locations shown in this map? Please explain why or why not.

$\square$ YES $\square$ NO 


\section{Scale bar}

2a. Is there a scale bar on this map?

YES $\square$ NO

2b. Does this map need a scale bar? Please explain why or why not.

$\square$ YES $\square$ NO

2c. Is this scale bar well placed on this map? If yes, please explain why. If not, please describe where this scale bar should be moved to and why.

$\square$ YES $\square$ NO

$2 \mathrm{~d}$. Does this scale bar help you measure distances on the map? Please explain why or why not.

$\square$ YES $\square$ NO

2e. Does this scale bar accurately represent distance for all locations shown in this map? Please explain why or why not.

$\square$ YES $\square$ NO 


\section{Title}

3a. Is there a title on this map? $\square$ YES $\square$ NO

If you were to create an informative title for this map, what would that title be?

3b. Does this map need a title? Please explain why or why not.

$\square$ YES $\square$ NO

3c. Where on this map would you choose to locate the title you created? Please explain the reasoning behind your location decision.

3d. Does this title help you know what is being mapped? Please explain why or why not.

$\square$ YES $\square$ NO

3e. Does this title accurately represent what is being shown in this map? Please explain why or why not.

$\square$ YES $\square$ NO 


\section{Legend}

4a. Is there a legend on this map? $\square$ YES $\square$ NO

4b. Does this map need a legend? Please explain why or why not.

$\square$ YES $\square$ NO

4c. Is this legend well placed on this map? If yes, please explain why. If not, please describe where this legend should be moved to and why.

$\square$ YES $\square$ NO

$4 d$. Does this legend help you know what every symbol on the map means? Please explain why or why not.

$\square$ YES $\quad \square$ NO

4e. Does this legend accurately represent the symbols on this map? Please explain why or why not.

$\square$ YES $\square$ NO 


\section{Inset map}

5a. Is there an inset map on this map? $\square$ YES $\square$ NO

5b. Does this map need an inset map? Please explain why or why not.

$\square$ YES $\square$ NO

$5 c$. Is this inset map well placed on this map? If yes, please explain why. If not, please describe where this location diagram should be moved to and why.

$\square$ YES $\square$ NO

$5 \mathrm{~d}$. Does this inset map help you know where on the earth this map is? Please explain why or why not.

$\square$ YES $\square$ NO

5e. Does this inset map accurately represent the location of the map area? Please explain why or why not.

$\square$ YES $\square$ NO 
6. Graticule

A graticule is a network of latitude and longitude lines

6a. Is there a graticule on this map? $\quad \square$ YES $\quad \square$ NO

6b. Does this map need a graticule? Please explain why or why not.

$\square$ YES $\square$ NO

6c. If you were to create a graticule on this map, what would it look like? Please describe your reasoning. 


\section{Metadata Elements}

Metadata elements include production information, map credits, data sources, publishing agency, contributors, and other information pertaining to how the map was made.

7a. Are there metadata elements on this map? $\square$ YES $\square$ NO

7b. Does this map need metadata? Please explain why or why not.

$\square$ YES $\square$ NO

7c. What metadata would be useful when interpreting this map? Please describe where these metadata elements should be placed on the map and why. 


\section{Marginalia Element Questionnaire for Map Volcano Map}

The following questions ask you to examine each marginalia element within the context of the historically active volcanoes of Alaska map. This map was published as a page-sized version of a large format map.

\section{North arrow}

1a. Is there a north arrow on this map? $\quad \square$ YES $\quad \square$ NO

1b. Does this map need a north arrow? Please explain why or why not.

$\square$ YES $\square$ NO

1c. Where on the map would you locate a North Arrow? Please explain why.

$\square$ YES $\square$ NO

1d. Would a north arrow help you orient the map? Please explain why or why not.

$\square$ YES $\square$ NO

1e. Would a north arrow accurately point toward north for all locations shown in this map? Please explain why or why not.

$\square$ YES $\square$ NO 


\section{Scale bar}

2a. Is there a scale bar on this map?

$\square$ YES $\square$ NO

2b. Does this map need a scale bar? Please explain why or why not.

$\square$ YES $\square$ NO

2c. Is this scale bar well placed on this map? If yes, please explain why. If not, please describe where this scale bar should be moved to and why.

$\square$ YES $\square$ NO

$2 \mathrm{~d}$. Does this scale bar help you measure distances on the map? Please explain why or why not.

$\square$ YES $\square$ NO

2e. Does this scale bar accurately represent distance for all locations shown in this map? Please explain why or why not.

$\square$ YES $\square$ NO 


\section{Title}

3a. Is there a title on this map? $\square$ YES $\square$ NO

3b. Does this map need a title? Please explain why or why not.

$\square$ YES $\square$ NO

3c. Is this title well placed on this map? If yes, please explain why. If not, please describe where this scale bar should be moved and why.

$\square$ YES $\square$ NO

3d. Does this title help you know what is being mapped? Please explain why or why not.

$\square$ YES $\square$ NO

3e. Does this title accurately represent what is being shown in this map? Please explain why or why not.

$\square$ YES $\square$ NO 


\section{Legend}

4a. Is there a legend on this map? $\quad \square$ YES $\quad \square$ NO

4b. Does this map need a legend? Please explain why or why not.

$\square$ YES $\square$ NO

4c. If you could include a legend in this map, what would its contents be and where should it be located? Please explain why.

$\square$ YES $\square$ NO 


\section{Inset map}

5a. Is there an inset map on this map? $\square$ YES $\square$ NO

$5 b$. Does this map need an inset map? Please explain why or why not.

$\square$ YES $\square$ NO

5c. Is this inset map well placed on this map? If yes, please explain why. If not, please describe where this location diagram should be moved to and why.

$\square$ YES $\square$ NO

$5 \mathrm{~d}$. Does this inset map help you know where on the earth this map is? Please explain why or why not.

$\square$ YES $\square$ NO

5e. Does this inset map accurately represent the location of the map area? Please explain why or why not.

$\square$ YES $\square$ NO 


\section{Network of latitude and longitude lines called the graticule}
6a. Is there a graticule on this map?
$\square$ YES
$\square$ NO

6b. Does this map need a graticule? Please explain why or why not.

$\square$ YES $\square$ NO

$6 \mathrm{c}$. Is the graticule well placed on this map? If yes, please explain why. If not, please describe where the graticule should be moved and why.

$\square$ YES $\square$ NO

$6 \mathrm{~d}$. Does this graticule help you know where on the earth this map is? Please explain why or why not.

$\square$ YES $\quad \square$ NO

6e. Does the graticules accurately represent the location of the map area? Please explain why or why not.

$\square$ YES $\square$ NO 


\section{Metadata Elements}

Metadata elements include production information, map credits, data sources, publishing agency, contributors, and other information pertaining to how the map was made.

7a. Are there metadata elements on this map? $\square$ YES $\square$ NO

7b. Does this map need metadata? Please explain why or why not.

$\square$ YES $\quad \square$ NO

7c. What metadata would be useful when interpreting this map? Please describe where these metadata elements should be placed on the map and why.

$\square$ YES $\quad \square$ NO

7d. Do these metadata elements help you know important production information about the map? Please explain why or why not.

$\square$ YES $\square$ NO

7e. Do these metadata elements accurately represent the map production details? Please explain why or why not.

$\square$ YES $\square$ NO 


\section{Marginalia Element Design Questionnaire}

This is an additional part of the questionnaire to specifically investigate potential designs for marginalia elements.

The following questions ask you to select a design that is most aesthetically appealing to you for small format maps published by DGGS. For each question, refer to the printed packet of Marginalia Element Design Choices.

\section{North Arrow}

Please consider the north arrow design choices on the page 2 of the design choices packet.

Which north arrow design do you feel is the most visually pleasing? Indicate your choice by checking the box corresponding to the appropriate letter indicator.

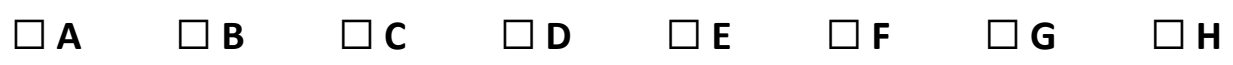

Please explain your choice. If none of these choices appeal to you, you may draw your own north arrow design or explain changes you would like to make to one of the illustrated designs.

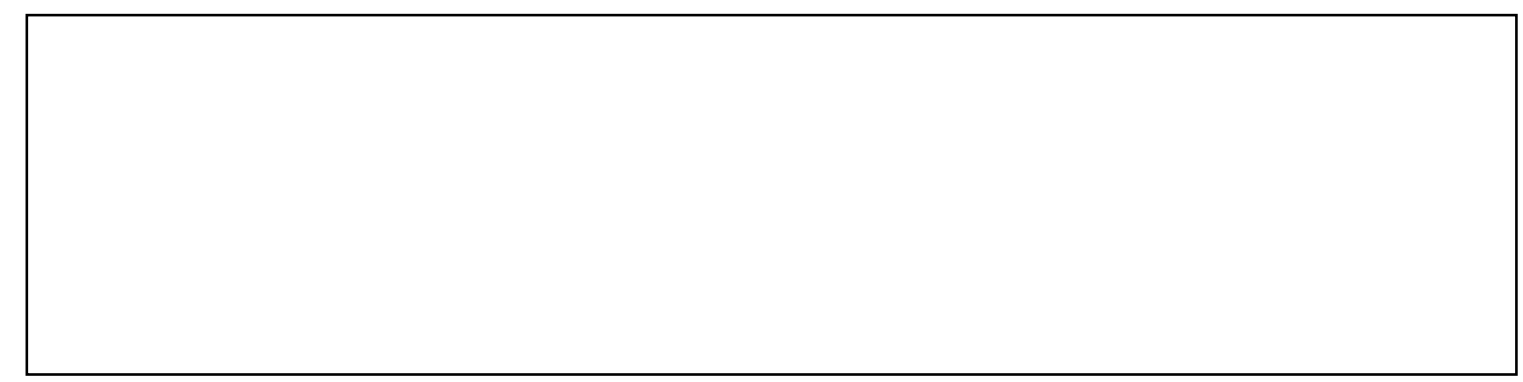

\section{Scale Bar}

Please consider the scale bar design choices on page 3 of the design choices packet.

Which scale bar design do you feel is the most visually pleasing?

$\square$ A $\square$ B $\square$ C $\square$ D $\quad \square$ E $\quad \square$ F $\quad \square$ G $\quad \square$ H

Please explain your choice. If none of these choices appeal to you, you may draw your own scale bar design or explain changes you would like to make to one of the illustrated designs. 
Please consider the title design choices on page 4 of the design choices packet.

What title design do you feel is the most visually pleasing?

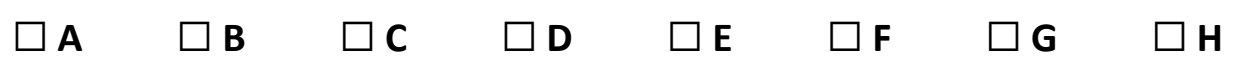

Please explain your choice. If none of these choices appeal to you, you may draw your own title design or explain changes you would like to make to one of the illustrated designs.

\section{Legend}

Please consider the legend design choices on pages 5 and 6 of the design choices packet.

What legend design do you feel is the most visually pleasing?

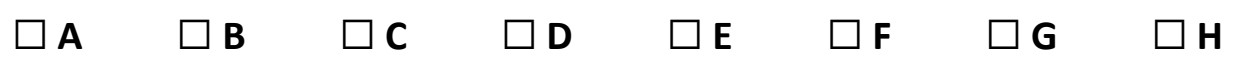

Please explain your choice. If none of these choices appeal to you, you may draw your own legend design or explain changes you would like to make to one of the illustrated designs. 


\section{Inset Map}

Please consider the inset map design choices on page 7 of the design choices packet.

What inset map design do you feel is the most visually pleasing?

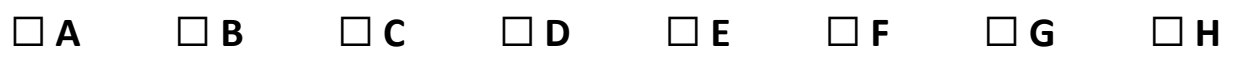

Please explain your choice. If none of these choices appeal to you, you may draw your own inset map design or explain changes you would like to make to one of the illustrated designs.

\section{Graticule for land and ocean areas}

Please consider the graticule design choices for land and ocean areas on page 8 of the design choices packet.

What graticule design do you feel is the most visually pleasing?

$\square$ A $\square$ B $\quad \square$ C $\quad \square$ D $\quad \square$ E $\quad \square$ F $\quad \square$ G

Please explain your choice. If none of these choices appeal to you, you may draw your own graticule design or explain changes you would like to make to one of the illustrated designs. 


\section{Graticule for land areas only}

Please consider the graticule design choices for land areas on page 9 and 10 of the design choices packet.

What graticule design do you feel is the most visually pleasing?
$\square A$
$\square$ B
$\square \mathbf{C}$
$\square \mathrm{D}$
$\square \mathrm{E} \quad \square \mathrm{F}$

Please explain your choice. If none of these choices appeal to you, you may draw your own graticule design or explain changes you would like to make to one of the illustrated designs. 


\section{Metadata ranking}

For each of these metadata elements, please indicate how important it is for it to be included on a small format map published by DGGS.

Names of the author(s) (the person who created the data and interpretation)

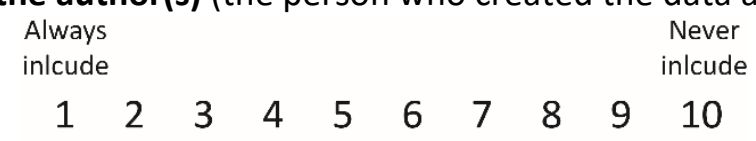

Credits or Acknowledgements to other contributors (cartographer, interns, editors, reviewers, etc.)

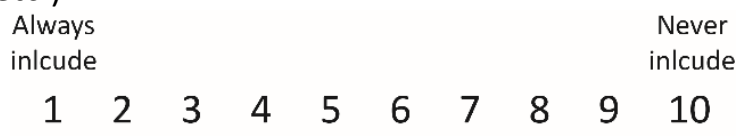

Affiliations of the author, cartographer, or other contributors

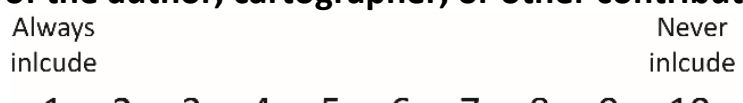

$\begin{array}{llllllllll}1 & 2 & 3 & 4 & 5 & 6 & 7 & 8 & 9 & 10\end{array}$

Name of the publishing agency

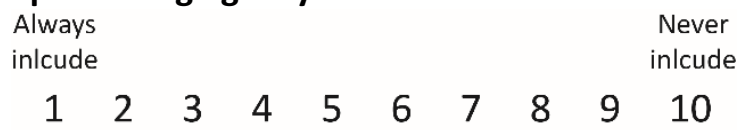

Logo of the publishing agency

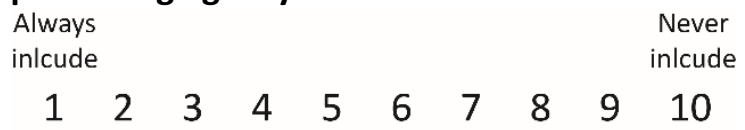

Name(s) of contributing agencies

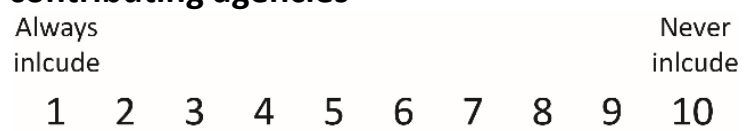

Logo(s) of contributing agencies

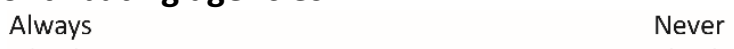

inlcude $\quad$ inlcude

$\begin{array}{llllllllll}1 & 2 & 3 & 4 & 5 & 6 & 7 & 8 & 9 & 10\end{array}$

Publication number

$\begin{array}{cccccccccc}\begin{array}{c}\text { Always } \\ \text { inlcude } \\ 1\end{array} & 2 & 3 & 4 & 5 & 6 & 7 & 8 & 9 & 10\end{array}$

Coordinate System Information (Datum and Projection)

Always Never

inlcude inlcude

$\begin{array}{llllllllll}1 & 2 & 3 & 4 & 5 & 6 & 7 & 8 & 9 & 10\end{array}$

Data Sources (including base map source)

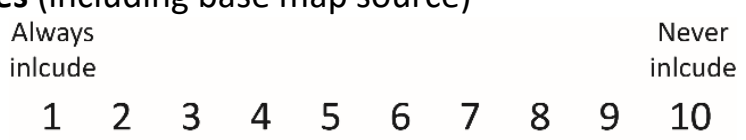

$\begin{array}{llllllllll}1 & 2 & 3 & 4 & 5 & 6 & 7 & 8 & 9 & 10\end{array}$ 
Thank you for participating in this survey! 
DEVELOPING MAP MARGINALIA DESIGN RECOMMENDATIONS FOR THE ALASKA DIVISION OF GEOLOGICAL \& GEOPHYSICAL SURVEYS

APPENDIX C: MARGINALIA ELEMENT DESIGN CHOICES FOR DGGS MARGINALIA QUESTIONNAIRE 


\section{Marginalia Element Design Choices For DGGS Marginalia Questionnaire}


1. North Arrow Design Choices

A)

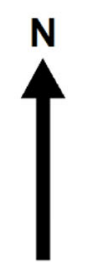

E)

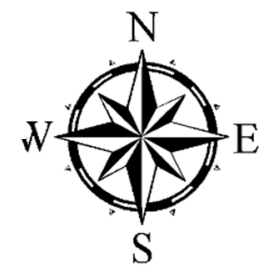

B)

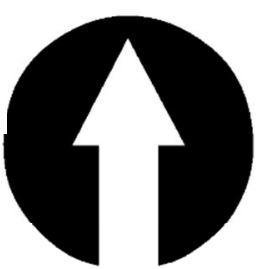

C)
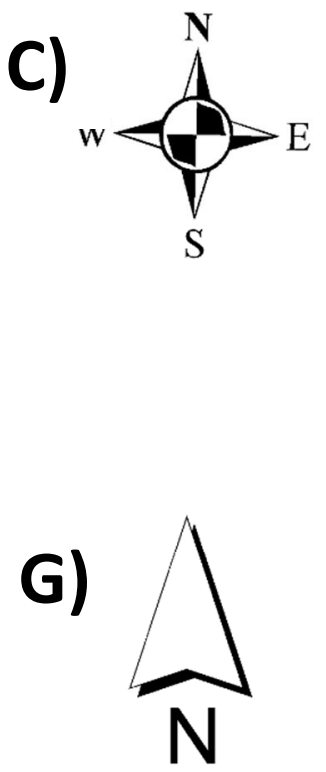

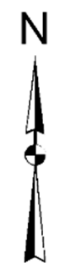

F)
D) $\mathrm{N}$

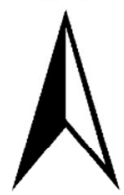

1)

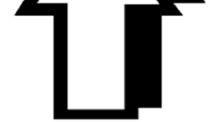



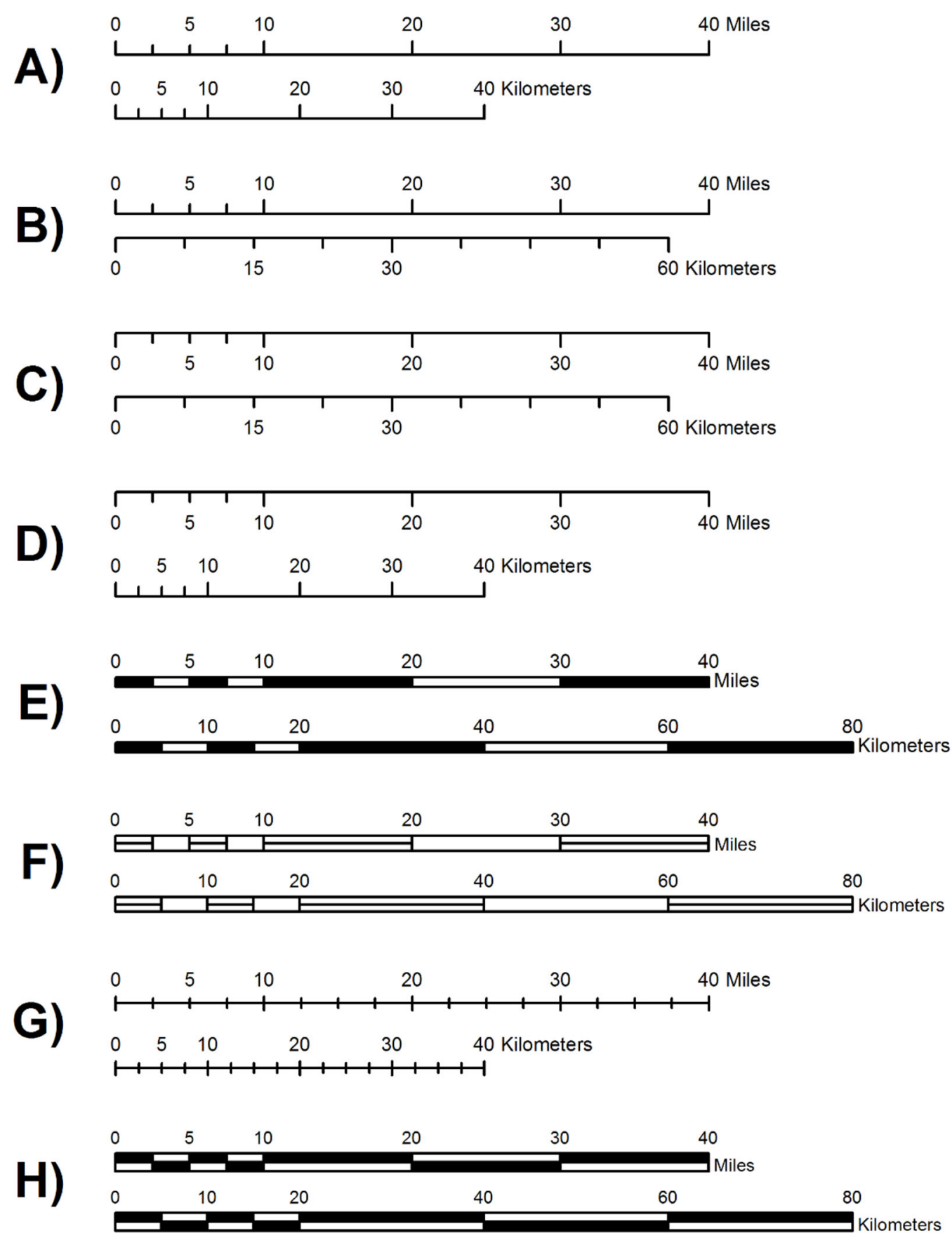
A) BEDROCK GEOLOGY OF COOK INLET

B) Bedrock Geology of Cook Inlet

C) BEDROCK GEOLOGY OF COOK INLET

D) Bedrock Geology of Cook Inlet

E) BEDROCK GEOLOGY OF COOK INLET

F) Bedrock Geology of Cook Inlet

G) BEDROCK GEOLOGY OF COOK INLET

H) Bedrock Geology of Cook Inlet 
A)

Legend

- Water Tower

- Pump station

- Power Pole

ㅁ Transformer Station

Roads

Railroads

Stream

River

Sand and gravel

Bedrock

State owned land

Federally owned land

C) Legend

Water Infrastructure

○

口

Electric Infrastructure

○

口

Transportation

Hydrology

\section{Earth Material}

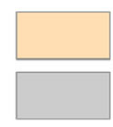

Land Ownership
B) Legend

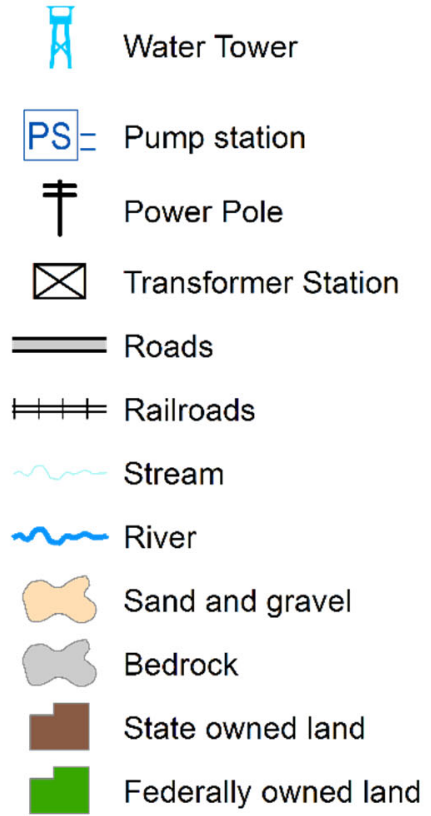

D)

Legend

Water Infrastructure

म

$\mathrm{PS}=$

Electric Infrastructure

†

$凶$

Transportation

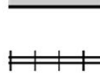

Hydrology

$\sim$

Earth Material

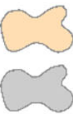

Land Ownership 
E)

Legend

Water Infrastructure

- Water Tower

- Pump station

Electric Infrastructure

- Power Pole

ㅁ Transformer Station

Transportation

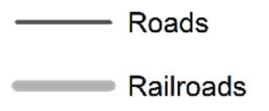

Hydrology

Stream

River

\section{Earth Material}

Sand and gravel

Bedrock

\section{Land Ownership}

State owned land

Federally owned land

\section{G)}

\section{Legend}

Water Infrastructure

- Water Tower a Pump station

\section{Electric Infrastructure}

- Power Pole a Transformer Station

\section{Transportation}

Roads

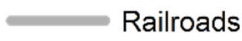

Hydrology

Stream River

Earth Material

Sand and gravel

Bedrock

\section{Land Ownership}

State owned land

Federally owned land
F)

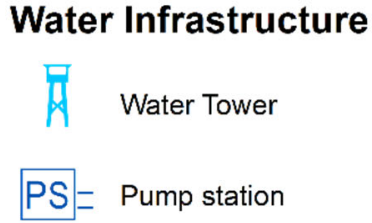

Electric Infrastructure

† Power Pole

$\triangle$ Transformer Station

Transportation

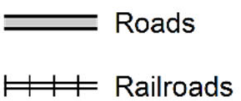

Hydrology

Stream

$\sim$ River

\section{Earth Material}

Sand and gravel

Bedrock

\section{Land Ownership}

State owned land

Federally owned land

H)

\section{Legend}

\section{Water Infrastructure}

P. Water Tower PS= Pump station

\section{Electric Infrastructure}

† Power Pole $\bowtie$ Transformer Station

\section{Transportation}

$=$ Roads $\Longrightarrow$ Railroads

Hydrology

Stream River

\section{Earth Material}

Sand and gravel

Bedrock

\section{Land Ownership}

State owned land

Federally owned land 
A)

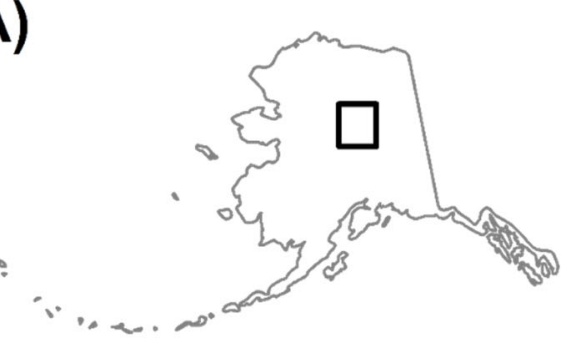

C)

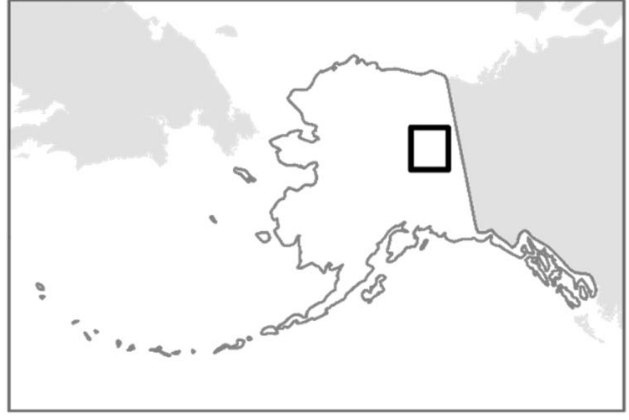

E)

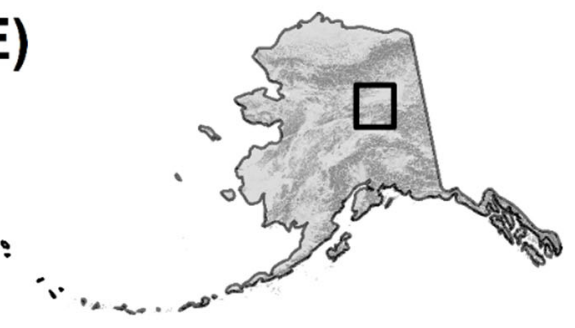

G)

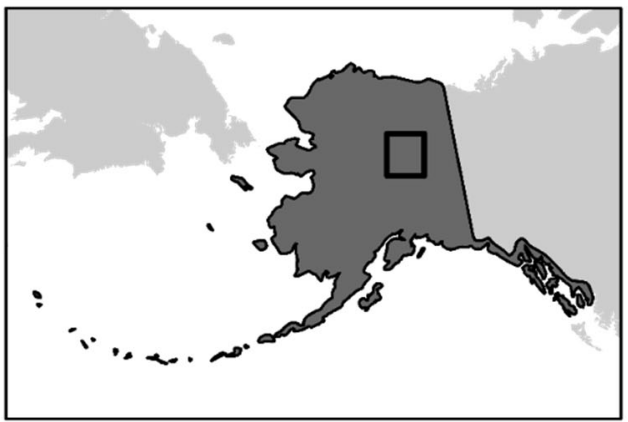

B)

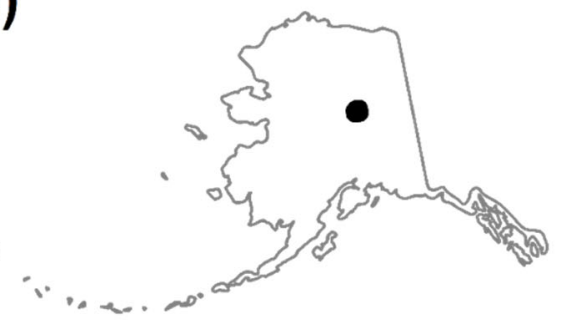

D)

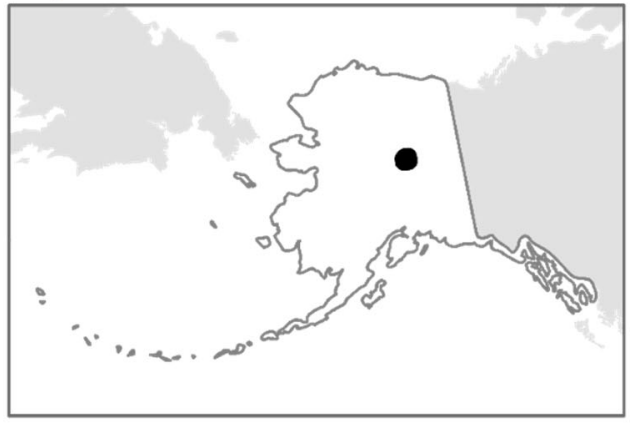

F)

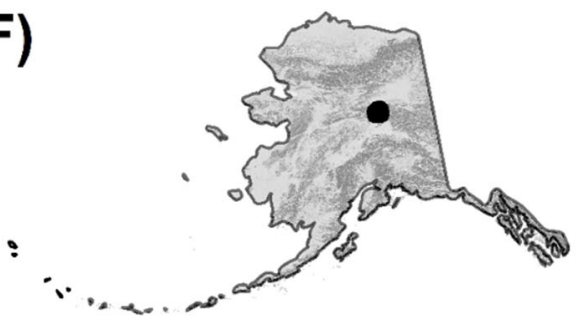

H)

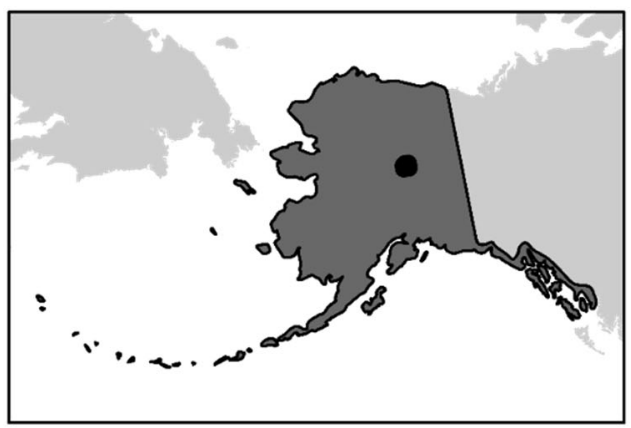




\section{Graticule Design Choices for Maps that Show Land and Ocean Areas}
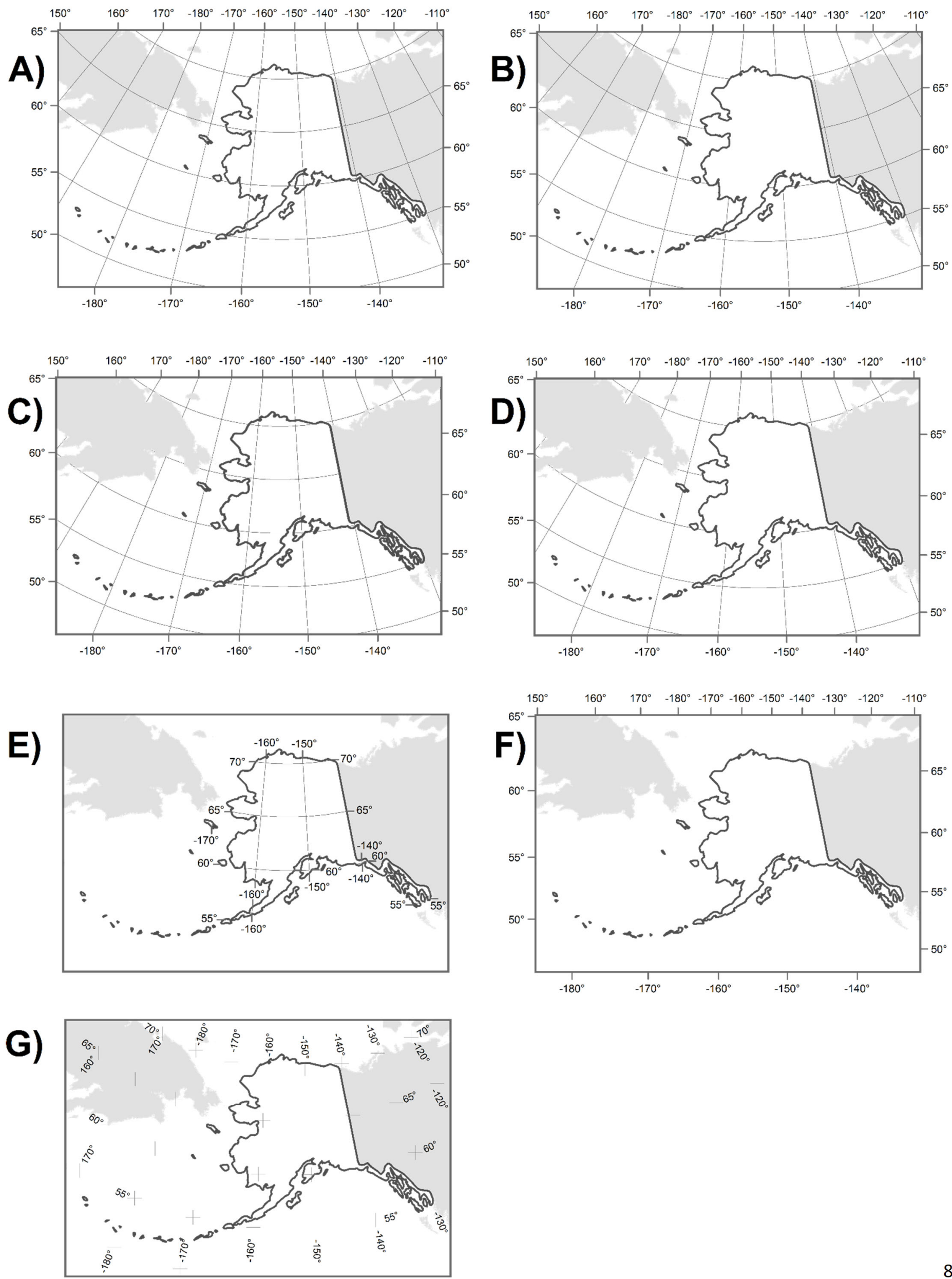
7. Graticule Design Choices for Maps that show Land Areas
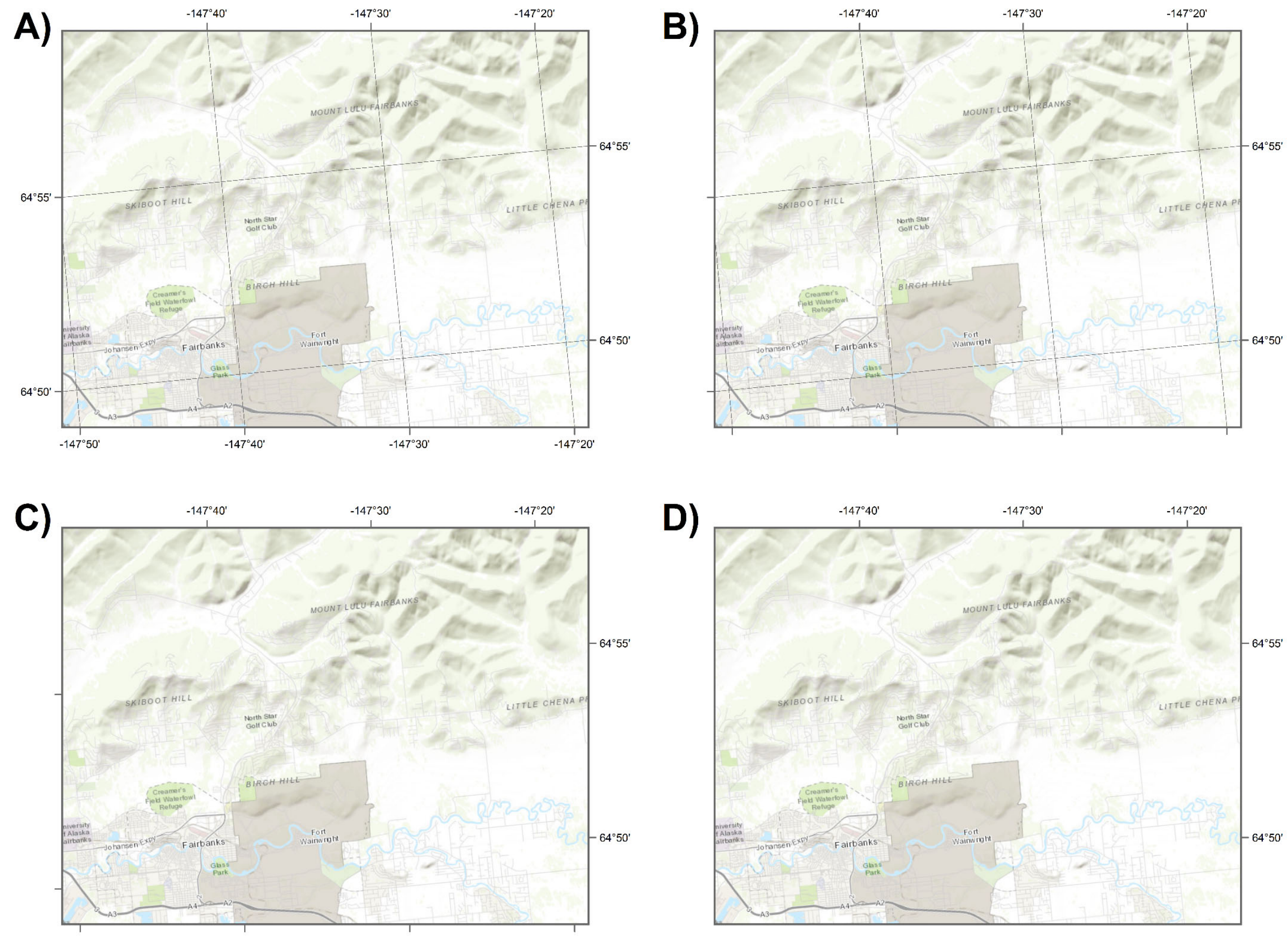

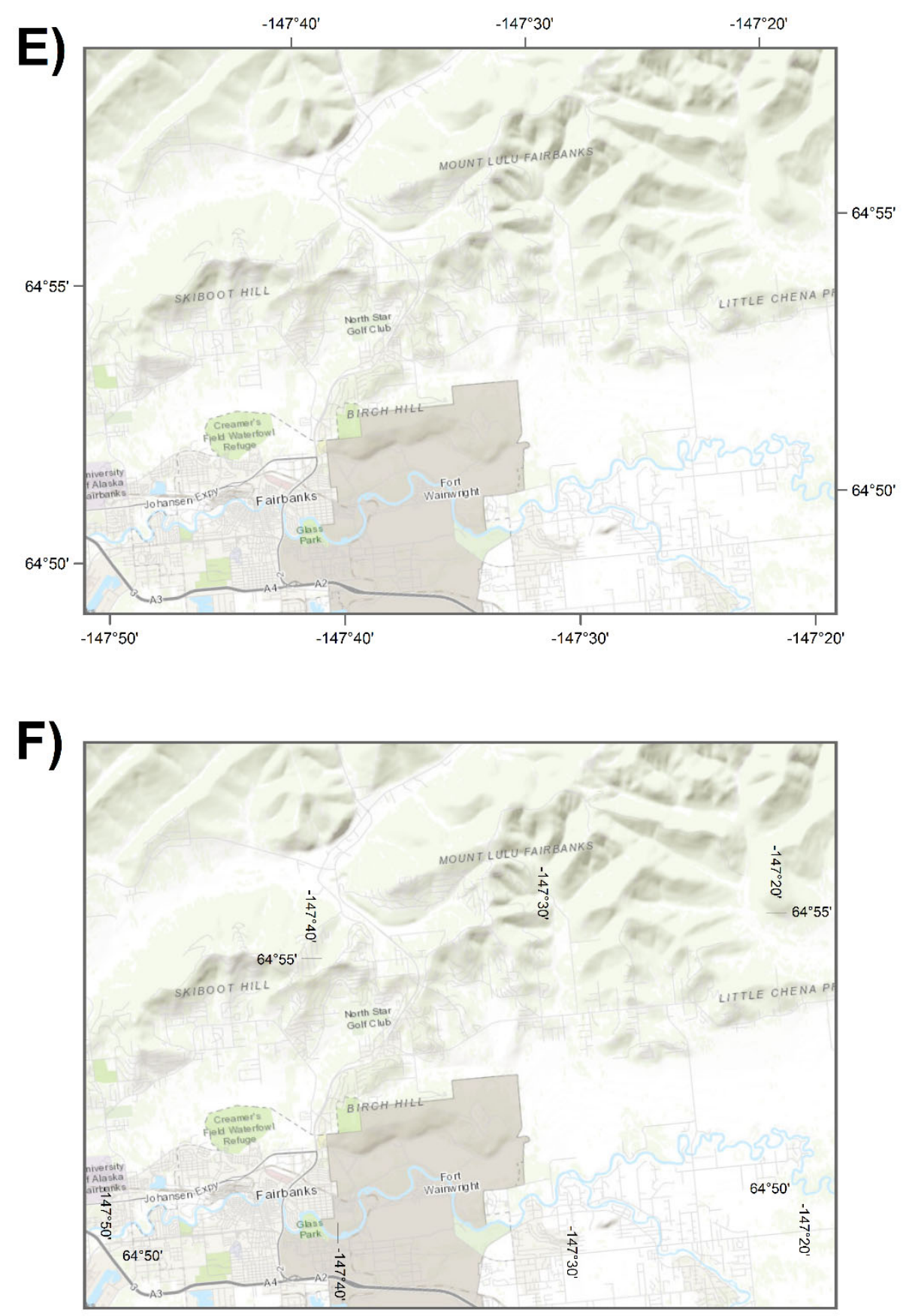